\title{
Increasing the Capacity of Photovoltaics using Proton Exchange Membrane Fuel Cell Backup within a Residential Community
}

\author{
by \\ Yawen Han, B.Eng. \\ A thesis submitted to the \\ Faculty of Graduate and Postdoctoral Affairs \\ in partial fulfillment of the requirements for the degree of \\ Master of Applied Science in Sustainable Energy \\ Department of Mechanical and Aerospace Engineering \\ Carleton University \\ Ottawa, Ontario
}

August, 2015 
(C)Copyright

Yawen Han, 2015 
The undersigned hereby recommends to the

Faculty of Graduate and Postdoctoral Affairs

acceptance of the thesis

\title{
Increasing the Capacity of Photovoltaics using Proton Exchange Membrane Fuel Cell Backup within a Residential Community
}

\author{
submitted by Yawen Han, B.Eng. \\ in partial fulfillment of the requirements for the degree of \\ Master of Applied Science in Sustainable Energy
}


Professor Ian Beausoleil-Morrison, Thesis Supervisor

Professor Xiaoyu Wang, Thesis Co-supervisor

Professor Metin I. Yaras, Chair, Department of Mechanical and Aerospace Engineering

Ottawa-Carleton Institute for Mechanical and Aerospace Engineering Department of Mechanical and Aerospace Engineering Carleton University

August, 2015

iv 


\section{Abstract}

The popularity of the Feed-in Tariff program in Ontario has brought in a large number of renewable energy suppliers, especially in solar photovoltaic (PV) on the residential level. Due to the intermittent nature of PV energy generation, the capacity of PV is limited by the grid's ability to provide backup. This research explores the use of residential proton exchange membrane fuel cell (PEMFC) for backup purposes.

Simulation was performed to assess the combined performance of PV and PEMFC systems in a grid-connected, hypothetical community located in Ottawa. A power management strategy was developed to operate the PEMFC system. The added PEMFC capacity in the community increased the PV capacity limit.

This thesis also examined the feasibility of bringing the PEMFC technology into the Ontario market. Learning from stakeholder interviews, policy recommendations of a rebate program and a net-metering scheme were formulated to engage customers while increasing the province's generation capacity. 
To my family, for their endless love and support. 


\section{Acknowledgments}

I would first like to acknowledge my supervisors, Dr. Ian Beausoleil Morrison and

Dr. Xiaoyu Wang. I am immensely thankful for this challenging learning experience. Thank you for your guidance and support throughout this work.

I would also like to express my gratitude towards Dr. Alexandra Mallett, for her patience in advising me through the policy portion of my work. Your knowledge and insight are greatly appreciated.

A special thanks to my colleagues in the Sustainable Building Energy Systems Laboratory. In particular, Tiwa Lawal, Adam Wills, Sebastian Brideau, Geoff Johnson, John Kopf, and Evan Boucher. Thank you for taking the time to help me when I needed it. Your support and friendship made my time here particularly enjoyable.

I wish to thank my parents, who have always supported me unconditionally. Your love and confidence in me gave me the strength to complete this work.

Finally, I would like to express my sincerest appreciation to Anthony Filgate. Thank you for your encouragement and complete faith in my abilities. Your support was an integral part of my success. 


\section{Table of Contents}

Abstract $\quad$ V

Acknowledgments vii

Table of Contents viii

List of Tables $\quad$ xii

List of Figures $\quad$ xiii

Nomenclature $\quad$ xvi

1 Introduction $\quad 1$

1.1 Motivation for Innovation in Renewable and Alternative Energy . . . 1

1.2 Motivation for PV Technologies . . . . . . . . . . . . . . 2

1.2.1 The Green Energy and Green Economy Act . . . . . . . . . . 3

1.2.2 Ontario's Long Term Energy Plan . . . . . . . . . . . . . . . 4

1.3 Challenges of PV Integration with the Grid . . . . . . . . . . . 4

1.3.1 Background on the Ontario grid . . . . . . . . . . . 7 
1.3.2 PV integration issues with the grid .......... 8

1.3.3 Source of backup generation . . . . . . . . . . . . . . 9

1.4 Benefits to Hybridization of PV with CHP . . . . . . . . . . . . 10

1.4.1 Micro-CHP: increasing utilization efficiency . . . . . . . . . 10

1.5 Literature Review . . . . . . . . . . . . . . . . . . . . . . 12

1.5.1 PV and micro-CHP systems . . . . . . . . . . . . . 12

1.5.2 Community Load profile . . . . . . . . . . . . . . . . 14

1.5.3 PV module and inverter selection . . . . . . . . . . . . . 16

1.5.4 Proton exchange membrane fuel cell . . . . . . . . . . . . . . . 18

1.5.5 Power management strategies . . . . . . . . . . . . . . 19

1.5.6 Thesis contribution ................ 20

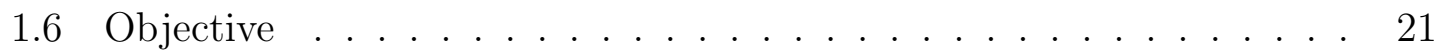

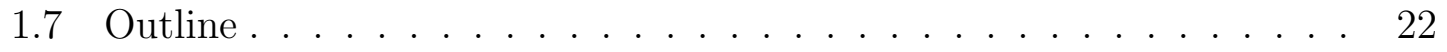

2 System Topology and Control 23

2.1 System Components and Layout . . . . . . . . . . . . . . . . . 23

2.1.1 PV sizing ........................ 24

2.1.2 PEMFC sizing . . . . . . . . . . . . . 26

2.1.3 System layout . . . . . . . . . . . . . . . . 27

2.2 Power Management Strategy . . . . . . . . . . . . . . . . . . . . 28

2.3 Scenarios for Simulation . . . . . . . . . . . . . . . . 32

2.3.1 Load-follow scenario . . . . . . . . . . . . . . . . 32

2.3.2 Grid-assist scenario . . . . . . . . . . . . . . . . 33

2.4 Comparison Metrics . . . . . . . . . . . . . . . 35 
3 Analysis Tools $\quad 38$

3.1 Simulation Tool: ESP-r . . . . . . . . . . . . . . . . . 38

3.1.1 PV model description . . . . . . . . . . . . . . . . . . . . 39

3.1.2 PEMFC model description . . . . . . . . . . . . . . . . 43

3.2 Choice of Weather Data Source . . . . . . . . . . . . . . . . . 45

3.3 Load Forecasting . . . . . . . . . . . . . . . . . 47

3.3.1 Load forecasting methods and selection . . . . . . . . . . . . 47

3.3.2 Holt-Winters double seasonal forecasting method algorithms . 48

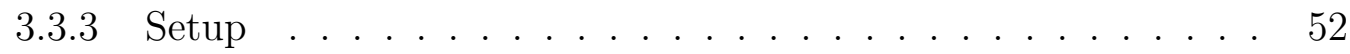

3.3.4 Accuracy analysis ................. 53

4 Results and Discussion $\quad 56$

4.1 Annual Results . . . . . . . . . . . . . . . . 56

4.1.1 Load-follow scenario . . . . . . . . . . . . . . . 59

4.1 .2 Grid-assist scenario . . . . . . . . . . . . . . . . . 61

4.2 Analysis of On-Peak Behaviour . . . . . . . . . . . . . . . . 64

4.2.1 Load-follow scenario . . . . . . . . . . . . . . . . 65

4.2.2 Grid-assist scenario . . . . . . . . . . . . . . . 67

5 Policy and Deployment Recommendations $\quad 70$

5.1 Interview Methodology . . . . . . . . . . . . . . . . . . . 71

5.2 Micro-CHP ....................... . . . 73

5.2.1 Technical challenges . . . . . . . . . . . . . . . . 74

5.2.2 Economic challenges . . . . . . . . . . . . . . 77 
5.2 .3 Social implications . . . . . . . . . . . . . . . . . . 80

5.3 Policy Landscape . . . . . . . . . . . . . . . . . . . . . . . . . 81

5.3 .1 Current state . . . . . . . . . . . . . . . . 82

5.3 .2 Future outlook . . . . . . . . . . . . . . . . . 82

5.3 .3 Policy drivers . . . . . . . . . . . . . . . . . . . . . . 85

5.4 Policy Recommendations . . . . . . . . . . . . . . . . . . . 87

5.4 .1 Type of policy . . . . . . . . . . . . . . 87

5.4.2 Steps of deployment and implementation . . . . . . . . . 90

6 Conclusions and Future Recommendations $\quad 95$

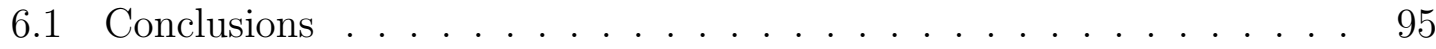

6.1 .1 Power management strategy . . . . . . . . . . . . . 95

6.1 .2 Simulation results . . . . . . . . . . . . . . . 96

6.1 .3 Policy . . . . . . . . . . . . . . . . . . . 96

6.2 Future Recommendations . . . . . . . . . . . . . . . . 97

$\begin{array}{ll}\text { List of References } & 100\end{array}$

$\begin{array}{ll}\text { Appendix A Interview Material } & 108\end{array}$ 


\section{List of Tables}

1.1 Electrical load consumption of the 12 houses . . . . . . . . . . 15

1.2 Solar panel and inverter selection from major solar distributors in

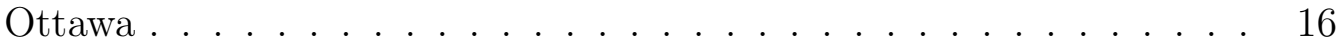

3.1 RMSD values for data comparison . . . . . . . . . . . . . 46

3.2 Smoothing factors used . . . . . . . . . . . . . . . . 52 


\section{List of Figures}

1.1 Ontario's electricity production; with permission (C) Queen's Printer for Ontario, $2013[1] \ldots \ldots \ldots \ldots$

1.2 Total generating capacity of resources in Ontario: 2013 \& 2025, with permission (C)Queen's Printer for Ontario, 2013 [1] . . . . . . . . 6

1.3 Example power flow of the Ontario electricity grid structure . . . . 8

2.1 Community level power electronics connections . . . . . . . . . . . 25

2.2 System layout and components . . . . . . . . . . . . . . . 29

2.3 Logic of the power management strategy . . . . . . . . . . . . . . . . 31

2.4 Ontario electricity time-of-use (TOU) pricing; with permission

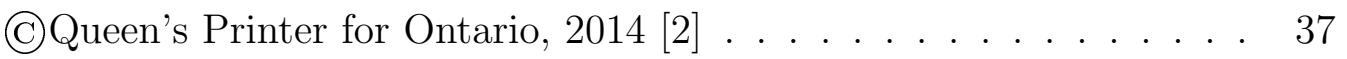

3.1 Equivalent network representation of the PV thermodynamic mode in

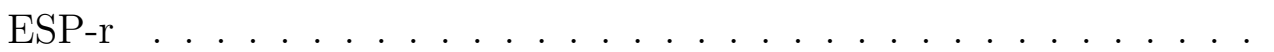

3.2 Schematic of the PEMFC model (reproduced with permission from Beausoleil-Morrison) [3] . . . . . . . . . . . . . . . . . 44

3.3 Electrical load data for the week of Monday, Jan 18, 2010 to Sunday $\operatorname{Jan} 24,2010 \ldots \ldots \ldots$ 
3.4 Holt-Winters double seasonal smoothing load forecast example, September 16, 2014 . . . . . . . . . . . . . . 54

4.1 Comparing the total energy imports and exports in the three scenarios 58

4.2 Comparing the peak power imported and exported in the three scenarios 58

4.3 Load following power balance example: Jan 15, 2010 . . . . . . . . . 60

4.4 Load following power balance example: Jan 21, 2010 . . . . . . . . . 62

4.5 Grid assisting power balance example: Jan 21, 2010 . . . . . . . . . 62

4.6 Load following power balance example: Mar 26, 2010 . . . . . . . . . 63

4.7 Grid assisting power balance example: Mar 26, 2010 . . . . . . . . . 63

4.8 Comparing the energy imports and exports in the three scenarios for on-peak TOU periods only . . . . . . . . . . . . . . . . . 65

4.9 Comparing the peak power imports and exports in the three scenarios for on-peak TOU periods only . . . . . . . . . . . . . 66

4.10 Comparing the duration of power imports and exports in the three scenarios for on-peak TOU periods only . . . . . . . . . . . . . 67

4.11 Load following power balance example: Oct 6, 2010 . . . . . . . . 68

4.12 Grid assisting power balance example: Oct 6, 2010 . . . . . . . . 68 


\section{Nomenclature}

AC alternating current

ARMA autoregressive moving average

BTM behind-the-meter

CDM conservation demand management

CEA Canadian Electricity Association

CEC California Energy Commission

CHP combined heat and power

DB dry bulb

DC direct current

DG distributed generation

DH diffuse horizontal

DHW domestic hot water

DN direct normal 


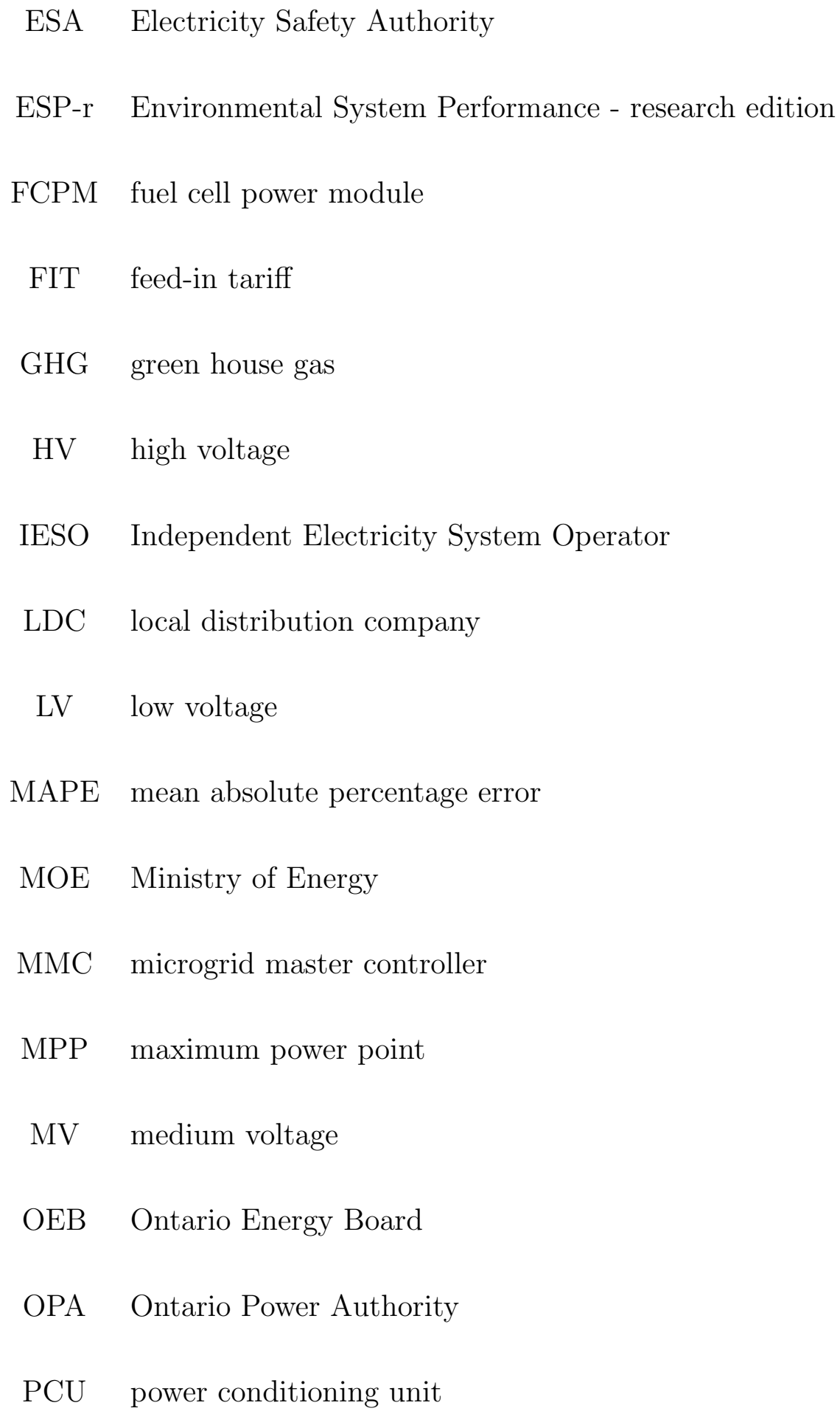




\author{
PV photovoltaic \\ RMSD root mean squared difference \\ R\&D research and development \\ TSSA Technical Standards and Safety Authority \\ TOU time-of-use
}

xviii 


\section{Chapter 1}

\section{Introduction}

This research thesis focuses on the study of residential photovoltaic (PV) hybridization with combined heat and power (CHP) generation systems at a community level. This chapter will outline the motivation for both technologies as well as the reason for their hybridization, providing justification from both political and technical perspectives. In addition, the goals and parameters of the proposed research will be described.

\subsection{Motivation for Innovation in Renewable and Alternative Energy}

The increasing development of renewable and alternative energy sources may be the result of two motivators. The first motivator is to reduce our carbon footprint and prevent the intensification of climate change. As greenhouse gas (GHG) emissions are impacting the global climate, various national policies are being put into place 
in order to reduce GHG emissions by using non-fossil fuelled energy resources [4]. Additionally, the need for increased energy security and diversification of energy resources are reasons for developing renewable and alternative energy generation [1]. Ontario has implemented many policies to increase renewable and alternative energy technology development, including the Green Energy and Green Economy Act, which will be further discussed in this chapter.

In Canada, the residential sector is responsible for $16 \%$ of total secondary energy use $^{1}$ and $15 \%$ of the country's GHG emissions [5]. This fact highlights the appeal of implementing renewable and alternative energy generation in the residential sector to reduce GHG emissions.

\subsection{Motivation for PV Technologies}

The motivation of PV technologies in Ontario stems from the province's financial incentives to increase PV energy generation capacity. This is known as the Feed-in Tariff (FIT) program implemented under the Green Energy and Green Economy Act. The province's demand for renewable energy generation is also reflected in its Long Term Energy Plan. Both of these political motivators are further discussed in this section.

\footnotetext{
${ }^{1}$ Primary energy is energy found in nature that have not been subjected to any conversion or transformation process. When primary energy sources are transformed in energy conversion into more convenient forms of energy, it is referred to as secondary energy e.g. electrical energy and refined fuels.
} 


\subsubsection{The Green Energy and Green Economy Act}

In 2009, the Green Energy and Green Economy Act was passed [6]. This Act implemented policies that encouraged renewable energy projects, conservation, and the creation of renewable investments and jobs. Ontario aimed to meet its growing electrical energy demand and ageing infrastructure through significant investments and renewal of its energy infrastructure. The Feed-in Tariff program was implemented with the Act to increase penetration of renewable technologies, including PV technology [7]. The FIT program focuses on the removal of deployment barriers in order to drive innovation, create a market, and increase production of renewable energy technologies [8]. In the three years since the deployment of the FIT program, solar and wind technologies have increased in popularity. Solar and wind operating capacity has increased by more than $500 \mathrm{MW}$ in three years since its deployment in 2009 [4].

The microFIT program is a subset of the FIT program that is designed for renewable energy technology installations of less than or equal to $10 \mathrm{~kW}$ in size. This consists of primarily residential scale installations. The most popular type of installation has been solar PV [4]. As of 2015, the program offers the price of 39.6 $\$ / \mathrm{kWh}$ of electricity produced from a solar rooftop installation [7]. The pricing rate of PV generated electricity has been declining since the roll out of the program. This is due to the withdrawal of political influence as market deployment advances. In the three years since the deployment of the program, the cost of PV systems has decreased by more than $40 \%$, and the industry aspires to reach grid parity [1]. Due to increased demand, competition and advancement in both technology innovation 
and market production have been prevalent. The microFIT policies are encouraging market development and innovation toward economic independence from political influences. The interested reader is directed to Stokes' publication for more details on politics of the program [4], and to Yatchew \& Baziliauskas' publication for an economic analysis of the program [9].

\subsubsection{Ontario's Long Term Energy Plan}

In 2013, solar PV represented 1\% (Figure 1.1) of Ontario's electricity production while having $2 \%$ of installation capacity [1]. Increasing capacity in solar PV energy is one aspect of Ontario's plan to diversify its energy resources. The Ministry of Energy published a Long Term Energy Plan that proposed increasing solar capacity to $8 \%$ by 2025 (Figure 1.2) [1].

Ontario's Long Term Energy Plan to increase solar capacity, along with the FIT programs, are policy drivers that may result in the economic stability of PV technologies. In the near future, PV deployment will be limited solely by technical factors, which is discussed in the next section [10].

\subsection{Challenges of PV Integration with the Grid}

The recent deployment of intermittent energy generation technologies brought with it various challenges in integrating with the existing electricity infrastructure. This section provides a brief background on the Ontario electricity infrastructure, commonly 


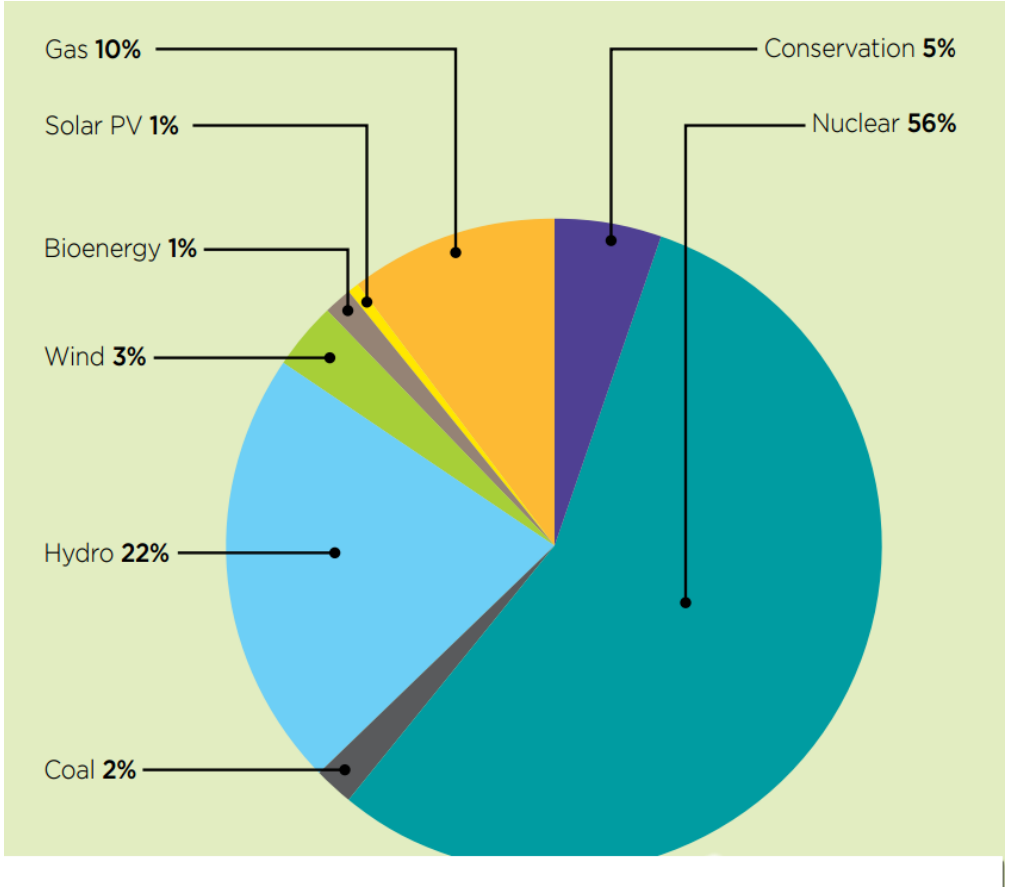

Figure 1.1: Ontario's electricity production; with permission (C)Queen's Printer for Ontario, 2013 [1] 


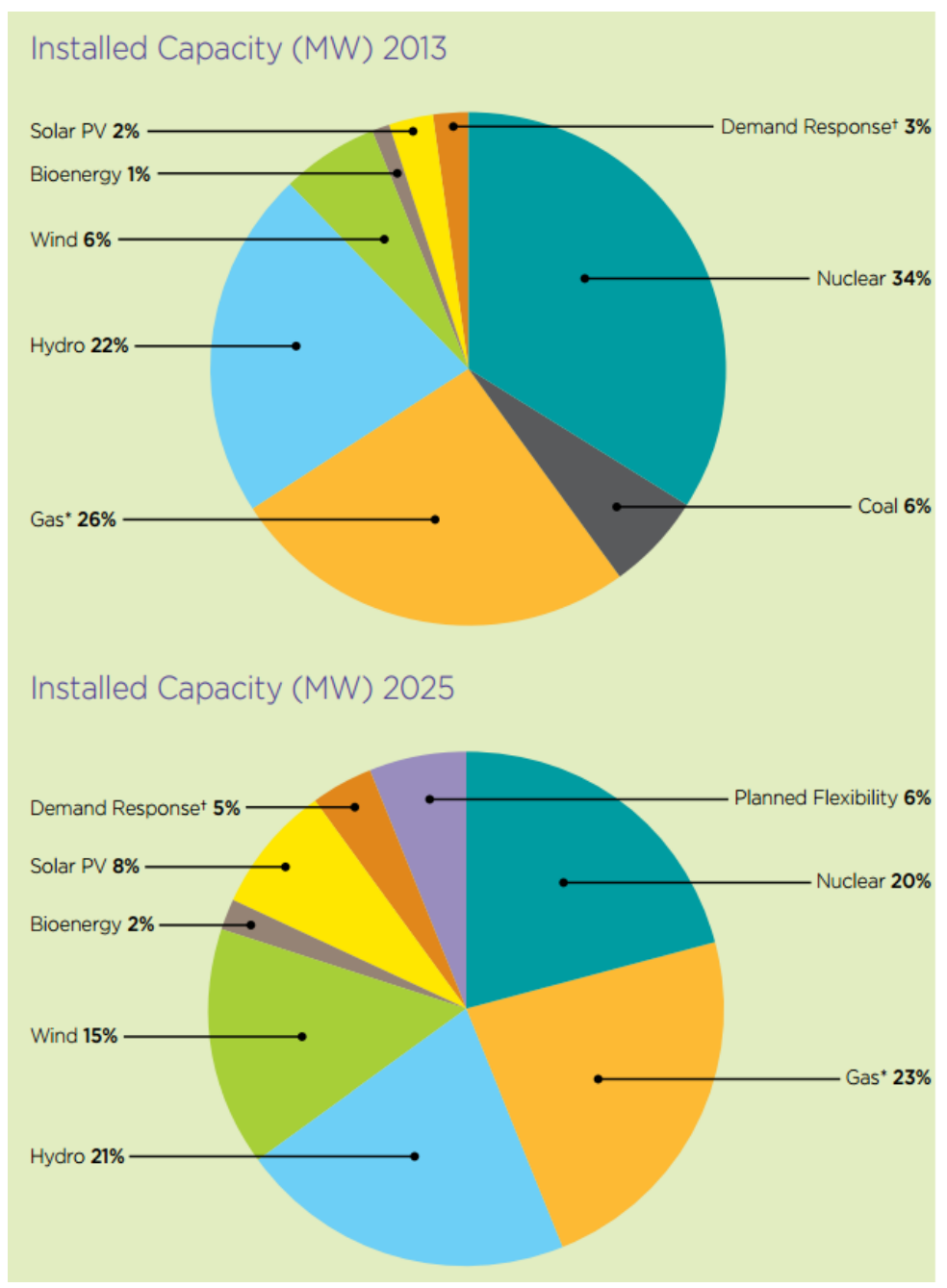

Figure 1.2: Total generating capacity of resources in Ontario: 2013 \& 2025, with permission (C)Queen's Printer for Ontario, 2013 [1] 
referred to as the Ontario grid. This is followed by a discussion of the intermittency of PV and how this creates issues for grid integration.

\subsubsection{Background on the Ontario grid}

As of 2013, power is generated at centralized power plants, transmitted, and distributed to various users. The delivery of power is possible through the utilization of transformers that transfers energy between circuits allowing power to be transmitted at different voltage levels. The increase or decrease of voltage from the primary side to the secondary side of the transformer is referred to as step-up or step-down.

A power flow example of the Ontario grid is illustrated in figure 1.3 [11]. Power is generated at a central plant at voltages of about $30 \mathrm{kV}$. It is stepped up to approximately $500 \mathrm{kV}$ to reduce losses during transmission. Substations that house transformers change voltage levels between high transmission voltages to lower distribution voltages. Several step-down transformers reduce the voltages at various distances across the transmission line. For the purpose of this discussion, lines with voltages of $69 \mathrm{kV}$ and above is the high voltage (HV) line; the $25 \mathrm{kV}$ line is the medium voltage (MV) line; and the residential voltage $(240 \mathrm{~V} / 120 \mathrm{~V})$ is the low voltage (LV) portion of the grid.

At the residential level, the power network is structured radially, as shown in figure 1.3. The radial structure distribution topology radiates a larger supply of power from the transformer substation to lower voltage lines until the consumer is reached. This type of design favours unidirectional power flow from the source to the load. Reverse power flow can negatively affect protection schemes in the system 


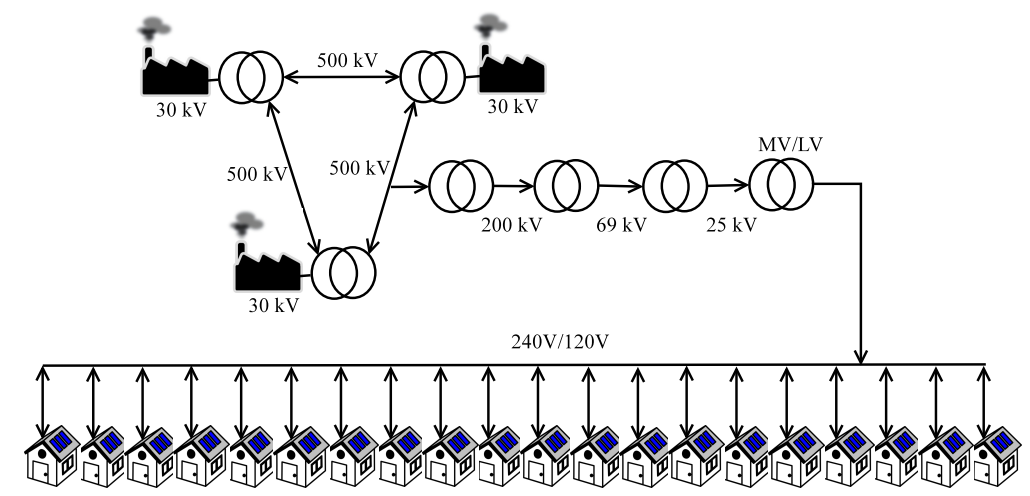

Figure 1.3: Example power flow of the Ontario electricity grid structure

that were designed for power flow in one direction. The original grid infrastructure was not designed for the backflow of electricity from low to high voltage levels. Upgrades to the transmission and distribution system was necessary to accommodate the backflow of electricity caused by distributed generation. The residential PV installations discussed in this thesis are located in the low voltage section of the grid, and may interact with the $\mathrm{MV} / \mathrm{LV}$ transformer.

\subsubsection{PV integration issues with the grid}

Similar to many renewable technologies, solar energy is intermittent. The performance of PV technology is highly dependent on solar irradiance and temperature [12]. Both of these parameters fluctuate with diurnal and seasonal patterns. They are also affected by shadows of adjacent objects (eg. trees and chimney) and passing clouds or birds. The result is an unstable source of energy generation. The intermittency of solar power causes various issues when interacting with the grid.

Two main issues are prevalent in the integration of distributed generation (DG) 
with the grid: exceeding voltage regulation limits and interfering with the fault protection system [13]. These issues become more prevalent as the penetration of intermittent distributed generation increase.

Overvoltage occurs when the PV generation is high during low load periods. In this case, voltage rises as power flow is reversed in the LV level. In the case where PV generation output rises to unacceptable levels, a protection device called the overvoltage rely, would be triggered to cause a disconnection between the DG and the utility lines [14].

Another issue deals with the coordination of protective devices. Conventional protection schemes were developed for radial distribution systems. The bidirectional power flow caused by distributed generators may cause miscoordination between protective devices. The interested reader is directed to the study conducted by Brahma and Girgis for a detailed description of this issue [15].

Upon applying to generate energy under the microFIT program, a distribution availability test is conducted to determine whether the distribution system has, or will have sufficient resources to accommodate the project [16]. At this point the local distribution company (LDC) conducts assessments based on the proposed DG system to ensure that integration issues, such as those mentioned above, are minimal.

\subsubsection{Source of backup generation}

PV energy generation requires additional electricity generation to maintain reliable electric supply and meet fluctuating demands. When more power is needed by the community than generated by the existing PV system, the panels operate at their 
maximum power point (MPP) to capture the most solar irradiance at the time. The rest of the load demand is met by the grid.

In Ontario, the grid views the intermittent generation pattern of PV as a load offset. As of 2015, the grid accommodates the changes in demand patterns through centralized power generation using mostly natural gas [1]. Since reliable electricity generation is dependent on the capacity of the grid to provide backup, the grid capacity is a limiting factor to the installation capacity of PV technology on the electrical grid.

\subsection{Benefits to Hybridization of PV with CHP}

The installed capacity of PV technology is limited by the grid's ability to provide backup to solar energy fluctuations. In order to increase this capacity to $8 \%$ as planned in Ontario, additional dispatchable backup generation is required to satisfy electrical demand needs. Dispatchable generators are those that can adjust their power output on demand. Current dispatchable backup generators are in the form of centralized gas power plants with electrical efficiencies averaging $40 \%$ [17].

\subsubsection{Micro-CHP: increasing utilization efficiency}

An alternative to centralized power generation is on-site power generation. On-site generation of power eliminates the transmission and distribution power losses. It may also help offset future requirements for grid infrastructure upgrades [1]. The advantage of on-site generation is the opportunity to utilize low grade heat for space 
heating and domestic hot water (DHW) purposes, as opposed to dumping the heat. This simultaneous generation of power and heat is referred to as combined heat and power (CHP) or cogeneration. Residential-scale cogeneration technologies have fuel to electricity conversion efficiencies (Equation 1.1) of up to $40 \%[18,19]$. In Equation 1.1, $\eta_{e l}$ is the electrical efficiency, $P_{D C}$ is the DC power output, and $L H V_{\text {fuel }}$ is the lower heating value of the fuel. Their total fuel utilization efficiency (Equation 1.2) is typically greater than $85 \%$ [20]. Equation 1.2 defines the total fuel utilization efficiency, $\eta_{C H P}$. Where, $Q_{C H P}$ and $W_{C H P}$ represent the thermal and electrical energy utilized, respectively, and $H H V_{\text {fuel }}$ represents the higher heating value of the consumed fuel. Micro-CHP has the potential to compete in the energy market with centralized power generators because of its transmission and infrastructure savings, and its significantly higher fuel utilization efficiency.

$$
\begin{gathered}
\eta_{e l}=\frac{P_{D C}}{L H V_{\text {fuel }}} \\
\eta_{C H P}=\frac{Q_{C H P}+W_{C H P}}{H H V_{\text {fuel }}}
\end{gathered}
$$




\subsection{Literature Review}

\subsubsection{PV and micro-CHP systems}

The components and operation of PV technologies are described by Romero-Cadaval et al. [21]. This paper was published to shed light on future improvements and research activities regarding PV technologies and its integration with the grid. It was suggested that emerging problems included the control of distributed generation plants integrated within a community of houses and the development of energy backup systems. PV integration studies and potential challenges were discussed by Atiraei and Aguero, [22], including the voltage rise and unbalance in the feeder, impact on voltage regulators, voltage fluctuation issues, and reverse power flow. The impact of these challenges varies with penetration level. The publication discussed the need for systematic interconnection studies and high-resolution load data specific to the location of study for an extended period of time. The technical and potential problems of PV power system integration with the grid are also discussed by Eltawil and Zhao [23].

Boait et al. studied micro-CHPs for their financial benefits and carbon miti-

gation improvements, and concluded that careful marketing and the application of appropriate metering will increase the uptake of the technology to benefit consumers and the environment [24]. The proton exchange membrane fuel cell (PEMFC) has been modelled in ESP-r several times. In 2004, Ferguson and Ugursal constructed a steady-state model of a PEMFC to study fuel use and energy production, climate suitability, sizing, and control strategies [25]. In 2012, Johnson et al. calibrated and 
validated a 1-kW PEMFC device using empirical data [19]. This was done so that future research will be able to use the model to examine the electrical and thermal performance of a PEMFC device under various operating scenarios.

Pearce provides arguments for hybridizing CHP with PV in order to increase PV penetration level. He argues that the deployment of PV technology is solely a technical issue since its economic case is rapidly improving [10]. PV hybridization with CHP overcomes the intermittency limitations of PV systems and allows the capacity of PV technology on the grid to increase without impacting the electricity network. Pearce's hybridization studies were done in Southern California [10]. This study took an analytical approach to determining the change in penetration level of PV as a result of the hybridization. He concluded that an increase to $25 \%$ of PV penetration from the status quo of $5 \%$ can be achieved. Derewonko \& Pearce conducted a similar study in Kingston [26]. The goal was to output reliable base load power to the grid with the assistance of a CHP system and a battery bank. This research developed an analytical approach to determining the performance of the PV, CHP, and battery bank systems using measured solar PV array data and manufacturer specifications on a Freewatt Honda 4-stroke single cylinder engine. It was concluded that further optimization was required to lower costs and emissions. Trigeneration ${ }^{2}$ and battery storage technologies have been considered, as proposed by Nosrat et al. [27]. However, due to the immaturity of absorption chiller and battery technologies for residential applications, these components will not be studied in this research.

\footnotetext{
${ }^{2}$ The simultaneous generation of electricity and useful heat, while serving cooling purposes, also known as combined cooling, heat, and power (CCHP)
} 


\subsubsection{Community Load profile}

In order to study the performance of distributed generation technologies in a community, the load profile in the community was used for control and evaluation purposes. This research used data from 12 electrical loads taken from residential houses located in Ottawa between the years of 2009 and 2010, Canada, collected in Saldanha \& Beausoleil-Morrison's study [28]. They revealed that residential electrical load profiles are strongly dependent on occupant behaviour. Their collection of data represented a range of occupant behavioural driven electricity consumption patterns. It was shown in Saldanha \& Beausoleil-Morrison's research that single residential load fluctuations are frequent and unpredictable.

The maximum power, the average power, and the ratio between the two are shown in Table 1.1. By measuring fluctuation as the power ratio between the maximum and the average power, aggregated electrical loads fluctuate by at least $45 \%$ less compared to that of a single residential house. The residential load data was collected from various geographic locations in Ottawa. This research makes the assumption that the range of occupant behaviour in the 12 residential electrical loads approximates the diversity of demand patterns that can be found in a neighbourhood community of 12 houses in Ottawa. Since the aggregation of electrical loads of 12 houses significantly reduced the fluctuation of the electrical load profile, and the diversity in the data represents one that can be found in a community, this study defines the load from these 12 houses as the load profile that can be found in a simulated community. 
Table 1.1: Electrical load consumption of the 12 houses

\begin{tabular}{|c|r|r|r|}
\hline House & Maximum Power $(\mathrm{kW})$ & Average Power $(\mathrm{kW})$ & Power Ratio \\
\hline 1 & 12.45 & 0.57 & 21.75 \\
\hline 2 & 10.05 & 0.35 & 28.42 \\
\hline 3 & 15.00 & 0.71 & 21.14 \\
\hline 4 & 11.85 & 0.69 & 17.08 \\
\hline 5 & 12.75 & 0.74 & 17.18 \\
\hline 6 & 14.62 & 0.80 & 18.19 \\
\hline 7 & 12.15 & 1.02 & 11.96 \\
\hline 8 & 14.48 & 1.16 & 12.53 \\
\hline 9 & 17.78 & 1.46 & 12.20 \\
\hline 10 & 16.65 & 1.86 & 8.95 \\
\hline 11 & 10.42 & 1.06 & 9.81 \\
\hline 12 & 11.48 & 1.35 & 8.50 \\
\hline Total & $\mathbf{4 9 . 9 5}$ & $\mathbf{1 0 . 6 4}$ & $\mathbf{4 . 6 9}$ \\
\hline
\end{tabular}


Table 1.2: Solar panel and inverter selection from major solar distributors in Ottawa

\begin{tabular}{|l|r|r|}
\hline Company & Module & Micro-Inverter \\
\hline Ottawa Solar & Hanwha 250W P / Conergy 260W P & Enphase \\
\hline Jazz Solar & Canadian Solar 250W/280W P & Fronius \\
\hline iSolara & Canadian Solar 250W P & Enphase M215 \\
\hline Solarcity & Canadian Solar 250W P & Enphase \\
\hline Clearly Solar & Conergy 250 W P & Enphase M215 \\
\hline Solar Logix & Jinko 250W P & Enphase M215 \\
\hline
\end{tabular}

\subsubsection{PV module and inverter selection}

The simulated community of 12 houses is located in Ottawa, Ontario. In simulating the community powered by distributed generators, realistic models of these technologies needed to be chosen. The most commonly installed solar modules are reflected in those used by local solar PV distributors. The main solar PV distributors in Ottawa were contacted to inquire about their choices of modules and inverters. Their responses are documented in Table 1.2.

In the selection of PV panels, 50\% of these distributors use the Canadian Solar CS6P-250P modules [29]. This Canadian Solar polycrystalline module has a maximum power output of $250 \mathrm{~W}$. Some of the other popular models used in Ottawa include the $250 \mathrm{~W}$ polycrystalline modules from Hanwha, Conergy, and Jinko. Due to the popularity of the Canadian Solar module and its comparable power output with the majority of other commonly used models, it was decided that the simulation inputs will be derived from the Canadian Solar module specifications. 
The electricity produced from PV is direct current (DC), unlike what we receive from the utility in alternating current $(\mathrm{AC})$. Inverters convert the $\mathrm{DC}$ power output from the PV module/array into AC power, so that the technology can feed power into the electrical grid.

All of the distributors used micro-inverters to pair with their panels for residential installations. Micro-inverters are attached to the back of each module to maximize power output. $83 \%$ of these distributors used micro-inverters from Enphase Energy (Table 1.2). A popular model that pairs well with the Canadian Solar 250P modules is the Enphase M215 [30]. Based on the specification parameters, The California Energy Commission (CEC) weighted efficiency was used in the simulation to model the energy lost through the inverter. The CEC weighted efficiency was proposed by the California Energy Commission [31]. It takes into account an averaged operation efficiency over a yearly power distribution (Equation 1.3). Where $\eta_{i} \%$ is the efficiency at $i \%$ nominal power.

$$
\eta_{C E C}=0.04 \cdot \eta_{10 \%}+0.05 \cdot \eta_{20 \%}+0.12 \cdot \eta_{30 \%}+0.21 \cdot \eta_{50 \%}+0.53 \cdot \eta_{75 \%}+0.05 \cdot \eta_{100 \%}
$$

Specifications from the most commonly installed PV and inverter models were used in the simulation, to more closely represent the technologies installed by distributed generators in Ottawa. The following section will discuss the choice of using proton exchange membrane fuel cells in the simulated community. 


\subsubsection{Proton exchange membrane fuel cell}

One of the micro-cogeneration technologies being studied at Carleton is the proton exchange membrane fuel cell (PEMFC). The PEMFC microcogeneration technology uses natural gas as its fuel source, similar to centralized power generators. Biofuel is an alternative fuel source that is carbon neutral. While producing power, the low-grade heat can be used for space heating and domestic hot water purposes. This technology was selected because its model was calibrated and validated with measured data to allow for an extensive analysis of the system [19].

Empirical data was used by Johnson et al. [19] to calibrate and validate a model for simulating the thermal and electrical performance of a PEMFC device. Annex 42 of the International Energy Agency's Energy Conservation in Buildings and Community Systems Programme developed a fuel cell micro-cogeneration model to be simulated in building performance simulation tools [3]. Johnson et al determined the calibration coefficients empirically to specifically represent a PEMFC on the 1$\mathrm{kW}$ scale, suitable for residential purposes. These calibration coefficients were used in this research to simulate the electrical performance of a residential scale PEMFC system.

In addition to the benefit of performing simulations with an accurate model, PEMFC is suitable for residential applications. PEMFC is a low-temperature fuel cell, operating at approximately $80{ }^{\circ} \mathrm{C}$ [32] ( other types of fuel cells operate at 200 ${ }^{\circ} \mathrm{C}-1000{ }^{\circ} \mathrm{C}$ ). Not only does this result in safer operation, it also allows the PEMFC to modulate quickly according to the load demands. Compared to combustion-based micro-CHPs, PEMFCs have fewer moving parts, allowing for a longer life-time and 
fewer maintenance requirements.

Aside from the low operating temperatures, PEMFC systems have solid electrolytes, avoiding any risk of electrolyte leakage. Additionally, compared to other fuel cell technologies, PEMFCs have the highest power density of $0.3-0.8 \mathrm{~W} / \mathrm{cm}^{2}$. A disadvantage of the PEMFC is that the membranes must maintain hydrated. Failing to maintain hydration would cause deterioration of the membranes and degradation of the fuel cell. Additionally, the platinum material used in PEMFCs is susceptible to carbon monoxide contamination, which is a product of the reforming process [32].

\subsubsection{Power management strategies}

In integrating the PV system, PEMFC system, electrical load, and electrical grid, a strategy for managing the behaviour of some of these components is required. Thale et al. [33] developed a control operation using a Microgrid Master Controller(MMC) that determines when to turn the fuel cell on, the voltage that the PV operates at, and the amount of load to shed. This research focused on the various modes of operation, such as grid-connected, islanding, and MPP modes. Khanh et al. [34] developed a power management system to operate PV at MPP and keep PEMFC within its high efficiency band. However, this method does not account for the modulation limits of the PEMFC. There have also been studies that integrate battery storage technology into the system. The power management strategy in these cases developed the control algorithm based on the state of charge of the battery storage system. For example, Dursun and Kilic [35] combined PV, wind, PEMFC, hydrogen storage, and a battery with a power management strategy that aimed to satisfy demand. Their strategy was 
focused on making sure that the state of charge of the battery was above minimum. Another study with similar system components focused on meeting the objectives of minimizing operating cost and pollutant emissions [36].

Past research on the power management of micro-CHP systems satisfying a residential load have also been conducted. Ferguson \& Ugursal [25] evaluated two control strategies, one that follows the electric load and one that follows the thermal load. Another micro-CHP system study determined the CHP output based on the room and domestic hot water temperatures [24].

In a past simulation research using the 1-kW PEMFC model proposed in this research and a battery, the PEMFC control strategy was developed based on seasonal parameters [37]. The PEMFC was modulated in consideration of the thermal requirements in the residence, the electrical output was maintained constant at the maximum power setting in the winter season, and at the minimum power setting during the summer season.

\subsubsection{Thesis contribution}

In order to further develop the previous work on the hybridization of PV and CHP systems discussed above, this research aimed to perform simulations in greater detail than previously considered. This research aimed to attain higher accuracy by using a calibrated PEMFC model and measured electrical loads. Additionally, the system simulations were performed at one-minute time steps. Unlike previous studies, the simulation was performed at a community residence level rather than a single residence level. To integrate the various components of the system, a power management 
strategy was developed specific to the capabilities and constraints of this system.

\subsection{Objective}

The objective of this research is to reduce the reliance of PV on the electrical grid in order to increase the capacity of PV. Distributed energy generation systems located at the source of solar energy production may be used to compensate for the impact of intermittent PV generation on the electrical grid.

A power management strategy was proposed to integrate the PEMFC and PV systems. The technical limitations of PEMFC and PV require an appropriate energy management strategy that integrates the two technologies while attempting to follow the electrical demand pattern. The power management strategy implemented involves forecasting the energy demand of the community and the PV generation pattern to determine the PEMFC operation strategy. At the same time, real-time monitoring of the PV power output, the load, and the grid behaviour will result in continuous updates on the energy demand forecast.

Two scenarios of PEMFC operation were analysed. The first operating strategy attempts to follow the electrical demands of the community, while taking the PV generated energy into account. The second operating strategy aims to assist the grid in providing service to its customers in addition to following the electrical demands of the community, as in the first scenario. A residential grid-connected community powered by the two technologies, PV and PEMFC, was simulated using the designed power management strategy under both proposed operating strategies to assess the 
change in grid interaction. Comparison parameters are used to evaluate the reliance of the community on the grid through their interactions.

Furthermore, this thesis examines the feasibility of deploying micro-CHP systems in Ontario. Through interviewing stakeholders and learning from past experiences, the technical, economic, and social challenges were explored. Considering the opportunities for policy potential, policy recommendations were made and steps involved in implementation were discussed.

\subsection{Outline}

The next chapter of this thesis will provide a layout of the system topology and the control strategy. This includes a discussion of the system layout and components, details of the power management strategy, implementation of the simulation scenarios, and the reasoning behind the comparison metrics chosen. This is followed by Chapter 3, which provides details on the analysis tools used in this research, including the simulation tool ESP-r and the load forecasting method. Then, in Chapter 4, the results will be discussed, comparing the two scenarios to each other and to the base-case scenario. Chapter 5 discusses the policy considerations and recommendations in providing subsidies for micro-CHP systems. Lastly, conclusions are drawn and recommendations are made on future research topics. 


\section{Chapter 2}

\section{System Topology and Control}

The residential energy generating components consist of PV modules and PEMFC units distributed within the community. The sizing of these components and the system layout are presented in this chapter. A power management strategy developed to integrate the power generating components with the load is also explained. Finally, the two scenarios for simulation as well as the choice of metrics for analysing performance are discussed.

\subsection{System Components and Layout}

The system components were sized with various considerations realistic to those encountered in industry. The system layout provides an overview of how the various system components are connected to each other and to the electrical grid. 


\subsubsection{PV sizing}

Several considerations were taken into account for the sizing of the PV modules. These include policy limitations, infrastructure constraints, and available roof space. The sizing strategy aimed to install the maximum number of panels while taking these restrictions into consideration.

The microFIT program (described in Chapter 1) applies to renewable generation projects that are less than $10 \mathrm{~kW}$ in size. Potentially, the community of 12 residential units is able to install systems totalling a capacity of $120 \mathrm{~kW}$. The feasibility of an 120 $\mathrm{kW}$ system was further analysed using the infrastructure and roof space constraints.

The grid infrastructure steps the voltage down through a transformer to 240/120 $\mathrm{V}$ to be used by residences at the community level. Please refer to Figure 2.1 for a schematic of the community level power electronics connections. The capacity of these distribution transformers in Ottawa is typically $50 \mathrm{kVA}$ (apparent power) [38]. The current capacity in the secondary drop lead is $185 \mathrm{~A}-325 \mathrm{~A}$ [38]. The secondary drop lead is the conductor that connects the transformer to the secondary bus, that then delivers power to the end-user. This value varies based on the age of the system. To be conservative in this evaluation, the $185 \mathrm{~A}$ current limit was used. The micro-inverters installed in the simulated community output nominal current at $0.9 \mathrm{~A}$. In order to abide by the current limit in the secondary drop lead, a maximum of 205 panels can be installed in the community, corresponding to $51.4 \mathrm{~kW}$ of solar capacity. Taking the infrastructure constraints into consideration resulted in a maximum capacity well below those specified by the FIT program. 


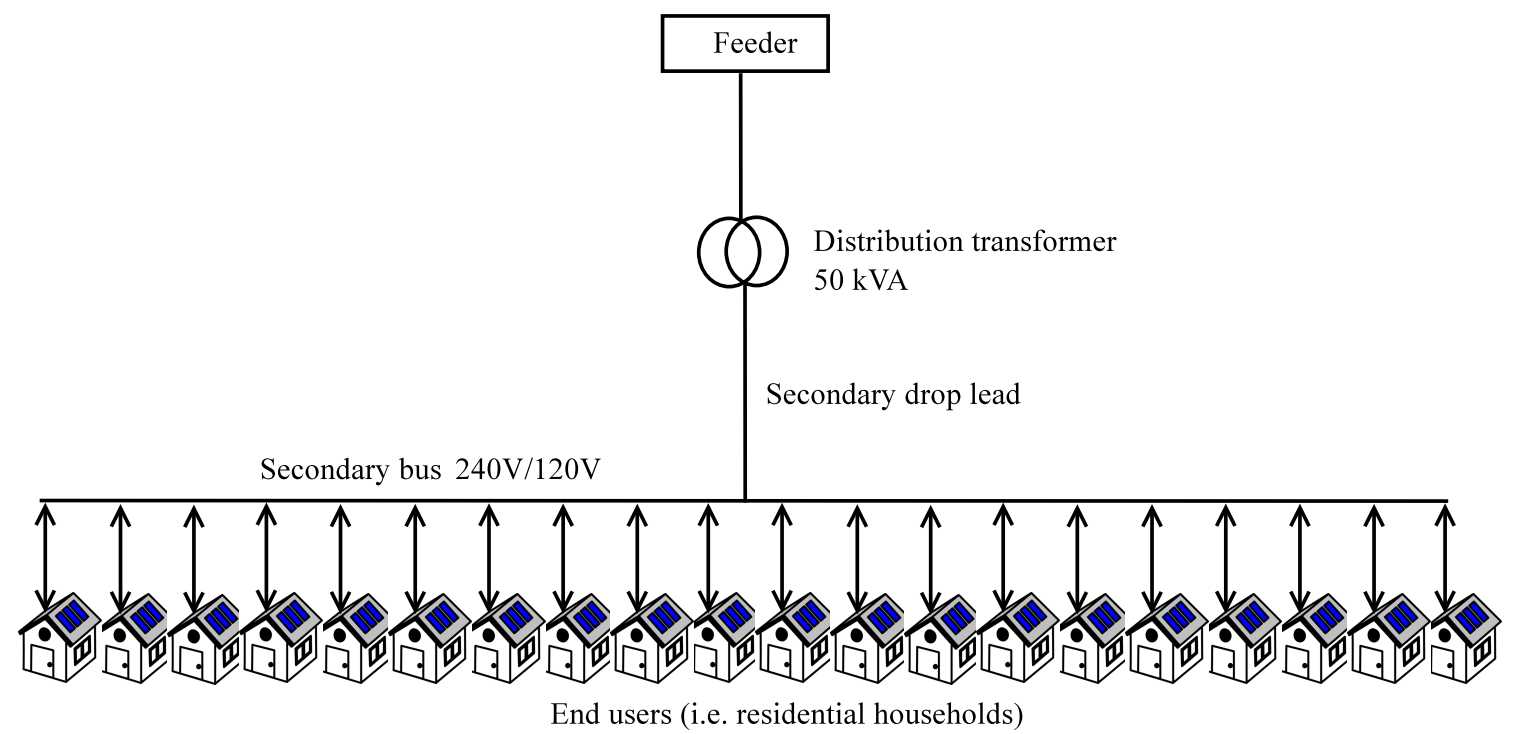

Figure 2.1: Community level power electronics connections

The available roof space is typically the main consideration in industry when sizing PV panels. In evaluating the amount of roof space available for PV installations, a conservative estimate was based off of the 2010 housing stock statistics [5]. Assuming that half of the roof space is facing in the South direction, and accounting for the space consumption of the racking system, a capacity of $51 \mathrm{~kW}$ can be installed. However, obstructions such as trees or chimneys may reduce the available roof space available. A reduction of 2 panels/house on average to take obstructions into consideration results in a total of 180 panels with a capacity of $45 \mathrm{~kW}$. After the determination of the PEMFC capacity, the combination of the sized PV and PEMFC units were simulated to ensure that the infrastructure constraints were still satisfied.

As an additional check to avoid over-sizing the system, the community's maximum noon load of $44 \mathrm{~kW}$ was used as a guideline. Since the proposed system sizing 
of $45 \mathrm{~kW}$ matches very closely with the maximum community noon load, excessive dumping of energy generated can be avoided. As a result, a PV capacity of $45 \mathrm{~kW}$ was simulated, since it met all of the considerations mentioned above.

\subsubsection{PEMFC sizing}

The sizing of the PEMFC units were dependent on two factors: the minimization of equipment cycling and the thermal requirements of the house. The PEMFC sizing strategy aimed to satisfy both requirements through an evaluation of the PEMFC performance parameters.

Each PEMFC unit has a maximum capacity and a minimum power output before shut down. Shut downs and start ups were avoided in the interest of minimizing equipment cycling. As a result, the minimum electricity demand in the community was used to size the system of PEMFC units so that shut downs would not be required. This strategy resulted in simulating 12 PEMFC units in the community, evenly placing one in each household.

An additional analysis was conducted to ensure that the thermal output from the units were not dumped or wasted. The thermal output of the PEMFC units was compared to the domestic hot water heating requirements in an average household. The DHW heating requirements of a typical household was found to be in the range of 29-45 MJ/day, based on the water temperature requirements of $49-60{ }^{\circ} \mathrm{C}^{1}$ [39]. The PEMFC thermal input into the DHW tank, less the tank losses, amount to approximately $30 \mathrm{MJ} /$ day. The thermal input was determined through calculations

\footnotetext{
${ }^{1}$ This range of temperatures is designed to prevent legionella bacteria growth while avoiding scalding.
} 
involving the specific heat capacity of water and the temperatures of the inlet and outlet nodes. The tank losses were estimated using the tank's heat loss coefficient.

Based on the comparison between the thermal output of the PEMFC and the DHW requirements of an average house, it was determined that one PEMFC per house was an acceptable size from a thermal requirement perspective. Additional thermal loads can be met by possible plant configurations discussed by McMurtry [40]. The sizing strategy of placing one PEMFC in each household was done to both avoid fuel cell shut downs and heat dump. This resulted in the sizing of twelve 1-kW PEMFC units in the simulated community of twelve houses.

\subsubsection{System layout}

Each household in the simulated community generates power from the installation of multiple PV modules and one PEMFC unit. The system layout for one house in the community is shown in Figure 2.2. In this layout, only 3 PV modules are shown for illustration purposes. In reality, approximately 15 modules on average are installed per household. The directions of electricity flow are shown in solid lines and the directions of fluid flow are shown in dotted lines.

Each PV module is connected to a micro-inverter that converts the DC power generated to an $\mathrm{AC}$ power output. The $\mathrm{DC}$ power is generated at $25-35 \mathrm{~V}$ and stepped up to $240 \mathrm{~V}$ through the micro-inverter. The AC power is then sent through the distribution panel. Metering of the amount of energy sold to the utility occurs just before the distribution panel. Similarly, The DC power generated from the PEMFC unit is converted to AC through the power conditioning unit (PCU). This 
power is then also sent through the distribution panel. The distribution panel is an electrical component located within each household that is responsible for dividing the electrical power into subsidiary circuits. It is also equipped with a fuse or circuit breaker to serve protective functions. While receiving energy inputs from both the PV modules and the PEMFC unit, the distribution panel supplies energy to the AC loads within the household. If excess energy is present, it is sent to the community to consume, and then to the grid. Metering of the power generated from the PEMFC unit isn't present in the system because the electricity generated through PEMFC cannot be sold to the utility under current policies. The feasibility of implementing a program to allow micro-CHPs to sell electricity to the grid is discussed in Chapter 5.

The PEMFC unit also supplies thermal energy to the household, through exchanging its waste heat with a DHW tank. An auxiliary DHW heater is also present to assist in meeting the DHW tank temperature requirements when PEMFC generation is low.

Through the system layout presented above, electrical loads are met through both the PV and PEMFC components, while DHW requirements are met through the thermal energy generated by the PEMFC unit.

\subsection{Power Management Strategy}

In order to operate the PEMFC system in conjunction with the PV system, a power management strategy for modulating the PEMFC system was implemented. This 


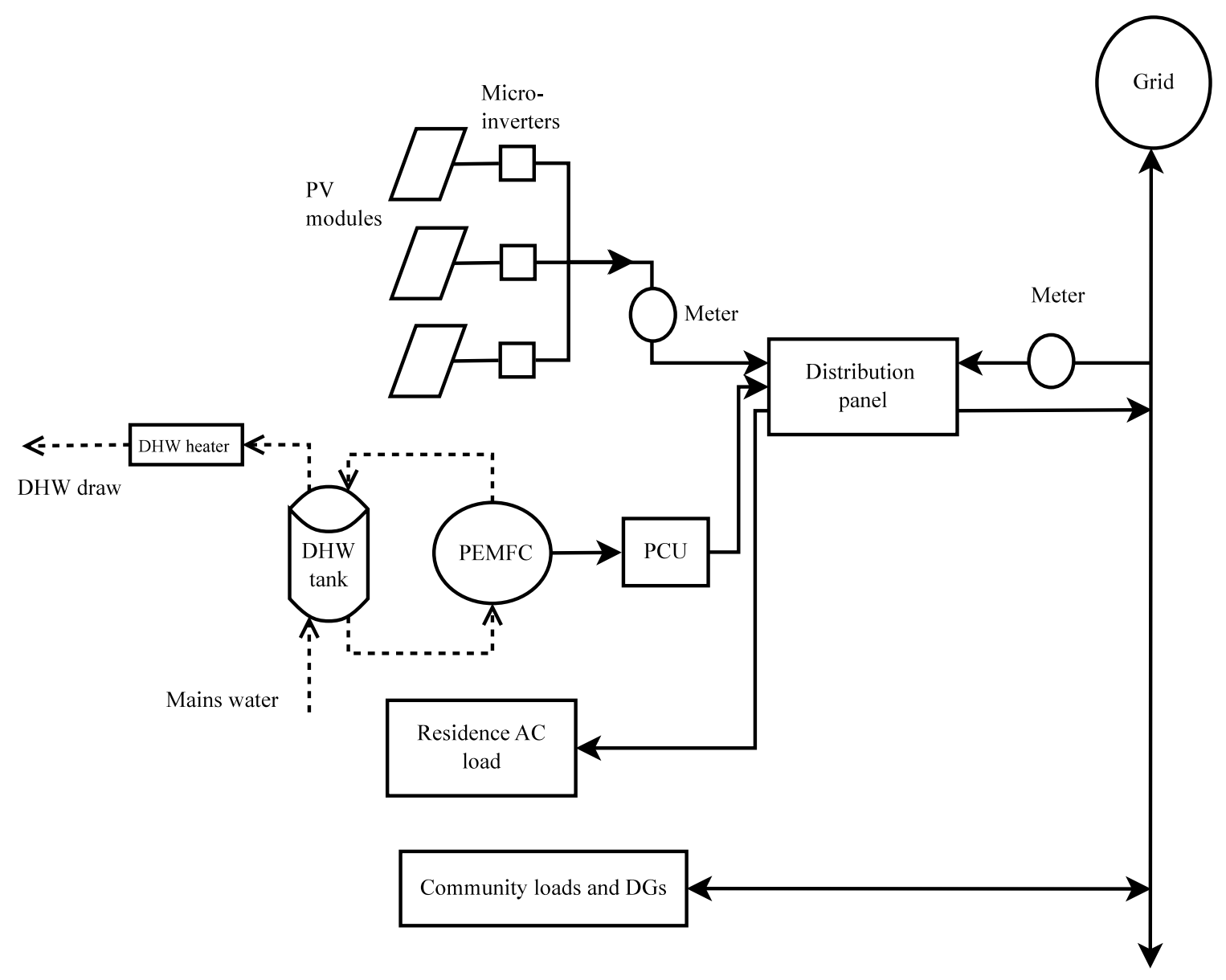

Figure 2.2: System layout and components 
strategy involves determining the output of the PEMFC system based on the amount of power needed currently and the predicted power generation needed. The objective of the PEMFC power management strategy is to complement the PV arrays in satisfying the load demand while abiding by the PEMFC operation limitations.

Two PEMFC system limitations must be considered for the purpose of providing back up to PV: the modulation rate and the range of applicability. Each 1-kW PEMFC unit is able to modulate its output at a rate of about $0.60 \mathrm{~W} / \mathrm{s}$. In a community of multiple PEMFC units, the units are able to modulate in parallel, achieving a higher overall modulation rate. The range of applicability for each PEMFC unit is between $314 \mathrm{~W}$ and $1113 \mathrm{~W}$ (DC). A power management strategy was developed to follow load while taking these system limitations into account. This strategy is further described below and illustrated in Figure 2.3.

The inputs to the control strategy are the power generated by the PEMFC units at the current time step, $P_{g e n, t}$, and the forecasted power needed from the PEMFCs on the next time step, $P_{\text {follow }, t+1}$. The load forecasting method is discussed in Section 3.3. $P_{\text {follow }, t+1}$ is the future power demand of the community after taking the PV power generation into account. Through the comparison of $P_{\text {gen, } t}$ and $P_{\text {follow,t+1 }}$, it is determined whether the power required is within the modulation limits and the applicable power range. If it is, the power generated at the next time step, $P_{g e n, t+1}$, will follow the power required.

Otherwise, further analysis is required. If the system is within modulation limits, but outside of the applicable power range, $P_{g e n, t+1}$ will modulate to the system range boundary. If the system is outside of the modulation limits, the time it would take 


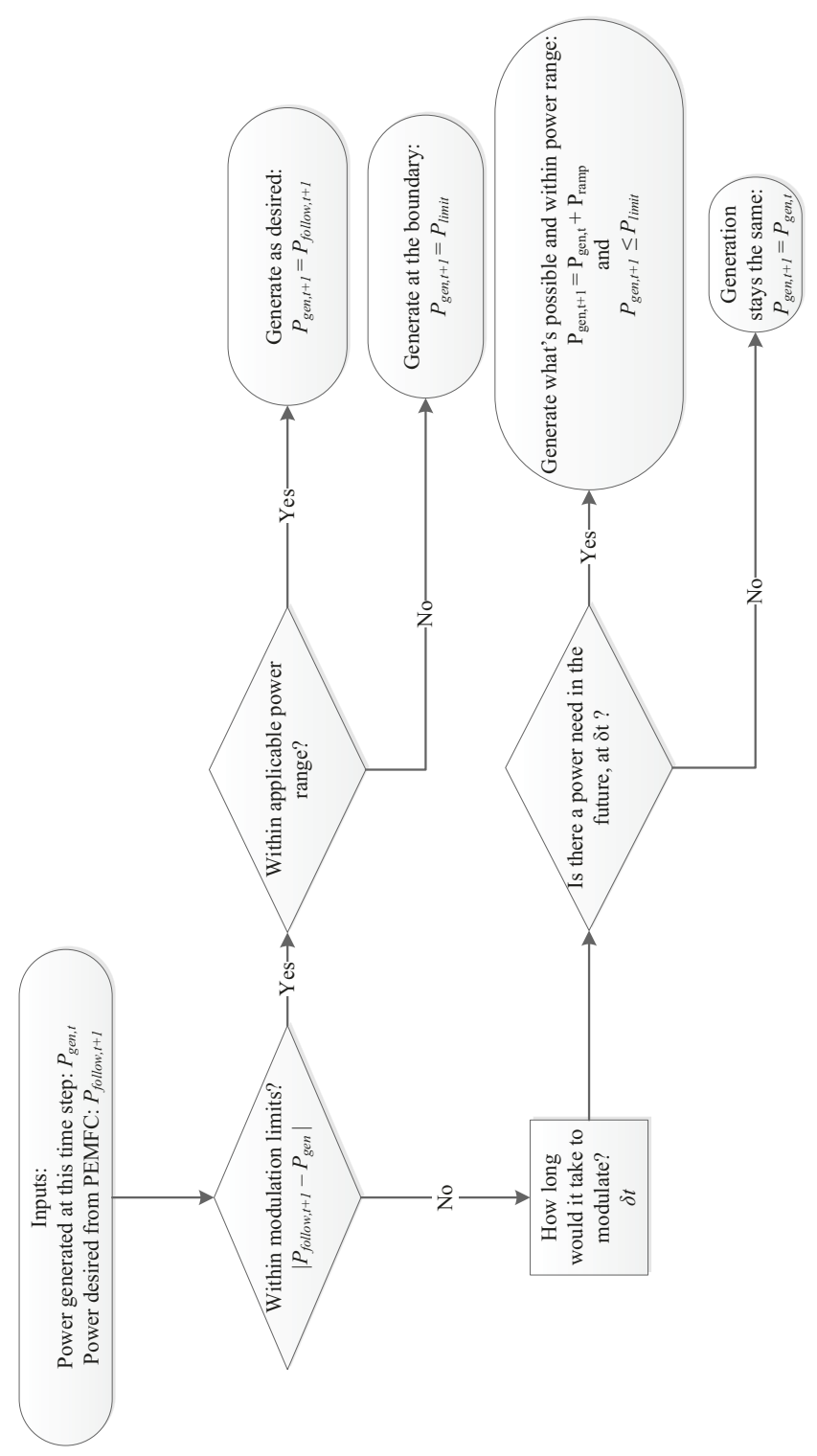

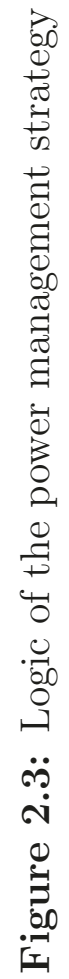


$(\delta t)$ for the PEMFC to modulate to the desired power, $P_{\text {follow }, t+1}$ is calculated. This is done to see if the power modulation would be needed at a later time, when the modulation is achieved (i.e. if power is being modulated up by 1 unit, it is necessary that at time, $\delta t$, the power desired is at least 1 unit higher than the present power generation). If the power level proposed, $P_{\text {follow }, t+1}$ won't be needed after time, $\delta t$, then the power generated in the next time step would remain the same. However, if the power modulation is needed in the future, power will be generated to attempt to follow load, within its modulation limits.

\subsection{Scenarios for Simulation}

Two scenarios were developed to study PEMFC operational strategies that followed the demands of the simulated community and that of the province. Both scenarios were evaluated against the base case, where the community is powered by PV only and is integrated with the grid.

\subsubsection{Load-follow scenario}

The ageing electricity infrastructure in Ontario favours the development of distributed energy generation, located close to the energy demand. Ideally, these distributed energy systems would be designed to produce reliable energy that satisfy the load requirements. The load-follow scenario aims to generate electricity to follow the electrical load demands of the community. Since the simulated community does not consider energy storage, excess electricity generated would be exported to the grid 
and any unmet load demands would be satisfied by grid imports of electricity. In an attempt to minimize wasting thermal energy, over-sizing of the system components was avoided. Nevertheless, this scenario attempts to satisfy the electrical demands of the community to the best of its ability with the system proposed.

\subsubsection{Grid-assist scenario}

In Ontario, the electricity demand from the grid is dependent on many factors, such as the weather, the time of the day, and the type of day (weekday vs. weekend vs. holiday). The Independent Electricity System Operator (IESO), is responsible for purchasing electricity to satisfy the province's demand from the electricity market. To do so, they are continuously forecasting the provincial load and the market prices.

Generally, the electricity demand is categorized into base load, intermediate load, and peak load. Base load is the provincial demand that is always required. As a province, the load is never below this basic amount. Ontario satisfies base load with nuclear energy, because of the high rate of energy generation capacity and poor modulation capability of nuclear power plants. Intermediate loads occur throughout most of the day, usually from 7 am to midnight. This is when the population is actively utilizing electricity at some capacity, at work or at home. The intermediate load generators are usually generated by hydro and natural gas, because they are capable of being modulated. Peak load occurs during times when a large amount of electricity demand is present. In the winter, peak load usually occurs around $6 \mathrm{pm}$, when most people arrive home to prepare dinner, do laundry, watch TV, etc. To satisfy peak load, the IESO usually purchases electricity from gas and hydro plants, 
in addition to their base and intermediate load generation. At times of peak load, the IESO dispatches most of their generators; this period is also the most costly.

The implementation of distributed micro-cogeneration systems in the simulated community was intended for the purpose of displacing centralized natural gas energy generation plants. If the PEMFCs are able to generate electricity in addition to the demands of the community during times when these peak-energy generators are online, multiple communities can potentially reduce the number of centralized natural gas powered plants.

From the IESO, the power energy production data of all generators in the province was obtained to differentiate the plants that were called upon for peak load. Since 2009 and 2010 (this corresponds to the years that were the source of the loads data used in this analysis, see Section 1.5.2), the energy landscape in Ontario has changed, mainly due to the phase out of coal that was completed in 2014. Because of the change in energy generators, the 2009 and 2010 generator data was not deemed relevant. Instead, the most recent annual data for the electrical output of generators, from the year 2014, was used to distinguish the peak-load following plants.

There are two types of gas plants in operation in Ontario, those with and those without cogeneration. In a central gas-fired cogeneration plant, a portion of the generated steam is used in a nearby process. Plants without cogeneration are not used as frequently as those with cogeneration in Ontario [17]. As a result, gas plants without cogeneration are targeted for displacement in this study.

Through the analysis of the generator output data, some hydro and gas plants were used to only satisfy peak load, meaning that they only operated a few hours a 
day (some only on certain days). The York Energy Centre, a natural gas-fired, simple cycle plant with a capacity of $393 \mathrm{MW}$, was the only non-cogeneration natural gas plant that was used to satisfy peak load. In the vision of phasing out centralized gas power plants, the peak load serving gas plant is the first replacement target. Therefore, in the grid-assist scenario, the simulated community attempted to maximize energy output during times when the York Energy Centre was in operation.

\subsection{Comparison Metrics}

In analysing system performance, various comparison metrics were used for evaluation. These metrics are the energy exchanged with the grid, the peak import and peak export of power, and the community's interaction with the grid during high-demand periods.

The electricity exchanged with the grid is in the form of imports and exports. When there's more demand than generation in the community, electricity is imported from the grid into the community to satisfy demand. The total amount of energy imported is an indication of the community's electricity bill. When there's excess production of electricity within the community, this energy is exported to the grid. This is an indication of the frequency in which the community load is satisfied by the energy generated within the community. Minimizing the combined total amount of electricity imported and exported minimizes grid interaction overall.

The peak import of power is the maximum rate of electrical energy purchased from the grid, used by the community. The peak import of power is an indicator of 
the installed centralized power generating capacity necessary to meet the electricity demands of the community. The peak export is the maximum rate of electricity produced by the community, less the amount that is consumed by the community. The peak electricity export was evaluated to ensure that the electricity production does not exceed the power limits that the power electronics equipments are rated for.

Another area for evaluation involves studying the community's interaction with the grid during on-peak periods. At on-peak periods, the utility would dispatch the highest priced generators in addition to their base load generators. Therefore, this is the best time to decrease reliance on the grid. In Ontario, the time-of-use (TOU) rates were implemented to shift some of the the usage of electricity from high-price on-peak hours to less expensive off-peak hours (Figure 2.4) [2]. By studying the community's grid interaction during on-peak hours, the effectiveness of the PEMFC units in alleviating the burden of providing backup to PV was further analysed.

These comparison metrics will be evaluated to compare the two simulation scenarios to the base case. The objective is to evaluate the two generation scenarios for how well they are able to reduce the community's reliance on the grid or assist the grid in replacing centralized gas power generation.

This chapter was dedicated to describing the system layout, the control scheme, and the reasoning behind the chosen scenarios and the comparison metrics. The next chapter will discuss some of the analysis tools essential to complete this research, including the building performance simulation tool and the load forecasting strategy. 


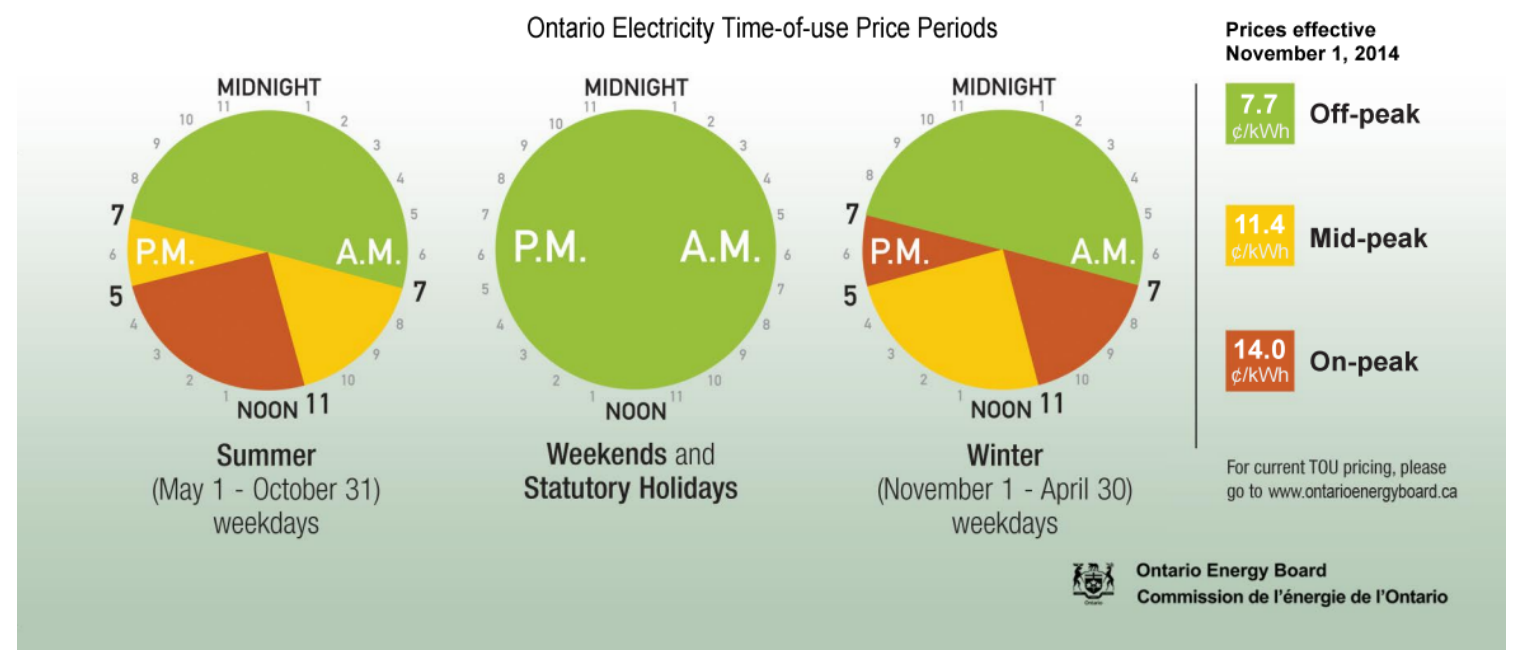

Figure 2.4: Ontario electricity time-of-use (TOU) pricing; with permission (C)Queen's Printer for Ontario, 2014 [2] 


\section{Chapter 3}

\section{Analysis Tools}

In order to analyse the system proposed in Chapter 2, several analysis tools were used. The simulation tool used for system modelling and the model descriptions are discussed in detail. The choice of weather data used in the simulation models is justified. The load forecasting method necessary in the power management strategy is also described in this section.

\subsection{Simulation Tool: ESP-r}

The Environmental System Performance - research edition (ESP-r) software program was used to model the PV, PEMFC, and the electrical demand components. ESP$\mathrm{r}$ is an integrated energy modelling tool for simulating the performance metrics of buildings and environmental control systems [41]. ESP-r is an open-source software that is constantly improved upon by developers worldwide since the 1970s. Due to the degree of detail in ESP-r models, it is mostly used as a research tool in academia. This tool was used because it contained the calibrated model for a 1-kW PEMFC 
unit. Since the use of ESP-r was integral to the research conducted, an overview of the ESP-r simulation methodologies for the PV and PEMFC components is discussed in this section.

\subsubsection{PV model description}

The PV model operates under the buildings domain in ESP-r, but as a special material. Special materials are active building elements within the model that change their thermophysical properties or alter their energy flows in response to an external excitation [42]. This is the case with PV technology as it responds to the flux of radiation that penetrates the module surface and the temperature of the PV cells.

The ESP-r PV model comprises of an equivalent diode model to calculate the electrical characteristics of the module, and a thermodynamic model for the purpose of calculating cell temperature [43].

\section{Equivalent diode model}

The short-circuit current is the current through the solar module when the voltage across the module is zero (Equation 3.1). The open-circuit voltage is the maximum voltage available from a module; this occurs when the current is zero (Equation 3.2).

$$
\begin{gathered}
I_{s c}=I_{s c, r e f} \frac{E_{T, e f f}}{E_{r e f}}\left[1+\alpha\left(T_{c}-T_{c, r e f}\right)\right] \\
V_{o c}=V_{o c, r e f}\left[1-\gamma\left(T_{c}-T_{c, r e f}\right)\right] \cdot \max \left(0,1+\beta \cdot \ln \left(\frac{E_{T, e f f}}{E_{r e f}}\right)\right)
\end{gathered}
$$


Where,

$I_{s c} \quad=$ short-circuit current $[A]$

$I_{s c, r e f}=$ short-circuit current under reference conditions $[A]$

$E_{T, \text { eff }}=$ effective solar radiation on the module $\left[\mathrm{W} \cdot \mathrm{m}^{-2}\right]$

$E_{\text {ref }}=$ reference irradiance $\left[W \cdot \mathrm{m}^{-2}\right]$

$V_{o c} \quad=$ open-circuit voltage $[V]$

$V_{o c, r e f}=$ open-circuit voltage under reference conditions $[V]$

$T_{c} \quad=$ cell temperature $[K]$

$T_{c, r e f}=$ reference temperature $[K]$

$P_{m p}=$ maximum module power $[W]$

$P_{m p, r e f}=$ maximum module power reference $[W]$

$\alpha=$ temperature coefficient of short-circuit current $\left[K^{-1}\right]$

$\beta=$ irradiance coefficient of open-circuit voltage [-]

$\gamma \quad=$ temperature coefficient of open-circuit voltage $\left[K^{-1}\right]$

Maximum power point trackers are typically used in conjunction with PV modules in order to generate the maximum power possible. This is done by adjusting the operating voltage based on the current generated. In this research, the maximum electrical output was calculated at each time step to simulate this effect. The maximum electrical output (Equation 3.3) is assumed to vary proportionally to the short-circuit current and the open-circuit voltage. Further details on the analysis method is described in Thevenard's report [44].

$$
P_{m p}=P_{m p, r e f}\left(\frac{I_{s c} \cdot V_{o c}}{I_{s c, r e f} \cdot V_{o c, r e f}}\right)
$$




\section{Thermodynamic model}

The incident solar radiation that reaches the module is comprised of direct beam radiation, sky diffuse radiation, and ground reflected radiation [45] (Figure 3.1). Fractions of the incident solar radiation are absorbed and transmitted into the material. The module also exchanges longwave radiation with surfaces in its surroundings, such as the ground. The convective heat loss is calculated by a convective heat loss coefficient defined by Mostrel \& Givoni [46].

In analysing conduction heat transfer, ESP-r applies a finite difference formation based on a control volume heat balance to represent the energy flows surrounding a particular node. Each material layer is assigned three nodes, two at their boundaries, and one within the layer (Figure 3.1). A heat balance of inter-nodal energy flows is conducted on the control volume of each node. Conduction in this case is treated as a one-dimensional transient conduction problem that is solved using Fourier's equations with finite differencing [47]. The interested reader is directed to Clarke's book on ESP-r's simulation methods [45] for further details.

Through conducting an energy balance on the PV cell encompassing all of its heat transfer methods,the cell temperature can then be determined. The cell temperature serves as an input to the equivalent diode model. The equivalent diode model calculates the current-voltage (I-V) characteristics after the thermodynamic model determines the cell temperature of the PV module. 


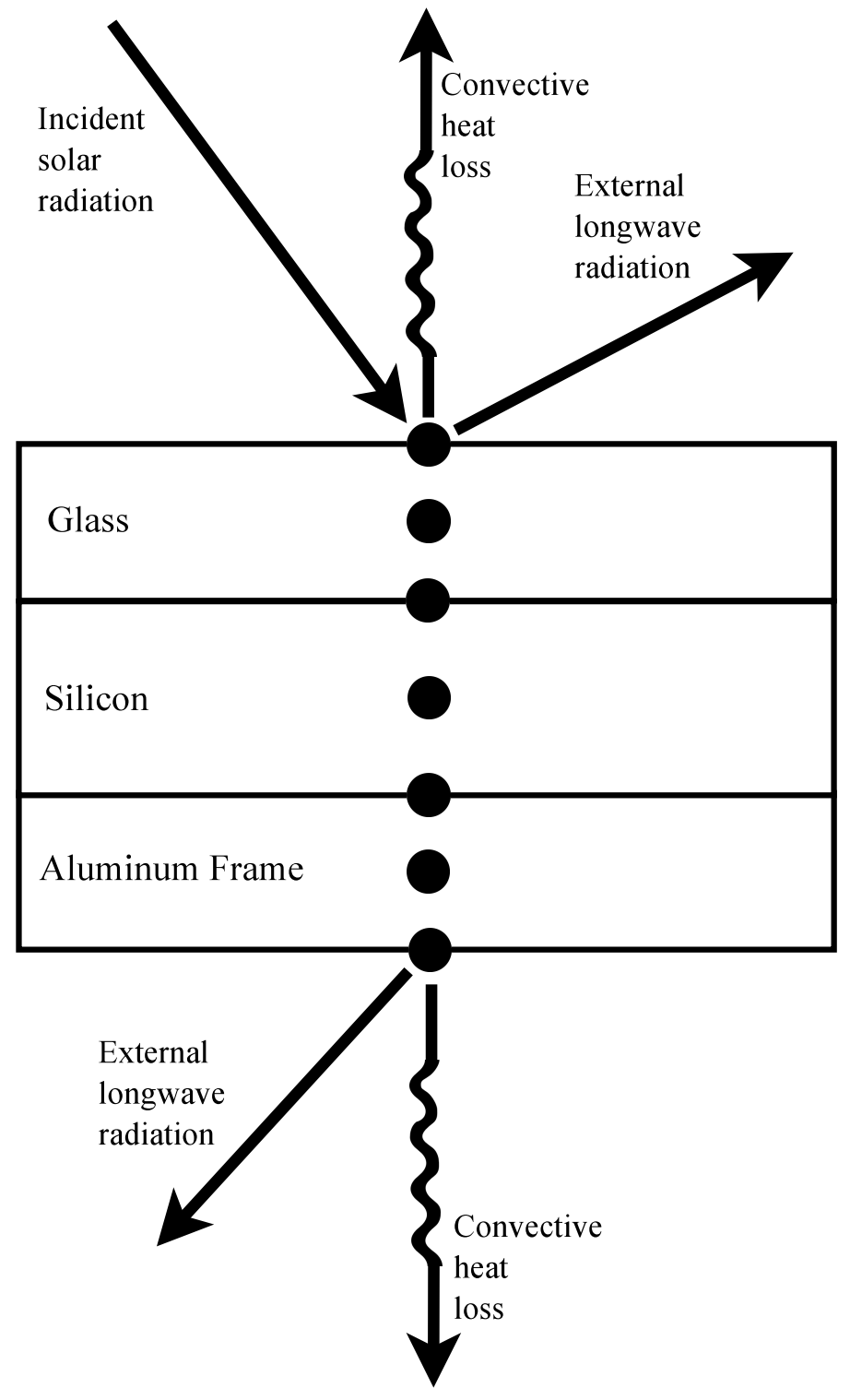

Figure 3.1: Equivalent network representation of the PV thermodynamic mode in ESP-r 


\subsubsection{PEMFC model description}

A 1-kW PEMFC device was calibrated and validated by Johnson et al. [19] in ESP-r. The ESP-r fuel cell model algorithm is a coefficient generator which integrates the fuel cell within the ESP-r matrix-based plant systems solver. Inputs to the model are derived from empirical measurements made from coherent system testing [19]. A schematic representation of the PEMFC model is provided in Figure 3.2. In simulating the performance of the PEMFC, each component is represented by a control volume, and their energy flows are illustrated by the arrows schematically.

The fuel cell power module (FCPM) produces heat and DC power. The FCPM control volume contains the following devices: the fuel cell stack, the fuel pre-heater, the fuel reformer, the air filter, the water preparation system, and central controllers, among other components.

With respect to the FCPM control volume, an overall energy balance can be written (Equation 3.4):

$$
\dot{H}_{f u e l}+\dot{H}_{a i r}+\dot{H}_{\text {liq-water }}+P_{\text {el,ancillaries-AC }}=P_{e l}+q_{s-\text { cool }}+q_{\text {skin-loss }}
$$

Where, $\dot{H}[W]$ is the total enthalpy flow rate (summations of the constituent enthalpies). The first three terms on the left side of the equal sign respectively refers to the total enthalpy flow rate $[W]$ of: the fuel downstream of the fuel compressor, the air downstream of the blower, and the liquid water downstream of the water pump . These components are also illustrated in Figure 3.2. $P_{\text {el,ancillaries-AC }}[W]$ is the $\mathrm{AC}$ power draw of the ancillaries (e.g. controls, pumps, fans) that are included 


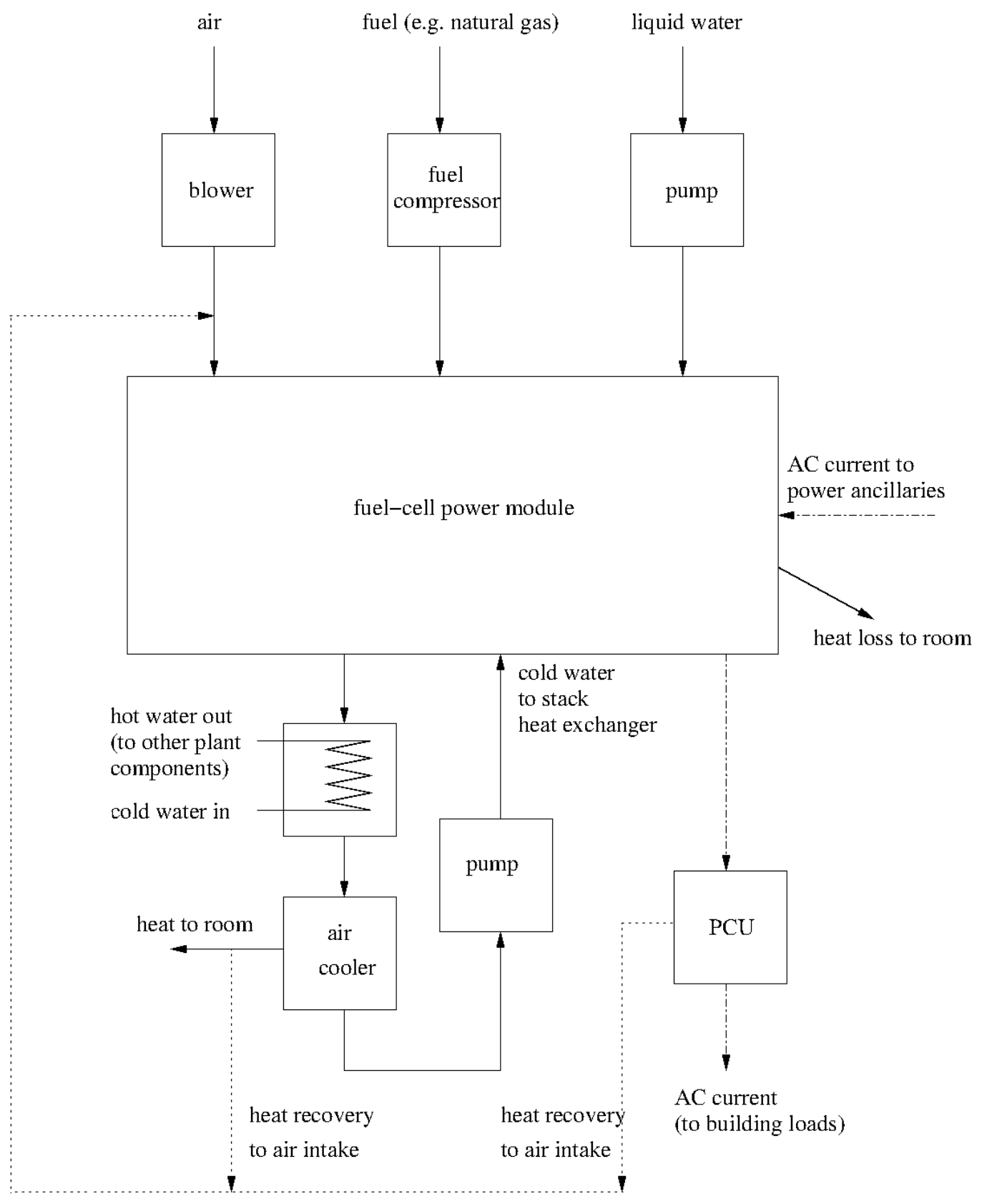

Figure 3.2: Schematic of the PEMFC model (reproduced with permission from Beausoleil-Morrison) [3] 
within the control volume, powered by the fuel cell after the DC-AC conversion in the power conditioning unit. $P_{e l}[W]$ is the net DC electric power produced by the FCPM (the power produced by the fuel cell stack minus the power draw of the ancillaries).

$q_{s-\text { cool }}[W]$ is the heat extracted from the stack by the stack cooling system. The stack cooling system controls the temperature in the PEMFC stack; it consists of a heat exchanger, an air cooler, and a pump. Lastly, $q_{\text {skin-loss }}[W]$ is the parasitic thermal losses from the FCPM to the containing room in the forms of radiation and convection heat transfer. The analysis of each of these energy balance components is further detailed in the publications of Kelly and Beausoleil-Morrison [3], and Johnson et al. [19].

\subsection{Choice of Weather Data Source}

The simulation model required weather information in order to accurately simulate the conditions in which the systems were operating. This is especially applicable to the PV model. The weather data sets that were integral to the model simulation were: dry bulb (DB) temperature, diffuse horizontal $(\mathrm{DH})$ radiation, and direct normal $(\mathrm{DN})$ radiation.

Typically, weather data from Environment Canada [48] are used in research modelling, due to the credibility of the source. However, Environment Canada data were not available for the time period in which the load data was measured. The most recently available Environment Canada data set was from the year 2008. The occupant electrical load data taken from the 12 houses were surveyed in the 2009-2010 
Table 3.1: RMSD values for data comparison

\begin{tabular}{|l|l|}
\hline Data & RMSD \\
\hline DB Temperature & $4.14^{\circ} \mathrm{C}$ \\
\hline DH Radiation & $62.7 \mathrm{Whm}^{-2}$ \\
\hline DN Radiation & $270 \mathrm{Whm}^{-2}$ \\
\hline
\end{tabular}

years [28]. Consequently, the weather data was taken from a commercial source, Weather Analytics [49].

Before utilizing the Weather Analytics weather data, the most recently available data set from Environment Canada was used to compare against the Weather Analytics data for discrepancies. Both sources obtained their data from the Ottawa International Airport. The root mean squared difference (RMSD) between the two data sets was used to assess the discrepancy between the data. The RMSD results are shown in Table 3.1.

The temperature and diffuse horizontal radiation values show slight discrepancies in the RMSD comparison. However, the direct normal radiation values don't show sufficient similarities. It is important to note that, the Environment Canada radiation data was modelled rather than measured [50]. The method that Weather Analytics used for obtaining radiation data was not disclosed, however, it is likely to have been modelled as well.

This assessment of weather data was essential to evaluate the closeness of the commercial data to the public ones. Even though the assessments do not show complete similarity, the 2009-2010 weather data isn't available elsewhere. Therefore, 
the Weather Analytics data was used with these discrepancies in mind.

\subsection{Load Forecasting}

Forecasting of the electrical load demand is a field of research on its own. Load demand forecasting is necessary for predicting the amount of generation required to satisfy the electricity demand. In Chapter 2, the power management strategy was described. The forecasted load is a necessary input to the power management logic used to determine the power generation in the near future.

\subsubsection{Load forecasting methods and selection}

In the field of electricity demand forecasting, short-term forecasts are used for the control and scheduling of power systems. Short-term forecasts are generally used for day-ahead predictions. Various methods of load forecasting exist, including neural network methods, exponential smoothing, regression method, etc. A common measure of accuracy in load forecasting is the mean absolute percentage error (MAPE), as defined in Equation 3.5. In this equation, $n$ is the total number of data points; $A_{t}$ is the actual value and $F_{t}$ is the forecasted value at time $t$.

$$
M A P E=1 / n \sum_{t=1}^{n}\left|\frac{\left(A_{t}-F_{t}\right)}{A_{t}}\right|
$$

Darbellay et al. [51] assessed the method of neural networks for short-term load forecasting to conclude that the neural networks method may not be optimal for demand prediction. They recommended the investigation of other methods. Taylor 
proposed the method of Holt-Winters double seasonal smoothing in 2003 [52]. Taylor's model resulted in MAPE values within $2 \%$. In 2006, Taylor et al. compared the method of Holt-Winters double seasonal smoothing with other forecasting methods [53]. These methods include the double seasonal autoregressive moving average (ARMA) modelling, the artificial neural network method, the regression method with principal component analysis, and simplistic benchmark methods. Their results showed that the Holt-Winters double seasonal smoothing method performed with the lowest MAPE. In 2007, Taylor \& McSharry continued to evaluate the performance of various methods, but using a different data set [54]. Once again, the results showed that the Holt-Winters double seasonal smoothing method outperformed all other forecasting methods.

Because of the amount of documentation on the Holt-Winters double seasonal smoothing method that demonstrated out-performance against other methods, it was decided that Holt-Winters double seasonal smoothing would be used for the forecasting of the aggregated load in this research.

\subsubsection{Holt-Winters double seasonal forecasting method al- gorithms}

The forecasting method of Holt-Winters double seasonal exponential smoothing [55] is a modification of the standard exponential smoothing method. This method can be used to produce smoothed data or make forecasts.

Exponential smoothing is a procedure that continually revises itself based on more recent data. It does so by assigning exponentially decreasing weights to older 
observations. In Equation 3.6, the level, $S_{t}$ is the smoothed estimate of the data value at the end of each time step, $t$. $X_{t}$ is the observed or actual data at the current time step. $\alpha$ is the the smoothing factor, ranging from 0 to 1 . If $\alpha=1$, the level would be equivalent to the observed value. As $\alpha$ decreases, it becomes less responsive to recent data changes, increasing the smoothing of the data. The level represents the weighted average of the data; this is the simplest form of exponential smoothing.

$$
S_{t}=\alpha X_{t}+(1-\alpha) S_{t-1}
$$

In electrical load data, short term cycles are observed daily as well as weekly. An example week is shown in Figure 3.3. In this week, the daily cycles involve a morning peak and a more pronounced evening peak. On the weekends, the occupants tend to use more energy than during the weekdays, and the evening peaks are more pronounced. Since this repetition of behaviour occurs in the daily as well as the weekly cycle, a modification of the simple exponential smoothing is necessary to take these cycles into account. Seasonality in the context of this smoothing method is the tendency of the data to exhibit a repetitive behaviour every cycle (over a certain period). The Holt-Winters double exponential smoothing takes the exponential smoothing method and modifies it to take into account the possibility that the data may exhibit seasonality and/or trend. The modified method comprise of the daily and weekly seasonal indices.

The daily seasonal index, $D_{t}$ is shown in equation 3.7 , where $\delta$ is the daily seasonal smoothing factor [52]. The weekly seasonal index, $W_{t}$ is shown in equation 3.8, where 


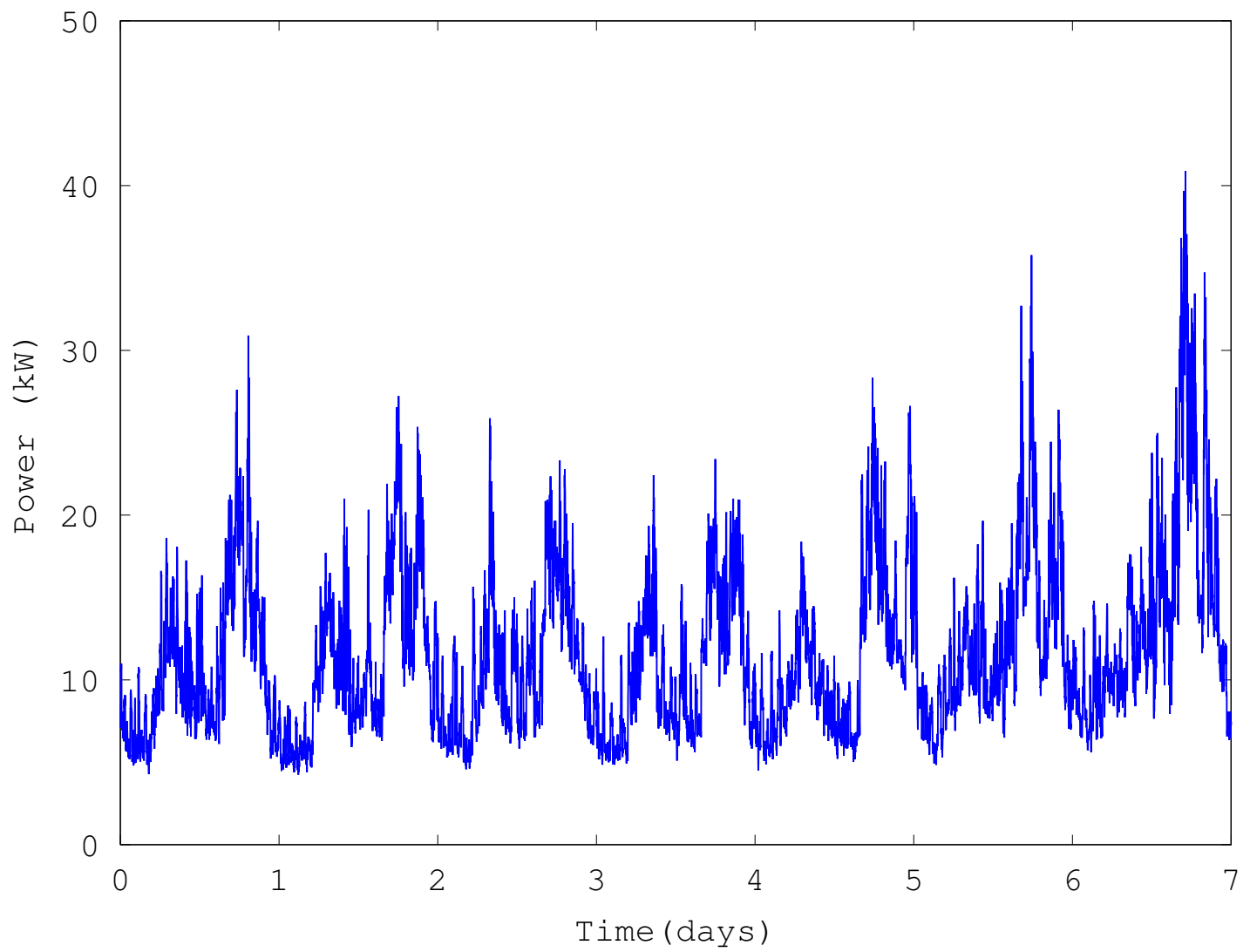

Figure 3.3: Electrical load data for the week of Monday, Jan 18, 2010 to Sunday Jan 24,2010 
$\omega$ is the weekly seasonal smoothing factor [52]. The periods $s 1$ and $s 2$ correspond to the lengths of the daily and weekly cycles, respectively.

$$
\begin{gathered}
D_{t}=\delta\left(X_{t} /\left(S_{t} W_{t-s 2}\right)+(1-\delta) D_{t-s 1}\right. \\
W_{t}=\omega\left(X_{t} /\left(S_{t} D_{t-s 1}\right)+(1-\omega) W_{t-s 2}\right.
\end{gathered}
$$

Taking the daily and weekly seasonality into account, the level becomes Equation 3.9 .

$$
S_{t}=\alpha\left(X_{t} /\left(D_{t-s 1} W_{t-s 2}\right)\right)+(1-\alpha)\left(S_{t-1}+T_{t-1}\right)
$$

Another cycle to consider is the annual cycle. With the change in weather and season, electricity consumption patterns vary throughout the year. The occupant behavioural change with respect to the time of the year is much more gradual. This gradual change is taken into account by the level, $S_{t}$ as it weighs recent data more heavily than previous data. If multiple years of simulation were performed, an annual seasonal index may be relevant. In the Holt-Winters double seasonal smoothing method, the daily and weekly cycles are taken into consideration in the seasonal indices, and the data smoothing is accounted for in the level. Finally, the forecasted value $\hat{X}_{t}(k)$, at $k$ time steps ahead is given in Equation 3.10 .

$$
\hat{X}_{t}(k)=\left(S_{t}+k T_{t}\right) D_{t-s 1+k} W_{t-s 2+k}
$$


Table 3.2: Smoothing factors used

\begin{tabular}{|l|l|}
\hline Smoothing factor & Value \\
\hline$\alpha$ & 0.5 \\
\hline$\gamma$ & 0 \\
\hline$\delta$ & 0.21 \\
\hline$\omega$ & 0.24 \\
\hline
\end{tabular}

The Holt-Winters double seasonal smoothing method also take trend into account. Trend in the data would involve a gradual increase or decrease in the average over time. In Taylor \& McSharry's latest forecasting paper [54], the trend in the data was ignored. The omission of trend was tested with the data in this research, and proved to output a smaller MAPE. Therefore, the forecasts in this thesis did not account for trend.

\subsubsection{Setup}

The load data used to conduct forecasting was the aggregated total electrical consumption from the 12 houses mentioned in Chapter 1 . The smoothing factors, $\alpha, \gamma$, $\delta$, and $\omega$ were adjusted to output the lowest MAPE values for the data in this study. The smoothing factors adjustment was done through testing the range of suggested values in previous research [52-55] with the load data in this research. The final values are shown in Table 3.2.

Additionally, applying the above method to the aggregated load data produced a sizeable first-order autocorrection, resulting in infinite power predictions. This 
was caused by reoccurring positive or negative departures from the mean, as future predictions rely on current and past data. A first-order autocorrection refers to autocorrection when there is correlation between the consecutive observations. Gardner proposed a simple adjustment using an autoregressive model [56]. This alters the forecast from Equation 3.10 to Equation 3.11 [53], where $\phi$ is the adjustment parameter for the first-order autocorrection. This adjustment was implemented for the load forecasting in this research to correct for the accumulation of errors. The interested reader is directed to Gardner's proposed method [56] and Chatfield's verification [57].

$$
\hat{X_{t}(k)}=\left(S_{t}+k T_{t}\right) D_{t-s 1+k} W_{t-s 2+k}+\phi^{k}\left(X_{t}-\left(\left(S_{t-1}+T_{t-1} D_{t-s 1} W_{t-s 2}\right)\right)\right.
$$

\subsubsection{Accuracy analysis}

The Holt-Winters double seasonal exponential smoothing method was performed on the aggregated electrical load of 12 houses that Saldanha \& Beausoleil-Morrison sampled [28]. Since the forecasting equation called upon past values to generate outputs, the first 2 weeks of data were used to generate the initial values for the forecast. The forecasting method was then applied to the latter 50 weeks of the year. As an example, the comparison of actual and forecasted values of a day is shown in Figure 3.4.

As illustrated in the power management strategy in Chapter 2, two types of forecasts were required. The next-minute forecast, $P_{\text {follow,t+1 }}$, and the forecast for a 


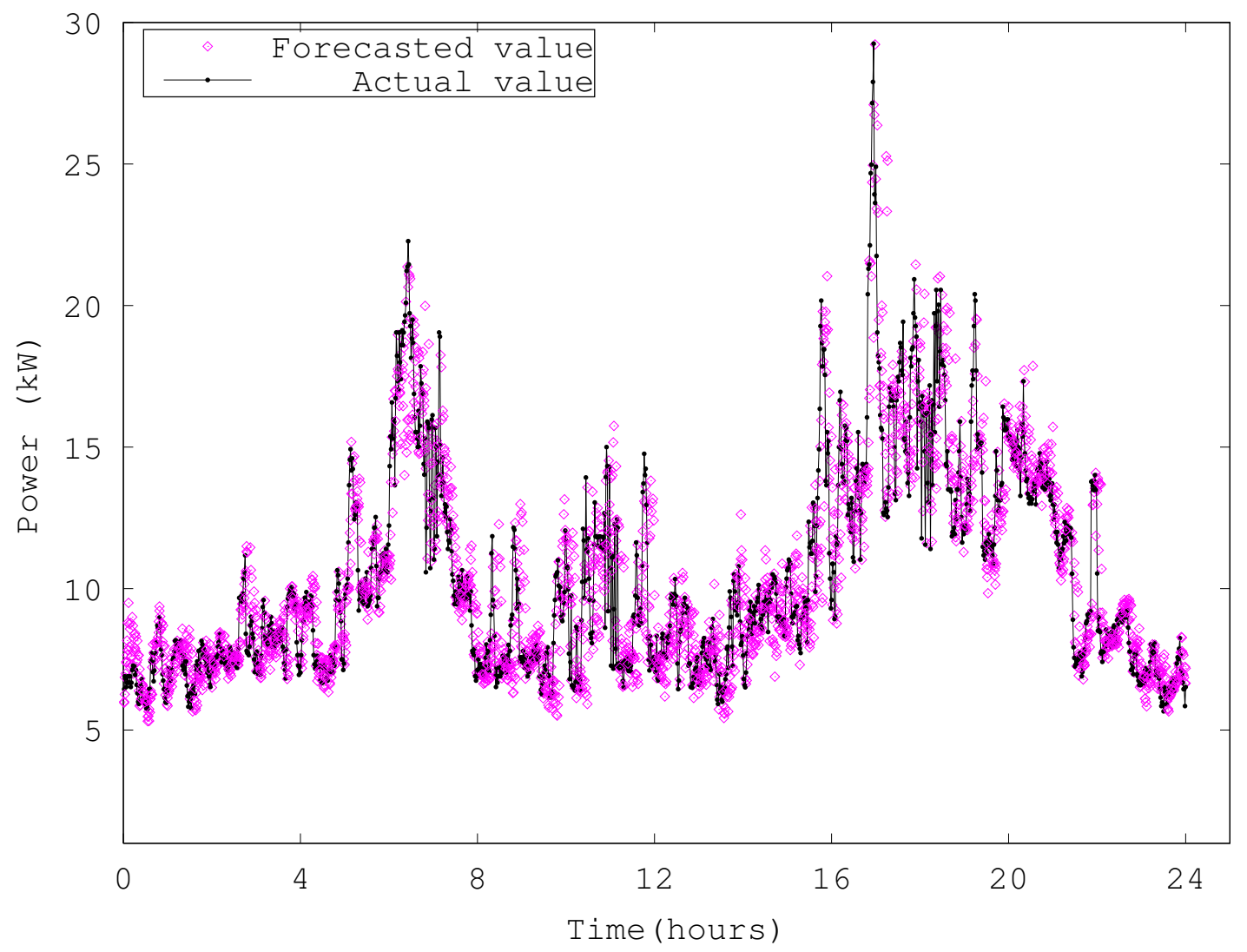

Figure 3.4: Holt-Winters double seasonal smoothing load forecast example, September 16, 2014 
time in the future, $\delta t$. The next-minute forecasts were executed in each time step, since it was an input to the power management logic. The forecasts for time, $\delta t$ were executed only when modulation limits were exceeded.

In analysing the accuracy of the forecasts for the 50-weeks forecasting period, the next minute forecasts produced a MAPE of $11.0 \%$ and the forecasts for time, $\delta t$ produced a MAPE of $16.8 \%$. When all forecasts in the year are analysed together, a MAPE of $13.6 \%$ is produced. In comparison with Taylor's forecasting result of $2 \%$ in MAPE [52], the 13.6\% MAPE in this research is not optimal. However,Taylor used the forecasting method for a grid-wide prediction, with data that contained less fluctuations than the aggregated load of 12 houses in this research. With this in mind, a MAPE of $13.6 \%$ is an acceptable error.

This chapter presented the analysis tools necessary in simulating the community distributed generation systems. Specifically, the simulation tool and its relevant model descriptions were discussed. Additionally, the weather data choices were justified. Lastly, the load forecasting method that was called upon in the power management strategy was explained and analysed for accuracy. The next chapter is dedicated to presenting and discussing the model simulation results. 


\section{Chapter 4}

\section{Results and Discussion}

The objective in studying the effect of installing PEMFCs in the community is to provide backup to the energy generated by the PV modules. The resulting impact on the community from the addition of PEMFC units is analysed and discussed here. Three scenarios were simulated: the reference PV-only scenario, the loadfollow scenario, and the grid-assist scenario. Discussion and comparison of the three scenarios are presented annually and for on-peak periods only.

\subsection{Annual Results}

In order to assess the effect of integrating PEMFCs in the community, a reference scenario was first established. In the reference scenario, PV is the only distributed generator in the community, the community is grid-tied, and the electric loads are taken from Saldanha \& Beausoleil-Morrison's study [28].

The load-follow scenario involves the operating scheme of following the demands of the forecasted community load. In this scenario, both the PV modules and 
PEMFC units are connected to the electricity distribution network. The PEMFC power output is managed with the control strategy described in Chapter 2.2 to follow the electrical demands within the capabilities of the PEMFC units.

The grid-assist scenario involves assisting the grid in displacing a peak load following natural gas plant. This operation scheme maximizes the PEMFC power output at times when the peak load following natural gas plant is called upon to output power, which occurs between zero and three times a day. At times when the central plant isn't required to output power, the PEMFC operates with the same community load following strategy as the previous scenario.

The results were obtained through an annual simulation using the system topology and methods described in Chapter 2. The load data from the first two weeks of the year were used to generate the initial values for the load forecaster, as discussed in Section 3.2. The system was analysed for 50 weeks of the year, after the first two weeks. The annual results here refer to the simulation results obtained in the 50 weeks after the initial values were generated.

In the annual results, the total energy exchange is presented in Figure 4.1. The annual peak power exchange behaviour of the three scenarios are shown in Figure 4.2. In these results, the negative values of power indicate imported power, whereas the positive values represent exported power. 


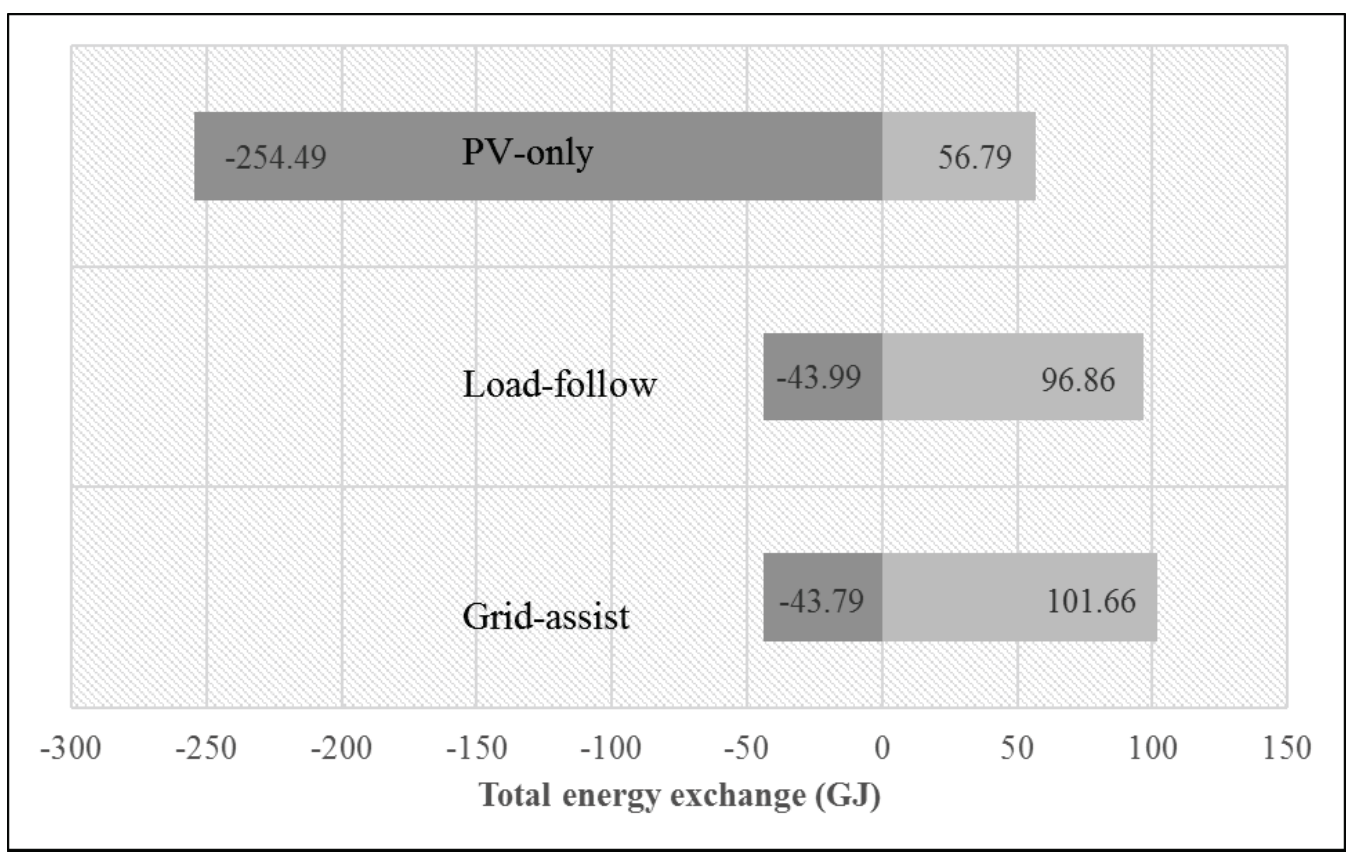

Figure 4.1: Comparing the total energy imports and exports in the three scenarios

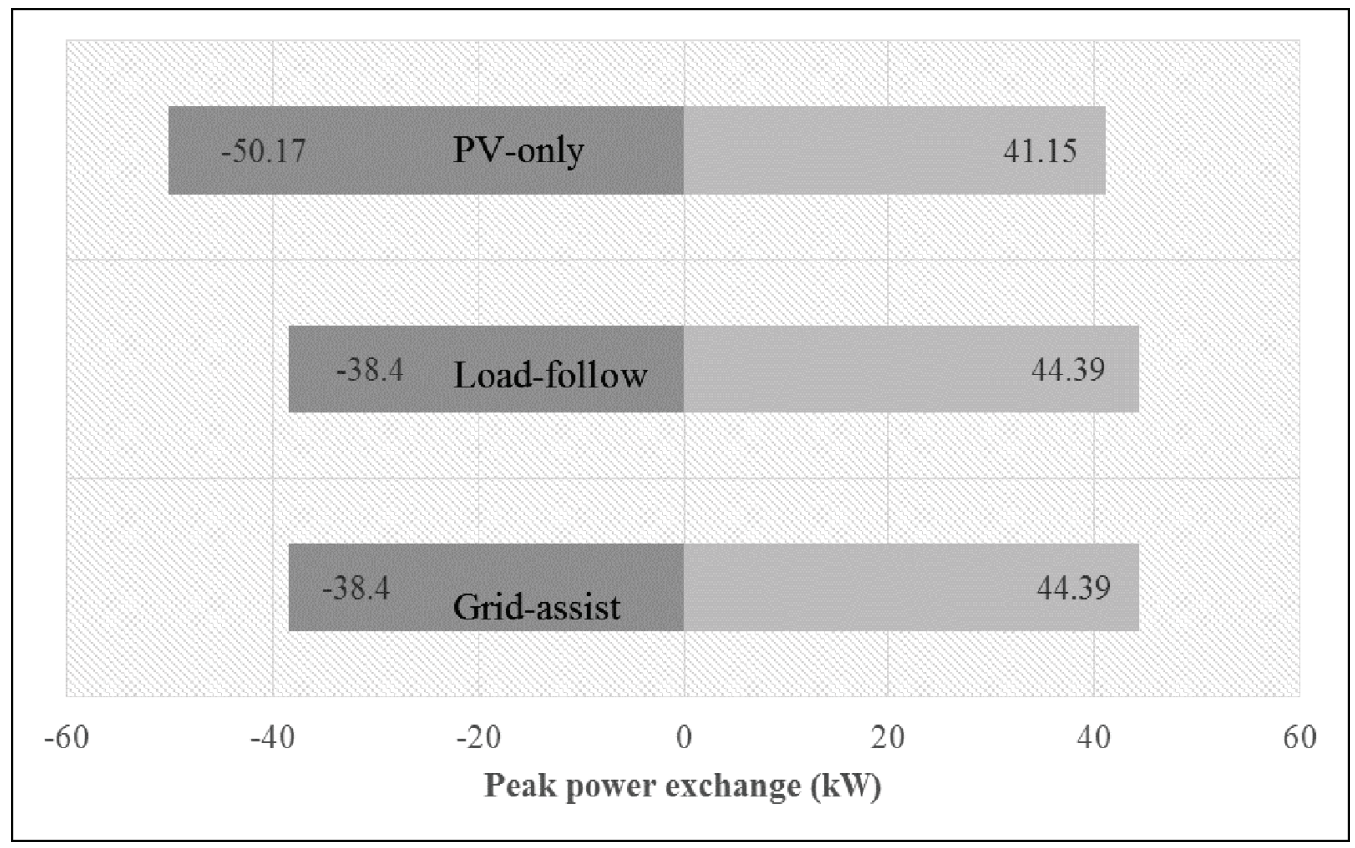

Figure 4.2: Comparing the peak power imported and exported in the three scenarios 


\subsubsection{Load-follow scenario}

In the load following scenario, the system was operated with the proposed power management strategy. Energy generated by PV was prioritized to satisfy demand before increasing the generation in the PEMFC units. An example day of the load following scenario is shown in Figure 4.3. In this figure, the negative power values indicate imports of electricity from the grid and the positive values indicate exports of electricity to the grid. This example illustrates the PEMFC units' attempt to follow the forecasted community load. As a result, the net power balance of the simulated community is brought closer to zero than the reference scenario of using only PV energy generation.

After integrating PEMFC into the system with the power management strategy proposed, a reduction in electricity imports from the grid and an increase in electricity exports to the grid is observed. In comparison to the reference scenario, the energy imported in the load following scenario decreased by $82.7 \%$ (Figure 4.1). This indicates that the community can now produce $82.7 \%$ of the energy that they were importing from the grid, for consumption within the community. Another result of the addition of PEMFC units is the increase of exports in addition to those generated by PV. The energy exported increased by $70.6 \%$ more than the reference scenario. The load-follow scenario changed the ratio between the energy imported and the energy exported from 4.5:1 to 1:2.2. Load following reduced the peak electricity import by $23.5 \%$. A reduction in peak import from the grid reduces the capacity of central generation required to provide backup to PV. Approximately $12 \mathrm{~kW}$ of central power 


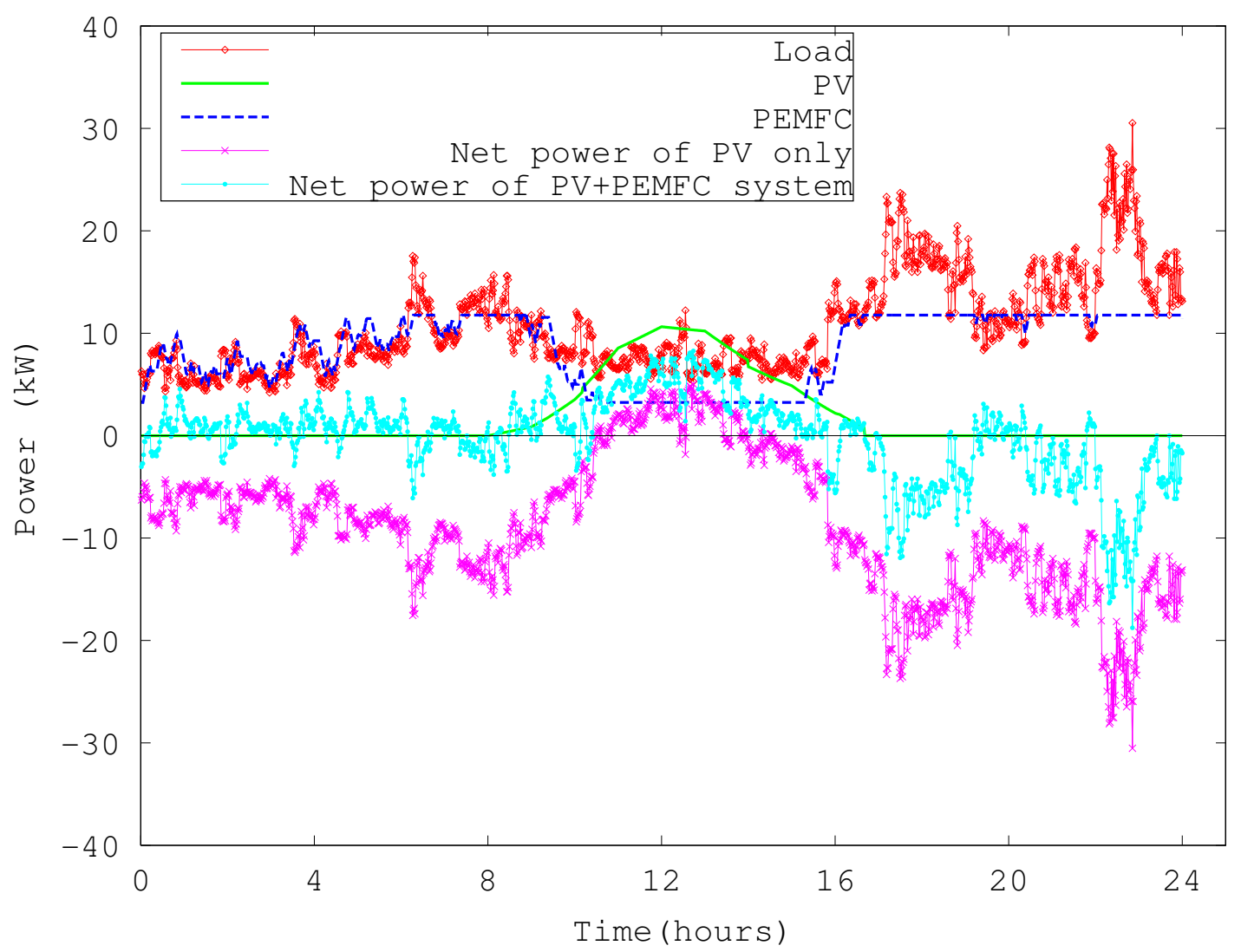

Figure 4.3: Load following power balance example: Jan 15, 2010 
generation can be displaced with the $12 \mathrm{~kW}$ of distributed PEMFC units, plus the advantage that the PEMFC units are able to supply both heat and power to the community.

\subsubsection{Grid-assist scenario}

In the grid-assist scenario, the PEMFC units were ramped up to maximum when the central gas plant was in operation. The load-follow and the grid-assist scenarios are plotted for the same day for comparison. Figures 4.4 (load-follow) \& 4.5 (grid-assist) illustrate a case where the central power plant operated 6:00-10:00 and 16:00-23:00. By comparing the two figures, it is apparent that in the grid-assist scenario, the PEMFC units disregard their community load following during the central gas plant operating hours and maximize their output. The grid-assist scenario illustrates an attempt to displace the central gas plant's generation. Figures $4.6 \& 4.7$ respectively show the load-follow and the grid-assist scenarios for a more typical day where the central gas plant was scheduled to operate for a few hours during the day, 6:00-10:00.

The grid-assist scenario performed identically to the load-follow scenario in terms of peak imports and exports (Figure 4.2). In terms of total energy exchange with the grid, the grid-assist scenario performed similarly to the load-follow scenario (Figure 4.1). A slight reduction in the total energy imported compared to the load following scenario may be caused by the combinations of two possibilities. The first being that during times when the PEMFCs are operating at their maximum because of the 


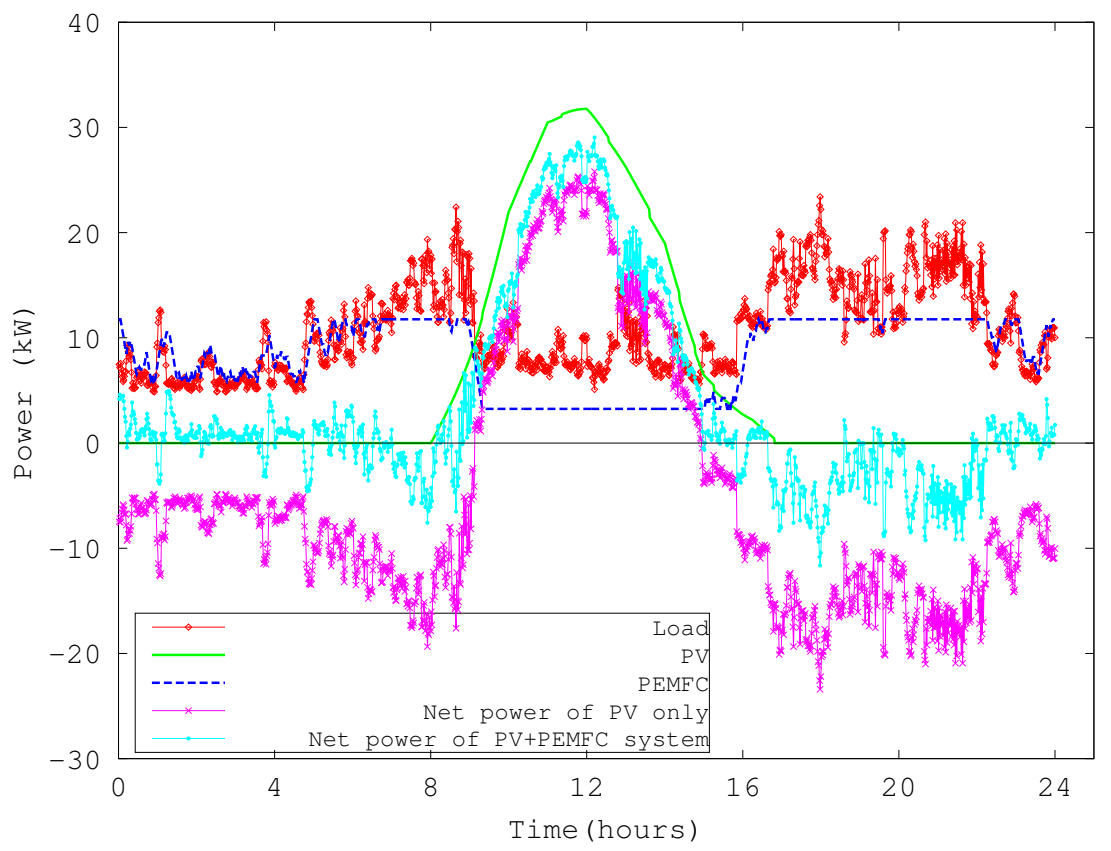

Figure 4.4: Load following power balance example: Jan 21, 2010

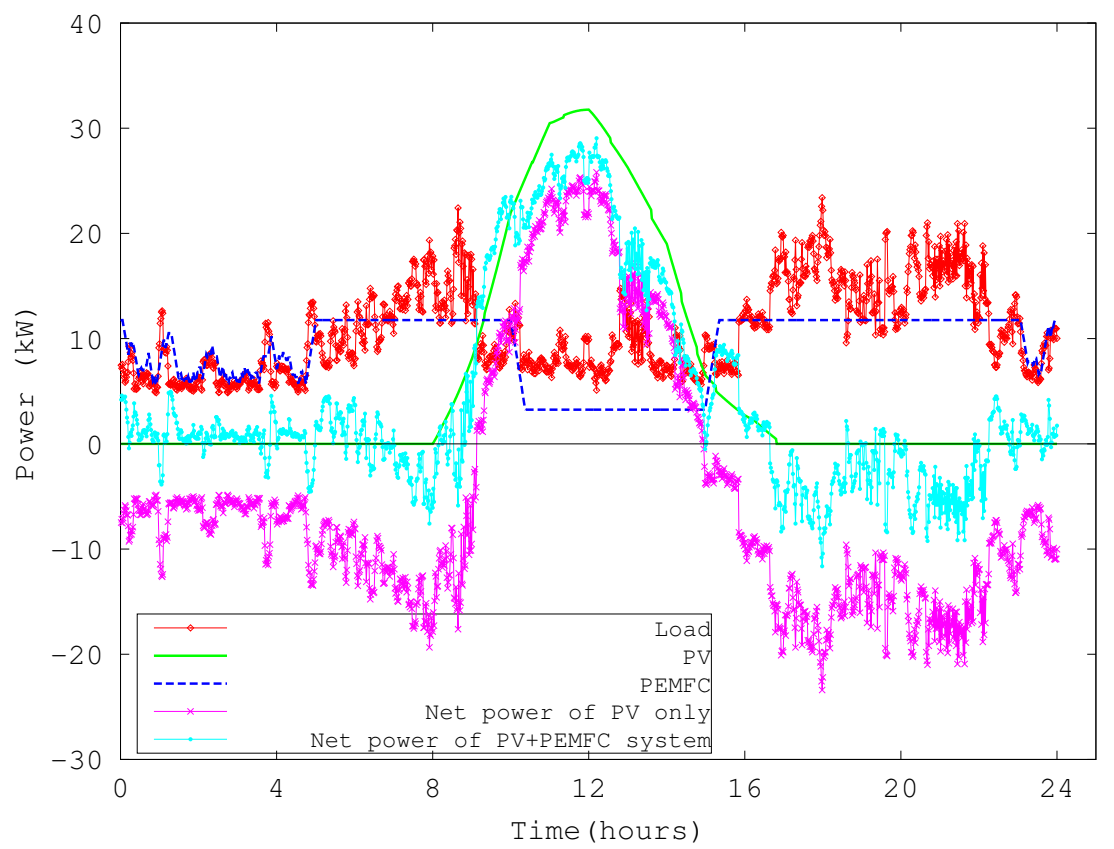

Figure 4.5: Grid assisting power balance example: Jan 21, 2010 


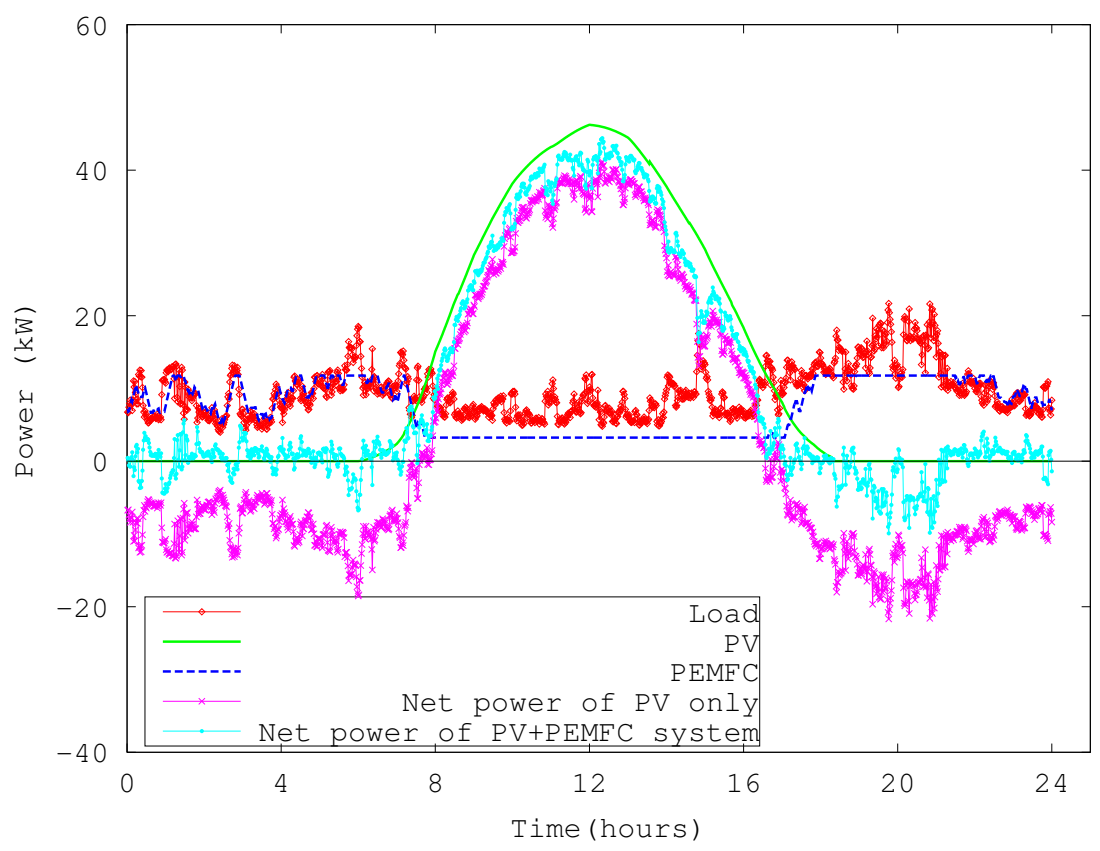

Figure 4.6: Load following power balance example: Mar 26, 2010

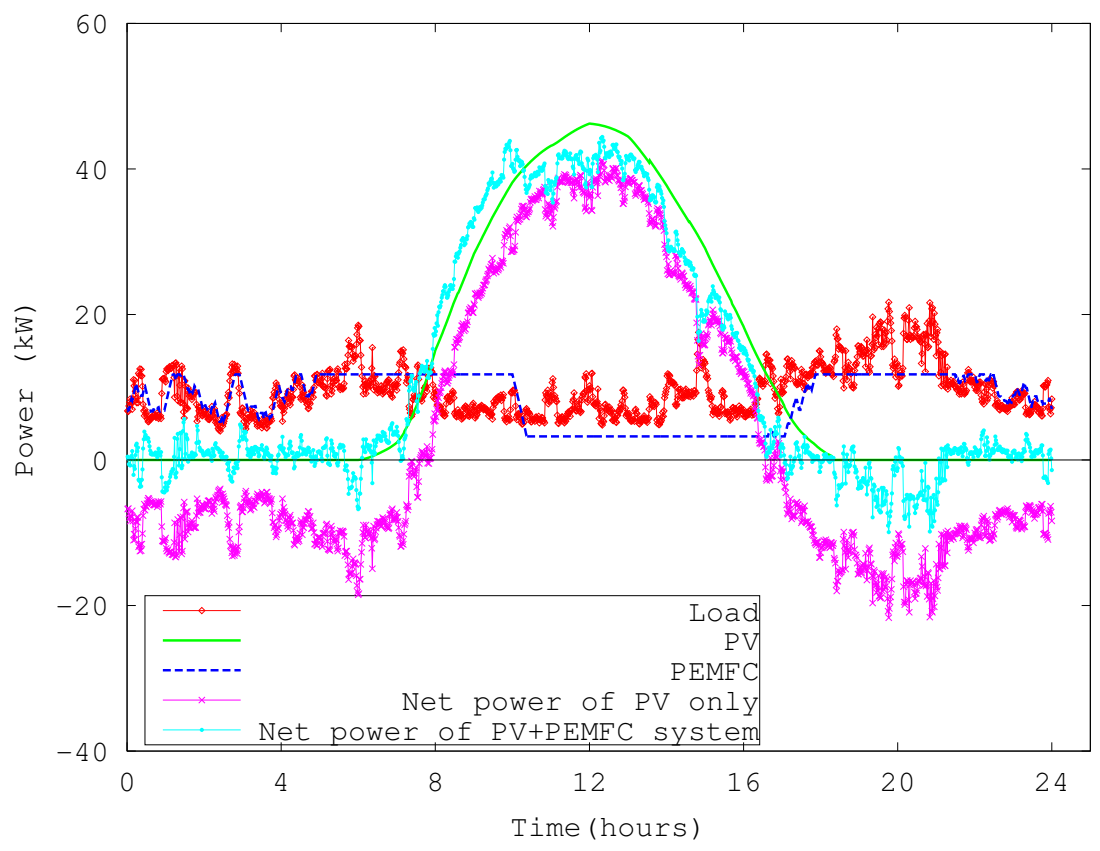

Figure 4.7: Grid assisting power balance example: Mar 26, 2010 
central plant operation, it is meeting some community loads that were not predicted by the load forecaster. In which case, imports from the grid were not necessary to supply the community load. An example of this possibility can be seen when comparing Figures 4.4 (load-follow) \& 4.5 (grid-assist), at around 16:00. The second possibility is that the PEMFCs were controlled to operate at maximum (according to the central plant operation) right before the load was predicted to increase. By the time the load increased, the generation was already at maximum. An example of this possibility can be seen when comparing Figures 4.6 (load-follow) \& 4.7 (gridassist), right after 4:00 when the load was satisfied sooner by a previous command to ramp up the PEMFCs. The increase in the total energy exported in the grid-assist scenario is due to the increase in generation to displace the central plant generation that would otherwise not have been generated in the load following scenario.

\subsection{Analysis of On-Peak Behaviour}

Another metric for comparison involves studying how the community's power exchange behaves during the on-peak TOU periods in Ontario. The on-peak periods are 11:00-17:00 on weekdays in the summer, 7:00-11:00 and 17:00-19:00 on weekdays in the winter, and none on weekends. For the three scenarios, the community's energy imports (negative) from and exports (positive) to the grid are shown in Figure 4.8. The peak energy exchanges with the grid is illustrated in Figure 4.9. The time duration of imports and exports of power for each of the three scenarios is also 


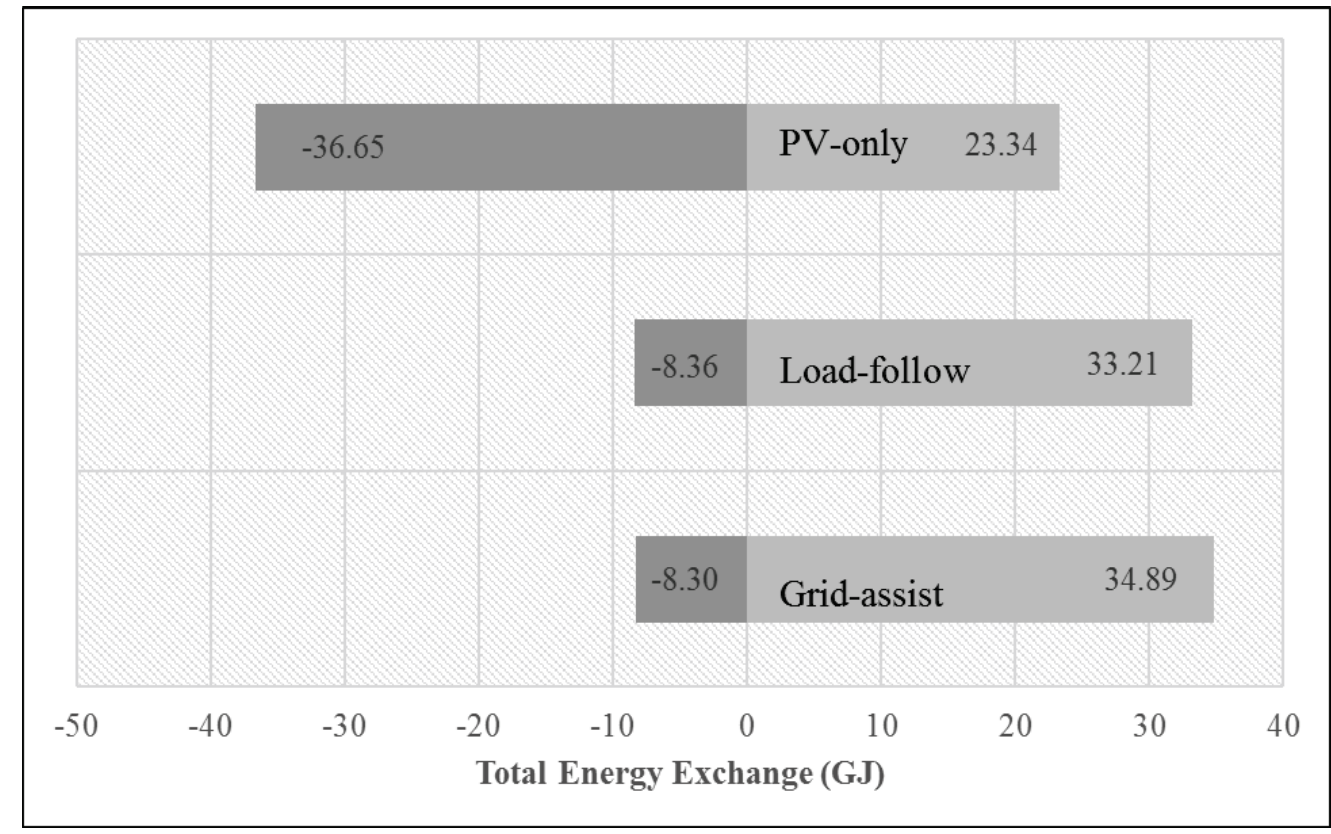

Figure 4.8: Comparing the energy imports and exports in the three scenarios for on-peak TOU periods only

studied and presented in Figure 4.10.

\subsubsection{Load-follow scenario}

By comparing the load-follow scenario to the reference scenario, it is observed that the integration of PEMFCs reduced the total energy imported during on-peak periods by $77.2 \%$. At the same time, the total export of energy increased by $42.3 \%$. Due to the high demand of electricity during the on-peak periods, the reduction of imports and the increase in exports are more advantageous in this period. In comparison to the annual results (Figure 4.1), the PEMFC integration was less effective in reducing imports and increasing exports during TOU periods. This is due to the fact that the 


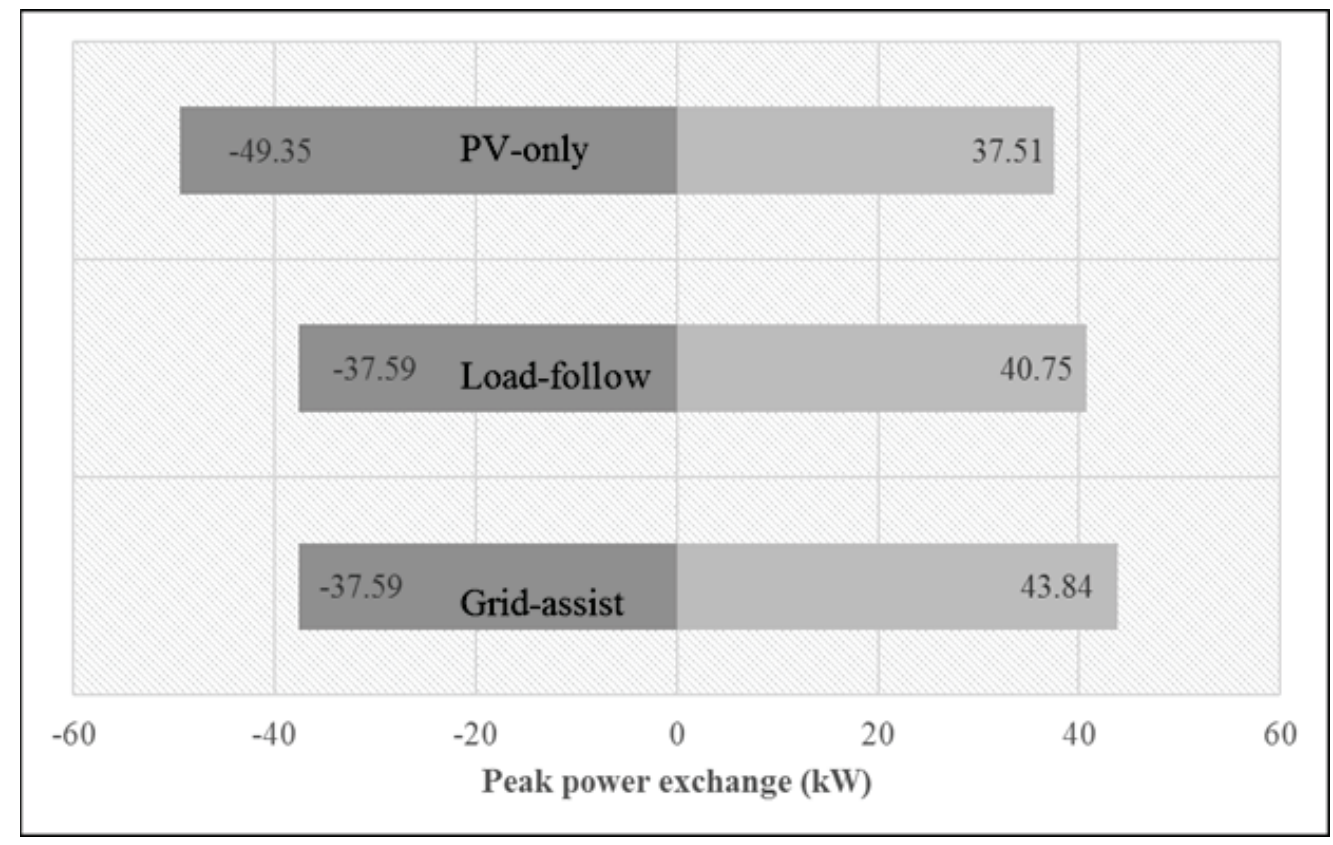

Figure 4.9: Comparing the peak power imports and exports in the three scenarios for on-peak TOU periods only

community loads are usually high when the provincial loads are on-peak.

The peak imports during peak periods is reduced by $23.5 \%$. A reduction in peak imports reduces the central capacity needed to provide backup to PV. This is more beneficial during on-peak periods because electricity prices are the highest and the highest electricity production occurs during on-peak periods.

In comparing the duration of energy exchange in the load following scenario and the reference scenario, it can be observed that by integrating PEMFC units in the system, the community spends more than double the time exporting as opposed to importing during on-peak periods. This behaviour is supportive of the grid's energy needs during on-peak periods. This pattern is observed in both the load-follow and the grid-assist scenarios. 


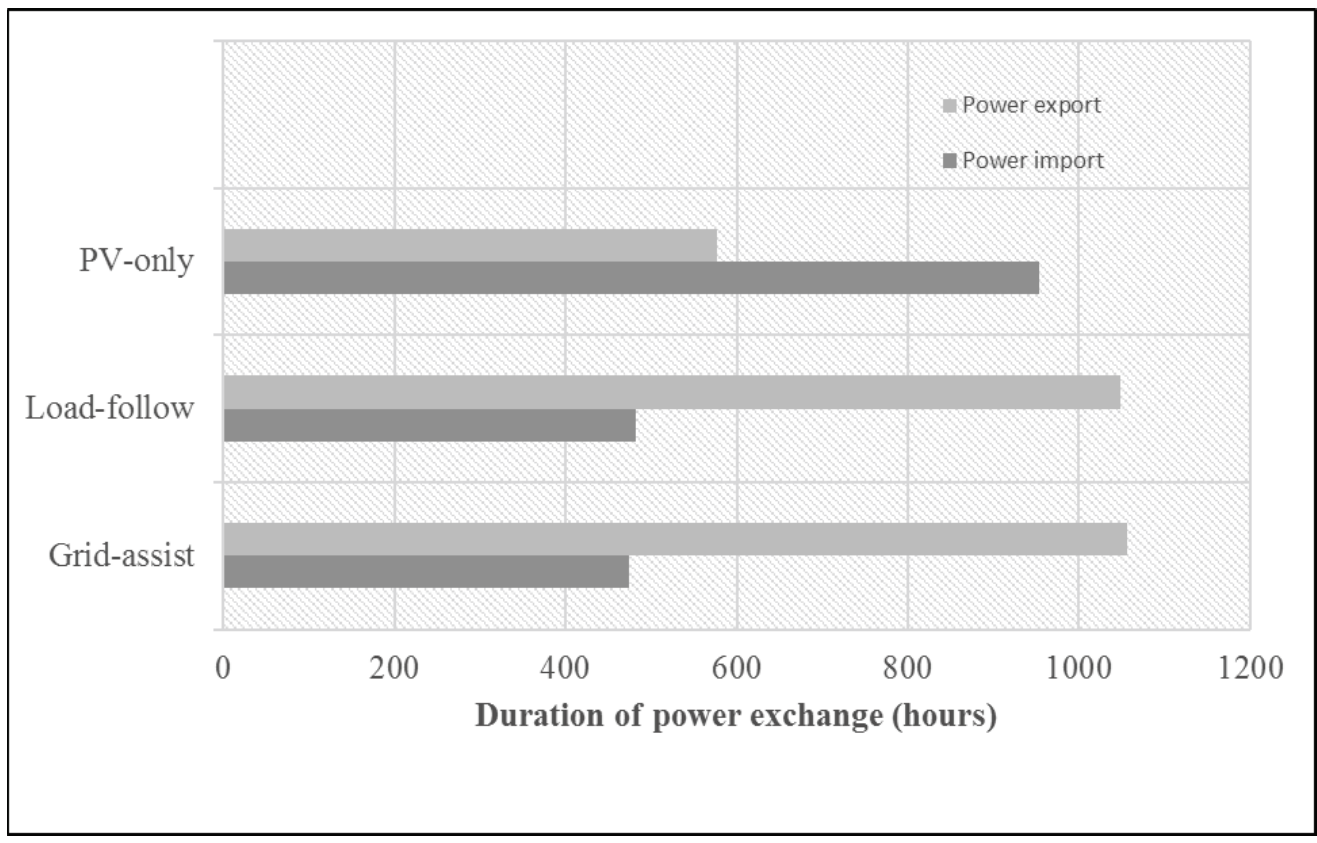

Figure 4.10: Comparing the duration of power imports and exports in the three scenarios for on-peak TOU periods only

\subsubsection{Grid-assist scenario}

The results for the grid-assist scenarios are very similar to those in the load-follow scenario. The total energy imported in the grid assisting case is slightly lower and the total energy exported is slightly higher, since more energy is generated. The performance in peak import of electrical power is the same for both scenarios. The peak power export is slightly higher when compared to the load-follow scenario. The similarity in behaviour between the load-follow and the grid-assist scenarios is due to the overlap between the community peaks with the grid peaks. For instance, on October 6th, the central plant is called upon to operate from 18:00 to 22:00. 


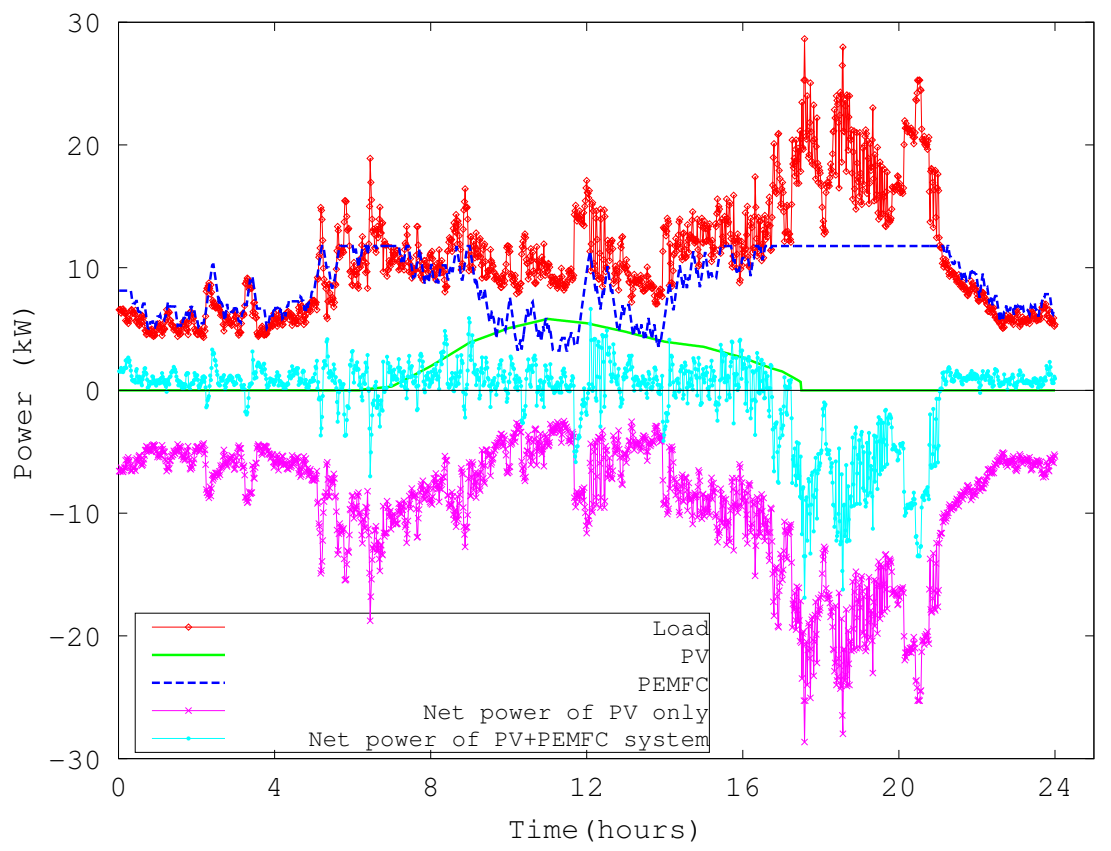

Figure 4.11: Load following power balance example: Oct 6, 2010

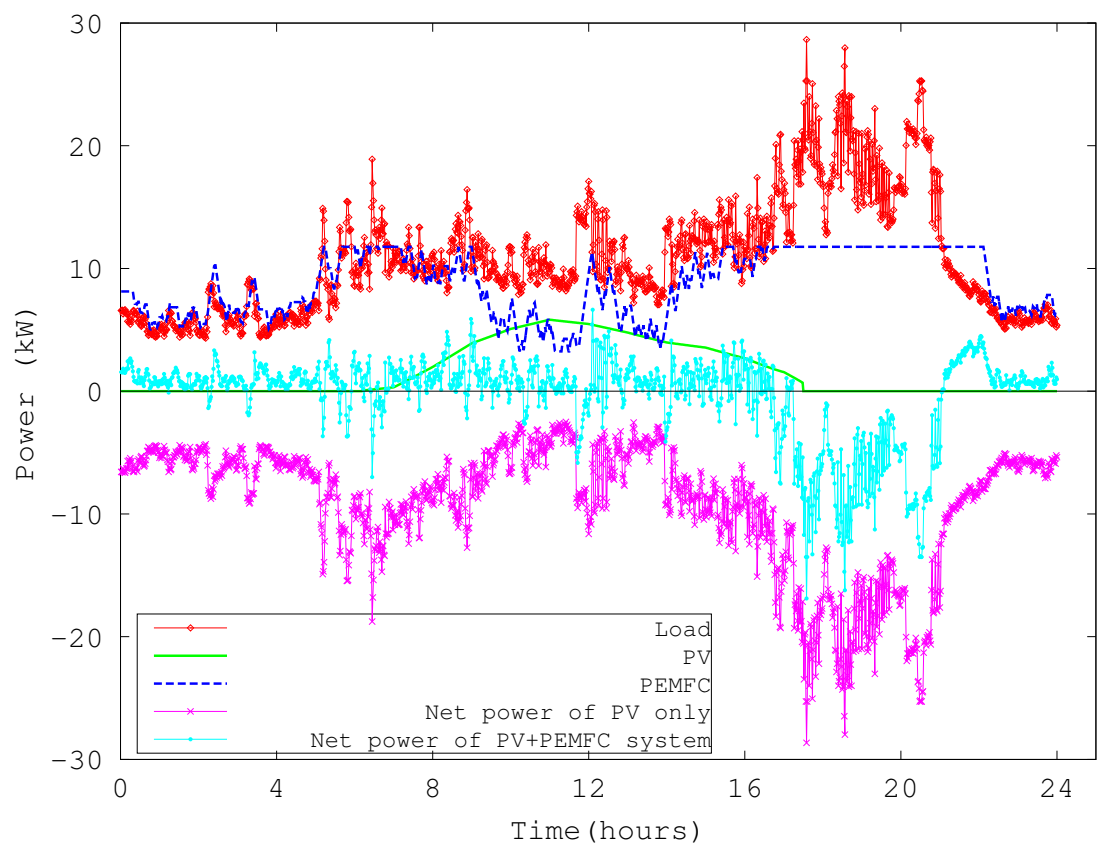

Figure 4.12: Grid assisting power balance example: Oct 6, 2010 
During this time, the community's demand for electricity frequently exceeds the PEMFC output. The PEMFC outputs are similar for both scenarios in Figure 4.11 \& Figure 4.12 because the community peak coincides with the central plant generation.

This chapter discussed the simulation results of integrating PEMFC units in a simulated community that is electrically powered by PV and the grid. Different PEMFC operation schemes were tested to assess the performance of the community's electricity generation in the load-follow and the grid-assist scenarios. The results analysis was conducted for two different time segments. One that analysed all 50-weeks of results (annual results) and one that only looked at the electrical behaviour during TOU periods. This chapter presented the electrical performance of a simulated, grid-connected community that is powered by PV modules and PEMFC units. The next chapter will look into the feasibility of implementing a policy that would allow the connection of micro-CHP systems, such as the PEMFC to sell electricity to the grid. 


\section{Chapter 5}

\section{Policy and Deployment Recommendations}

The uptake of PV technology in Ontario has been motivated by the Green Energy Act (refer to Section 1.2.1 for more detail). The microFIT program under the Green Energy Act provided the incentives that resulted in the popularity of PV installations on a residential level [4]. The second technology critical to this research, residential PEMFC, is not currently produced or sold in North America. In order to apply the simulated system in Ontario, residential scale combined heat and power (CHP) or micro-CHP units need to be commercially produced or imported.

The modelling research conducted in this thesis draws the conclusion that using PEMFCs to follow demand is a feasible solution to increasing PV capacity. If this finding is proven true in practical applications, a deployment strategy may be implemented to assist in the commercialization of micro-CHP technologies in Ontario. The environmental benefit of combined heat and power production derives from its higher fuel utilization and the reduction of the inefficiencies attached to transporting electricity from generation to demand. Moving from centralized to distributed 
energy generation is also aligned with the desire to increase reliability and resilience in energy generation.

This chapter presents the various considerations that are relevant to the commercialization of micro-CHPs in the Ontario market. The discussions in this chapter include the insights and recommendations of industry experts, as well as past results of micro-CHP implementations in Ontario and internationally. The international experiences of micro-CHP deployment were gathered through literature research while the local experiences were obtained from interviewing stakeholders. Other sources of information include publications from the Ontario Energy Board and the Canadian Electricity Association.

\section{$5.1 \quad$ Interview Methodology}

The interviewees were selected based on their experiences to provide diverse considerations on the commercialization and deployment of micro-CHPs. Relevant stakeholders were chosen based on their experience and involvement in the energy industry. The targeted groups include government bodies such as the Ontario Ministry of Energy (MOE) and Sustainable Development Technology Canada (SDTC), bodies associated with the delivery of electricity including the Independent Electricity System Operator (IESO) and local distribution companies (LDCs), advocates of the technology such as the CHP Association, relevant university professors, non-profit organizations, and private companies. 
Candidates were reached through personal connections, the connections of colleagues and professors, as well as recommendations of other interviewees. Not all contacted candidates agreed to be interviewed. Attempts to interview the Ontario MOE, SDTC, the CHP Association, and university professors were not successful. However, many key stakeholders and experts were interviewed, formulating perspectives that would be used for policy decisions.

Nine candidates that hold relevant roles and possess valuable experiences were interviewed to provide a range of perspectives on the deployment of micro-CHP technologies. Learning from previous attempts of similar policy implementation may be beneficial. A recent example of this is the microFIT program. Robert Sinclair is involved in the program and policy design for microFIT at the IESO. He also manages the implementation and operation of renewable energy procurements on various scales. Additionally, Mr. Sinclair was formerly a Senior Policy Advisor in the Ontario MOE. Similar to Mr. Sinclair, many interviewed candidates fit into more than one targeted stakeholder group. Mr. Jan Buijk is the CEO of EPS Ltd., a Canadian company that specialises in clean energy projects such as CHP technologies. He is also on the board of directors at Decentralised Energy Canada, a not-for-profit corporation committed to accelerating the commercialization of decentralised energy technologies. Other experts in CHP technology include Darryl Yahoda from the IESO who helped develop CESOP $^{1}$ and Tim Short, from Enbridge, who was involved in the field testing of micro-CHPs in residential homes. Mr. Short is also

\footnotetext{
${ }^{1}$ Clean Energy Standard Offer Program (CESOP): In 2010, the Ontario MOE authorized the Ontario Power Authority (OPA) to procure cost-effective and beneficial CHP projects of $20 \mathrm{MW}$ in capacity or less (designed for the commercial and industrial sector).
} 
a customer that took advantage of the microFIT program to install PV panels on his roof. On the ground, the LDCs are crucial to the implementation of program details. Raed Abdullah from Hydro Ottawa, Dave Wilkinson from Waterloo North Hydro, and Neetika Sathe from Powerstream were also interviewed to discuss various challenges they faced in program implementation. The insights obtained from the interviewees are the primary source of information for the design of micro-CHP deployment strategies and recommendations.

Semi-structured personal interviews were conducted over the phone. Themecentered interview questions were tailored to the specialization of the interviewee. Initial questions were open-ended to provide the participants the freedom to express their views in the direction of their specialized knowledge while encouraging a thoughtful response. Subsequent questions were designed to pertain specifically to the cases familiar to the interviewee while maintaining relevance to the themes in the research. The interviews were voice recorded, with the permission of the participants, to allow transcription and analysis. Ethics clearance for conducting these interviews was obtained from the Research Ethics Board. The ethics clearance, a list of initial interview questions, and interviewee backgrounds can be found in Appendix A.

\subsection{Micro-CHP}

An important motivation of this research was the microFIT program that provides subsidies for PV installations. In proposing the integration of PEMFC units in the community, a strategy for the uptake of this arrangement needs to be studied further. 
Discussions with interviewees on micro-CHP centered on technical, economic, and social challenges of deployment on a residential scale.

\subsubsection{Technical challenges}

The first theme identified by interviewees as being a major technical issue is the long term reliability of micro-CHPs. A variety of micro-CHP engines exist, including steam turbines, combustion engines, and fuel cell-based units. Mr. Buijk advised that engines and turbines require regular maintenance and service. Therefore, fuel cell units are better suited for residential application, due to the reduced number of moving parts and thus reduced maintenance requirements.

The connection of micro-CHP with PV is the second challenge identified by the interviewees. Mr. Wilkinson described that the metered connections for micro-FIT customers consist of a standard meter for the load and a separate meter for the generator. This unique metering scheme has added complexity to the distribution system connection. Connecting micro-CHP to the distribution system would not be feasible under an additional program with a unique metering scheme. This is due to the administrative and financial limitations that comes with separate programming and meter installations. Based on the interviewees' remarks, it is apparent that setting up both PV and micro-CHP technologies under the same program with a common meter would be a priority. Mike Smith, a retired engineer in Ontario experienced in this field, remarked on the creation of the inverter market that was driven by the deployment of the Green Energy Act. The design challenge of DC to AC conversion

to synchronize PV with Ontario's frequency and phase angles was accomplished. The 
inverter technology can now be used for any DC to AC conversion on the Ontario grid. This allows Ontario to import fuel cell units from international manufacturers, without the cost of the engineering required to design for compatibility with the Ontario grid. Three of the interviewees pointed out that the technology of PV inverters with two discrete inputs already exists to allow the electricity generated from PV and micro-CHP to feed into the system with protection. Adopting these dual-input meters for micro-CHP and PV connections would decrease the system complexity for connecting the generators to the distribution system.

The third area of complication involves electrically configuring the micro-CHP unit to provide backup to PV. Ali Golriz, a project manager for clean energy procurement at the IESO, described that PV units are not electrically connected to the load, but connected in parallel to the grid. Even under the metering scheme suggested above, the load and generation units would not be electrically connected. Communication would need to be established between the systems in order to provide backup. After establishing communication, a power management strategy, such as the one proposed in Section 2.2 may be used to balance supply and demand.

The last area of concern surrounds the appropriate application of micro-CHP systems. Mr. Sinclair argued that the high coefficient of performance ${ }^{2}$ in microCHP units may not be suitable for providing electrical backup. During times of high electricity demand, the thermal load may not be present. Two other interviewees added that micro-CHP is more suitable for multi-residential, condo-building, and commercial applications, due to reduced demand fluctuations.

\footnotetext{
${ }^{2}$ ratio of heating provided to electrical energy consumed
} 


\section{Case study: Enbridge}

In addition to the technical challenges discussed above, concerns may arise when systems are implemented in the field. Enbridge's implementation of micro-CHP prototypes was an experience that future projects can learn from. Tim Short, the Manager of Distributed Energy at Enbridge Gas Distribution recollected their experience with micro-CHP.

In 2006, Enbridge installed five 1.2-kW Honda freewatt CHP systems in residential homes. The Honda freewatt is a combustion engine-based technology that uses natural gas as input fuel. The implementation of these units faced many challenges. The high unit cost of $\$ 20,000$ was an economic challenge. Mr. Smith commented that the cost of the demonstration unit does not reflect the anticipated cost when the technology is deployed in large numbers. Technically, the set up faced some difficulties. The unit was not flexible in furnace connection; a specific furnace was required to pair with the micro-CHP system. The furnace was used to meet the thermal load when the micro-CHP unit couldn't. When the micro-CHP's thermal output was insufficient on cold days, the furnace would take over. This occurred frequently and reduced the run hours of the micro-CHP unit. Iterations of operational software improvements took place to increase the micro-CHP's operating hours.

Various safety concerns resulted in additional protective measures and permitting requirements. For example, the cooling system in the micro-CHP used glycol as the coolant and exchanged heat with water that came from the city's potable water

distribution system. The city was concerned with the possibility of a glycol heat exchanger wall failure, which would pollute the potable water. The installation of a 
back-flow preventer valve and the performance of annual check-ups was required.

Since the permit reviewers were unfamiliar with the technology and there was a lack of documentation in the Technical Standards and Safety Authority (TSSA), the micro-CHP units were installed under a field test exemption. At the end of the field test permit period, Enbridge decided to remove the units from the homes because they were operating at a low efficiency of $20 \%$ and reduced run hours. They also did not have any more funds to further improve the software.

Even though this project was not able to demonstrate the value proposition expected, it generated valuable learning about the balance of plant issues, control, and trades. Mr. Short recommended that future projects be sized based on the base thermal load of the residence (i.e. DHW). Learning from the experience of this project, future development of the technology should focus on improving efficiency and designing for flexible integration with existing furnace models.

\subsubsection{Economic challenges}

The economic challenges for fuel cell based micro-CHP technology are substantial, as it is a technology in its prototype stage in North America, and therefore has not seen price decreases resulting from mass production. In Mr. Buijk's experience, the economics are challenging for CHP projects on the micro level. Mr. Yahoda revealed that a demonstration scale micro-CHP fuel cell project has been proposed to the IESO in the past and was rejected due to its economic challenges. Mr. Smith explained that manufacturers in North America have been building custom made prototypes that would not be able to compete in the market. Experience curves suggest 
that as cumulative production of technology increases, cost should decline [58, 59]. A marketable price can truly only be arrived at when large volume manufacturing is in place, as these devices are in fact consumer products. Ms. Sathe reasoned that micro-CHP technology can be an alternative that competes in the market for consumers in Canada given its efficiency benefits, resulting in energy savings. Additionally, the stability of natural gas prices is a motivator for the development of natural gas fuelled micro-CHPs.

Mr. Abdullah raised the concern of stranding assets. There's a risk of stranding centralized power generation plants with added distributed generation. If microCHP systems become competitive, distribution facilities that were required to be constructed to meet a utility's obligation to serve may no longer be needed [60]. If the transition of adopting micro-CHP technology is not accomplished appropriately, stranding assets on the utility side may result in increasing electricity prices for customers. It is important to strategically match the installation of additional generation with demand requirements and the retirement of old technology.

Japan's micro-CHP policy is driven by a need for additional generation. The case study below describes the strategy that Japan employed to meet the economic challenge of establishing a market for residential-scale fuel cell systems.

\section{Case study: Japan}

The Great East Japan Earthquake in 2011 resulted in the suspension of nuclear plants, which caused electricity shortages [61] and the increase of electricity prices [62]. At the same time, energy demands in DHW and space heating in the residential 
sector were increasing [61]. Japan views the use of residential fuel cell units as a stepping stone to a future of energy generation through manufactured hydrogen without emitting $\mathrm{CO}_{2}$ (using techniques such as carbon capture and storage) [63].

Subsidies were given for research and development $(\mathrm{R} \& \mathrm{D})$ projects, and a feed-in tariff program and tax reductions were implemented. R\&D funds were first implemented to invest in fuel cell technology development [64]. The Ministry of Economy, Trade, and Industry worked with manufactures such as Panasonic and Toshiba to develop safe and efficient residential fuel cell units [61]. A FIT program was put in place to allow fuel cell owners to sell the electricity produced to the utility. Since the roll out of the first household fuel cells in 2009, more efficient fuel cells have been developed. The interested reader is directed to Panasonic's product description [65] for more details on the latest technology. The price of fuel cell systems reduced by 4-5 times in the first three years of deployment [61]. With the drop in retail prices, government subsidies have also been decreasing [66]. Consumers that purchased residential fuel cells are eligible to claim tax incentives in the form of deductions from income or corporation taxes [66].

As a result of residential fuel cell uptake, a decrease in pricey electricity consumption and an increase in cheaper gas consumption has been prevalent in the country. This resulted in annual household expense reductions by an average of $\$ 803$ CDN [61]. This outcome also reduced pressure on the electricity utility and increased financial gains for the gas companies and fuel cell manufacturers, who joint ventured the fuel cell systems in the $R \& D$ phase of the program. Japan views natural gas as a transition fuel towards a hydrogen economy. The deployment of residential fuel 
cell units in Japan provides an example of overcoming the technical, economic, and social challenges through stakeholder engagement and policy implementation.

\subsubsection{Social implications}

Discussions with interviewees surrounding the social barriers of micro-CHP deployment were centered on education, preventing undue burden on non-participating customers, and practical concerns. The lack of knowledge of micro-CHP technologies among the general public has been stated by the LDC interviewees. The LDCs have spent considerable effort in raising awareness of energy use in their customers. Mr. Abdullah remarked that the need for education in self-generating customers is important as they may have a tendency to ignore the importance of energy conservation.

Mr. Smith described the public perception of the microFIT program. The public have been complaining about the increasing electricity prices due to the redistribution of costs associated with the microFIT program. Ms. Sathe advised against creating a program that would incur additional costs onto customers who do not benefit from it. Mr. Sinclair added that microFIT is eligible to a restricted group of home owners. The commercial community, on the other hand, have greater access to capital, lower borrowing rate, and tax benefits. The recommended policy will attempt to create a program that is inclusive of a various groups, without burdening the non-participants.

Practical concerns including noise levels and space consumption were mentioned by two of the interviewees. Mr. Smith spoke of his experience exposing the general public to the sound of micro-CHP systems. The sound quality was perceived to 
be more important than sound level. It was observed that members of the public reacted more favourable to the quality of the sound that the fuel cell units were making, in comparison to older air conditioners. Mr. Abdullah brought up the trend of intensification, the development of properties towards increasing population density. This would mean more people living in a smaller area, making it more difficult to find the space to install devices such as micro-CHP units.

In order to make policy decisions, a complete understanding of the limitations of the technology is crucial. Additionally, awareness of the current policy landscape and the goals that drive future policy making are also essential to decision making.

\subsection{Policy Landscape}

This section will discuss three different programs of relevance, the microFIT, Conservation Demand Management (CDM), and Net-Metering programs. The microFIT program was rolled out in 2009 and is the most popular program for residential renewable energy installations. In 2015, changes in the CDM program opened up opportunities for micro-CHP. In the near future, net metering is expected to play a more important role in increasing renewable energy generation capacity. These various programs will be discussed in this section to explore the opportunities that exist for influencing the policy process. 


\subsubsection{Current state}

Since 2009, the microFIT program has been successful in bringing in a large number of suppliers. Mr. Sinclair stated that about 20,000 microFIT contracts have been signed to date. Mr. Smith explained that the popularity of the program was induced by the simplified application process and the guaranteed payment rate. The program was established with the goal of creating a manufacturing industry and renewable

generation capacity in Ontario. Mr. Sinclair explained that the provincial system operator perceives the intermittent generation capacity from microFIT as a minor adjustment in demand. MicroFIT generation totals $0.88 \%$ of the typical provincial power load of $20 \mathrm{GW}$.

More challenges are seen on the local level. Mr. Wilkinson disclosed various concerns that the LDCs have regarding the microFIT program. In the proposal stage of each project, the LDCs undergo a robust assessment process to ensure that it does not pose any harm to the system or other customers. In the installed PV system, protection is built into the inverter so that the generator may be disconnected to avoid harm. This is done to avoid the risk of unintentional backfeed into the distribution system during times of light load or when the utility needs to do work on the lines.

\subsubsection{Future outlook}

Discussions with interviewees on the electricity landscape provided a forecast for relevant programs that may present opportunities for deploying micro-CHP. Mr. Sinclair delivers the forecast for microFIT as less involvement from the IESO and 
increased micro-renewable programs offered by the LDCs. Additionally, focus is centered around conservation initiatives rather than generation procurement. Mr. Yahoda added that the electricity landscape is moving from procurement activities to open market competitions. The demand response programs, conservation incentives, and smart grid construction are the main initiatives moving forward. To expand on the direction of the electricity landscape in relevance to micro-CHPs, emphasis will be placed on two particular programs: the Conservation Demand Management (CDM) program and the net-metering program. Both programs and the opportunities for policy potential are further discussed in this section.

The Ontario Energy Board (OEB) establishes targets of reduction in electricity consumption and peak demand for each LDC connected to the IESO-controlled grid. In 2015, the OEB issued renewed guidelines for the 2015-2020 term [67]. The CDM program now allows each LDC to design, obtain approval, and implement their own conservation programs to meet the established target. The new CDM guidelines confirms the shift in framework from IESO/OPA retail-based programs to LDC conservation responsibilities, which was mentioned by Mr. Sinclair. Both Mr. Wilkinson and Mr. Short agreed that the intention of this program is to emphasize behindthe-meter (BTM) generation ${ }^{3}$. The authorities want to reduce electricity backflow. Mr. Wilkinson also suggested that BTM generation is more favourable for industrial customers with a consistent base load.

The program that is more inclusive of residential customers is the net-metering program. Net-metering allows customers with generators to send electricity to the

\footnotetext{
${ }^{3}$ Power produced is intended for on-site use, without export to the electric utility.
} 
utility's distribution system for a credit towards their electricity costs. This credit may be carried forward for a set time period (e.g. one year), to offset future electricity costs. Since the deployment of the FIT and microFIT programs, net-metering has not been popular among utility customers, stated Mr. Wilkinson. At Waterloo North Hydro, out of the 55,000 customers, less than a dozen have net-metering contracts, signed before the implementation of microFIT. However, a change in policy is forecasted to take place in the next few years. The IESO is performing ongoing work in transitioning the microFIT Program to a net-metering initiative [68]. Ms. Sathe reasoned that the microFIT program was an incentive designed to promote the renewable technology market and improve energy literacy. After which, the market needs to get back to demand and supply matching, and this will be taken care of by net-metering. Mr. Short agreed that as grid parity approaches, it makes sense to move towards a net-metering program. The net-metering scheme is open to all participants. Mr. Sinclair predicts there may be a significant expansion in netmetering uptake because of its broader eligibility of applicants. The net-metering program is a part of the shift in framework from IESO generation procurement to LDC conservation efforts. Mr. Sinclair explains that the LDCs may have more responsibilities in organizing, offering, and executing net-metering projects.

Along with the motivations for a net-metering scheme, the interviewees also discussed foreseeable challenges. Mr. Wilkinson spoke of some of the challenges that need to be overcome before the successful implementation of the net-metering program. The main issue that the LDCs faced in the past involved dealing with the unique customer and information billing required for net-metering contracts. The 
unique net-metering situations in credit building and forward tracking added complexity to the billing engine. The small number of contracts added a disproportionate amount of financial costs to the LDC for making changes to the billing system. This issue was also experienced by other LDCs such as PowerStream, mentioned by Ms. Sathe. Mr. Wilkinson did not perceive this as a major challenge because it would be economically feasible to upgrade the billing software once net-metering become more popular. Ms. Sathe agreed that with the growth of a net-metering customer base, challenges will be overcome more easily. Another challenge Mr. Wilkinson spoke of was the reverse power flow situations in high uptake neighbourhoods. To overcome this challenge, extensive modelling and assessment studies should take place in order to prevent harm to the system. Mr. Yahoda added that even though a substantial penetration of residential-scale intermittent resources needs to be installed before any major issues would arise for the LDCs, visibility and forecasting tools are crucial for balancing supply and demand. Transitioning into net-metering will require various assessments, upgrades, and additional tools. However, in comparison to the current microFIT program, there is wide expectation that the net-metering program will be less bureaucratic, onerous and costly to connect.

\subsubsection{Policy drivers}

Policy drivers define the motivation behind the creation of policies. This section will describe the policy drivers that support the adaptation of micro-CHP technology. The residential fuel cell incentives in Japan originated from their need for electricity generation after the suspension of nuclear plants and their vision for a hydrogen 
economy. Policies promoting micro-CHP in the UK, Germany, Netherlands, Italy, and Belgium are mainly driven by GHG emission reduction targets [66].

The plan of action proposed by the Canadian Electricity Association (CEA) in Vision 2050 to rejuvenate existing, and add additional electricity infrastructure resonates with the benefits of micro-CHP [69]. The first concern noted by the CEA is increasing supply to respond to the increasing demand of electricity. Ms. Sathe explained that the challenge is in demonstrating quantitatively how the thermal outputs in micro-CHP can be used to supply heating needs. The second Vision 2050 plan of action is to understand the new relationship with consumers, who are becoming providers and engaged partners in electricity generation. The increased engagement of consumers in supplying electricity has been seen as the next step by IESO, LDCs, private industry, and the consumer. Mr. Smith maintained that promoting distributed generation (DG) as the grid of the future is the primary policy driver for micro-CHP deployment. Increased DG will, in turn, lead to increased reliability as the number of DG plants escalate. Along with these goals, the reduction of carbon footprints in Canadian electricity generation is another commitment. Canada has committed to achieving a 17\% reduction in GHG emissions from its 2005 levels by 2020 [66]. Ms. Sathe stated that the policy will be driven by the rationale of increasing efficiency and thereby reducing natural gas consumption.

This section presented the various challenges of the micro-CHP technology, the future direction of the electricity landscape in Ontario, and the various policy drivers for the deployment of new technology. The next section will take what has been recommended by the stakeholders and learnings from case studies to make policy 
recommendations for the deployment of micro-CHP.

\subsection{Policy Recommendations}

Various perspectives were gathered from the stakeholders, including views from the IESO, LDCs, Enbridge, private industry, the consumer, and the non-profit. Policy makers in the Ontario MOE need the inputs of these stakeholders in order to design and implement programs. The policy recommendations made based on various stakeholder perspectives are presented here. This section will outline the most suitable type of policy and the steps necessary for deployment.

\subsubsection{Type of policy}

Literature research of micro-CHP incentives in other jurisdictions provide examples of the types of policies that may be feasible. Japan put subsidies towards research and development (R\&D), implemented a FIT program, and offered tax reductions for residential fuel cell units of less than $1 \mathrm{~kW}$. In the UK, two types of payments are awarded to micro-CHP system (less than $2 \mathrm{~kW}$ ) owners: a generation tariff and an export tariff [70]. The generation tariff is applied to all energy produced by the unit. The export tariff is applied in addition to the generation tariff, to subsidize for the energy exported to the distribution network. In Germany, various incentives exist to support the deployment of micro-CHP systems. Under the Cogeneration Law, a support program for systems less than $20 \mathrm{~kW}$ in size provides discounts on the capital cost of the system $[71,72]$. Additionally, the Cogeneration Law includes 
a FIT mechanism to support micro-CHP energy generation [73]. Under the German Energy Tax Law, the fuel used in a CHP system is waived of taxes [74]. Furthermore, the owners of any new residential building have obligations to use renewable sources or CHP for space heating [75]. In Italy, a trading mechanism is in place. A microCHP unit that is high in efficiency may obtain white certificates ${ }^{4}$. In addition to obtaining white certificates, micro-CHP owners may also receive advantages such as dispatching priority, fuel tax reduction, and net-metering [76]. Similarly in Belgium, a trading scheme exists in Flanders for qualified CHP and micro-CHP installations. White certificates are issued based on the absolute primary energy saved as compared to separate production of electricity and heat $[77,78]$.

In Canada, the provincial governments regulate energy policies, though federal programs and incentives have existed in the past. Examples of programs that support micro-CHP implementation can be found in other provinces. The provinces of Manitoba, Saskatchewan, Alberta, and British Columbia approve of net-metering of micro-CHP systems [66]. In Alberta, energy generated from micro-CHP is also eligible to contribute towards white certificates.

Each province has a unique energy framework. The interviewees were asked to discuss the types of incentives that would work for Ontario. Three of the interviewees recommended simple incentives that are transparent in their price signal. Mr. Abdullah remarked on the importance of a long-sighted policy with a future end goal. Mr. Buijk suggested a program similar to microFIT, where investment can be justified by the pricing scheme. The microFIT program in Ontario is being replaced with

\footnotetext{
${ }^{4}$ White certificates are used to certify that certain energy requirements have been met. It can be traded or used to prove the meeting of certain energy efficiency or $\mathrm{CO}_{2}$ reduction obligations.
} 
a net-metering incentive in the near future [68]. Mr. Short plainly stated that a FIT program would not be advisable for micro-CHP. Two of the three other interviewees with suggestions on the type of policy agreed with this statement.

The net-metering program is aligned with the movement from active procurement to open-market participation from consumers. Mr. Short revealed that Newmarket Hydro included a program in their conservation plan that provides customers with incentives to install PV for net-metering. The LDC would pay the consumer 25 cents/kWh of the typical annual solar output to subsidise for some of the capital required in PV installations. Similar to Newmarket, other LDCs can design and implement programs that add generation capacity towards their conservation targets under CDM. Additionally, technical concerns on the LDC side can be addressed with a net-metering program. In comparison with the microFIT program, the netmetering program can be designed to cap generator export allowance, encouraging appropriate sizing of units and preventing damaging reverse electricity flow. Mr. Smith remarked on the grid backfeed issue in Germany due to a high penetration of intermittent renewables. They are now capping capacity by asking home owners to size their systems so as to use most of the power generated on site. A netmetering incentive applied across different technologies, PV and PEMFC in this case, is supported by existing dual-input inverter technology and would only require a single meter. Mr. Smith recommended a scheme that involves consumers buying power at TOU rates (current net-metered customers are not billed at TOU rates but rather at a flat rate, due to the unique meter used) and selling power at a rate one step lower than the current TOU purchase rate in effect. Under this pricing plan, 
this scheme clearly identifies the buy and sell rates for the home owner at all times. While at the same time creating a differential in these rates to allow the utility to offset some of the cost of the program, thereby, encouraging the participation of both the home owner and the utility.

In combination with the net-metering program, a rebate program may be necessary to contribute to the capital cost of micro-CHP. Rebate programs are simple to calculate and easy to set up and terminate. Both Mr. Smith and Mr. Buijk saw the need of federal and/or provincial rebates to drive technology development towards constructing an economically viable industry. In order for this to work, a technology or size specific program is required to target the specific market of micro-CHPs. Mr. Smith suggested that the rebate should be adjusted for the price difference in the less efficient technology that it is replacing. Initially, the program will require a price premium as the technology is being produced at low volume. Once the market is established, the incentive could be reduced.

The combination of a rebate program and the inclusion of micro-CHP in the netmetering program may lead to the successful deployment of micro-CHPs in Ontario. Price levels in the microFIT and the rebate incentives must be set to improve the economics of micro-CHP through mass production. The details of program deployment and implementation are discussed in the next section.

\subsubsection{Steps of deployment and implementation}

The first step to deployment is to engage customers. In order for micro-CHP to be adopted by home owners, its application in offsetting electrical demand in buildings 
with a heat load need to be understood (commented by Mr. Wilkinson). The value of the thermal output may not be easily understood by customers. The interaction of micro-CHP systems with existing appliances will differ case-by-case. The LDCs do not have an inventory of building heating systems. The challenge is quantifying the thermal output and engaging consumers to increase energy literacy. Mr. Abdullah from Hydro Ottawa sees education as a positive step that will provide the opportunity for customers to learn about energy usage and efficiency.

To assist in energy literacy and encourage adoption, Mr. Smith remarked on the importance of creating a policy that allows participation at various scales. The early market targets may involve larger customers, allowing the public and commercial sector to set examples. Hospitals, retirement homes, restaurants, and other businesses sensitive to power outages may be first encouraged to participate. Unlike the microFIT program that was designed exclusively for residential customers, the netmetering program should encourage participation from all sectors. The exclusivity of the microFIT program to restrict involvement from residential customers was seen as a downfall of the program design. The net-metering program will aim to encourage investment from all customers, given that certain requirements are met.

Welcoming the participation in distributed energy generation must be done strategically so as to avoid stranding assets and incurring additional costs for customers, especially those not directly benefiting from the net-metering scheme. Studying the placement of generators prior to approval to ensure that the additional capacity would not cause any harm to the system and nearby customers is standard procedure. The approval process should also assess the need for generation capacity 
in the area of application. For instance, Mr. Wilkinson recalls the issue of high density PV in rural areas. The infrastructure in these areas is 70 years old, and the load is light due to the small number of customers, especially in the spring and fall. In these two seasons, the inverters would frequently trip out the generators as generation exceeded demand to the point of increasing voltage regulation beyond acceptable limits. As the electricity infrastructure ages, matching the additional capacity installation with scheduled system upgrades and placing them in areas of demand would prevent additional expenditure and stranding existing assets.

To encourage the development and use of the technology in an appropriate context, certain rules and requirements should be implemented. For example, Mr. Short suggested the implementation of efficiency requirements based on the system size. Emission standards and maintenance schedules are examples of safety requirements that apply specifically to micro-CHP. Mr. Abdullah commented that the LDC and the Electricity Safety Authority (ESA) are responsible for reviewing the safety of proposed generators. After determining the location of the install, the LDC advices the customer on safe installation. It is crucial for the LDCs to retain a record of all generation devices to be able to isolate and disconnect the generators in case of meter changing and utility work. The gas connection would be installed by licensed gas-fitters, and an appliance installer would be contracted to integrate the appliance with the house. The municipality may impose other safety requirements for the installation, similar to the back-flow preventer valve requirement for the Enbridge project. A long term concern in the implementation of micro-CHP systems was described by Mr. Abdullah. Over time, customers may become complacent and 
neglect the maintenance and inspection required on the micro-CHP units. This may pose a serious safety issue for the home owner and the utility. Aside from safety regulation requirements, Mr. Abdullah suggested that the realistic representation of the potential issues involved and comparisons of the various options is necessary.

\section{Powerstream's microgrid experience}

Ms. Neetika Sathe was involved in Powerstream's implementation of a microgrid at their office in Vaughan, Ontario. In this project, they wanted to learn about the interoperability, controlling, and optimization of a microgrid. The microgrid composed of solar, wind, and natural gas generators, along with batteries, EV charging, and a solar carport.

Ms. Sathe spoke of the challenges that they had met through the implementation of the microgrid and the lack of previous sites to learn from. By learning from their experience, foresight can be obtained for the potential difficulties in the deployment of integrated PV and micro-CHP technologies. The amount of lead time required to set up and integrate these technologies was underestimated. They found early on that the different equipment were not compatible in communicating with each other.

However, they were glad to have picked collaboration partners that had the expertise to improve on these issues. The system components operated seamlessly together after iterations of interoperability and grid integration improvements. Software integration was also implemented to allow the system to be operated by non-experts.

In the near future, Powerstream wishes to install an energy management system that will allow for the input of weather information and electricity prices. Through 
iterations of improvements, Powerstream is learning to use their system more efficiently and economically, with better operational experience and forecasting abilities.

Learning from the experiences of Powerstream and Japan, it is clear that the selection of collaboration partners is important for obtaining the necessary expertise and directing the benefits to the appropriate stakeholders. Additionally, the establishment of a board and setting up regular reviews of the program implementation will allow for iterations where the program may be improved based on its progress.

The policy recommendations involve the establishment of a net-metering scheme across distributed generation technologies and a rebate program to develop the market production of micro-CHP. The recommended policy adopts learnings from the experiences of past policies and projects. With careful implementation, this deployment strategy aims to balance the province's supply and demand needs, increase efficiency, and encourage customers to invest in energy generation. 


\section{Chapter 6}

\section{Conclusions and Future Recommendations}

\subsection{Conclusions}

\subsubsection{Power management strategy}

A power management strategy was designed specifically for the 1-kW PEMFC units under study. The strategy was meant to complement the community's PV power generation and electric load, while giving priority to PV generated power. The strategy operated the simulated PEMFC within the modulation and capacity limitations. Together with the load forecasting method, the power management strategy generated power to follow the demand pattern of the actual load within the PEMFC's capacity. This strategy attempted to more closely match the community's demand, in comparison to previously simulated control schemes [37]. 


\subsubsection{Simulation results}

It was observed that by integrating PEMFCs in the community, more energy was generated within the community, and less was required as imports from the grid. More than $80 \%$ of reduction in energy imported was achieved in 50 weeks. The maximum power imported was reduced by $23.5 \%$. This indicated a reduced capacity requirement from the central natural gas plants to provide backup to intermittent technologies.

The pattern of increased energy generation and decreased imports was also observed during periods when the provincial grid was on-peak. The reduction of peak imports during on-peak periods remained the same as those obtained in the annual study. Additionally, the community spends more than double of the time exporting rather than importing energy during TOU periods, which may benefit the utility by decreasing generation during expensive, on-peak periods.

The results from the two scenarios studied, the load-follow and the grid-assist scenarios, are very similar. This results from the similarity of demand patterns between the community and the provincial loads.

\subsubsection{Policy}

Through learning from the experiences of stakeholders and projects of various scales, recommendations were made on an appropriate policy that would increase the adoption of micro-CHP units. Procuring additional generation will meet the province's challenges of upgrading infrastructure, supplying the increasing electricity demand, and engaging customers. The net-metering scheme allows the utility to do so in a 
controlled manner that would minimize harm to the system and other customers. Its implementation on various scales will gather experience and set examples that encourage adoption. A strategic acceptance procedure will prevent stranding existing assets and avoid incurring excess costs on utility customers.

The technology needs to be mass produced in order to be economically marketable. An initial rebate program that covers the price difference between the new and less efficient technologies will help to develop the market. Japan took the opportunity to collaborate with industry partners to encourage R\&D of more efficient developments at lower prices. We may be advised to do the same or import the developed technology from Japan. The establishment of manufacturing and maintenance markets for micro-CHP units may be economically appealing to the province.

\subsection{Future Recommendations}

- An objective of this research was to study the interaction of PV and PEMFC sytems with the grid. The incorporation of energy storage systems was not considered. As the containment technology for hydrogen storage advances, research into how it can be applied to maximize the utilization of PV generated energy and decrease the fluctuation of PEMFC generation outputs should be studied. Aside from hydrogen storage, other alternatives can also be studied. In 2015, Tesla commercialized battery storage technology by introducing Powerwall. This provides motivation for research into increasing reliability and resilience using battery storage with these community energy generation units. 
- Another method for offsetting generation is to distribute the PV module orientations, aside from South-facing. The optimization of panel orientations may be the focus of a separate thesis. The results of creating a different generation profile, and the assessment of the economic trade off would be valuable for future DG designs.

- The thermal output of the PEMFC was not applied to space heating because it was out of the scope of this research. Its contribution to DHW was also assessed to a limited degree. A more comprehensive study should consider detailed house models for thermal analysis.

- Based on the data available, this study assumed that a residential community of 12 houses formed a typical neighbourhood with diverse load patterns. Further research may assess this assumption and study different scales of communities (with the resource of more data).

- The increased total efficiency provided motivation for applying micro-CHP units to residences. However, its environmental impact was not studied and compared. With the attainment of data from centralized natural gas plants, the environmental footprint of generation on the two scales may be compared.

- The policy design process will require an economic analysis for micro-CHPs. The predicted prices under mass production and the time it would take to reach marketable prices are important factors for policy decisions. On the consumer side, the payback period, return on investment, and capital costs need to be attractive enough to encourage investment. These economic factors need to be 
studied and predicted realistically prior to any further policy design. 


\section{List of References}

[1] Ontario Ministry of Energy, "Achieving balance - Ontario's long term energy plan," Ontario Ministry of Energy, Tech. Rep., Dec 2013. [Online]. Available: http://www.energy.gov.on.ca/en/ltep/\#.UufD8tL8W9I

[2] Independent Electricity System Operator, "Demand response in Ontario." [Online]. Available: "http://www.ieso.ca/Pages/Ontario\%27s-Power-System/ Reliability-Through-Markets/Demand-Response.aspx"

[3] N. Kelly and I. Beausoleil-Morrison, Specifications for Modelling Fuel Cell and Combustion-based Residential Cogeneration Devices Within Whole-building Simulation Programs: A Report of Subtask B of FC+COGEN-SIM, the Simulation of Building-integrated Fuel Cell and Other Cogeneration Systems: Annex 42 of the International Energy Agency Energy Conservation in Buildings and Community Systems Programme. Natural Resources Canada, 2007.

[4] L. C. Stokes, "The politics of renewable energy policies: The case of feed-in tariffs in Ontario, Canada," Energy Policy, vol. 56, pp. 490-500, 2013.

[5] Natural Resources Canada, "Energy use data handbook," 2013.

[6] Ontario Power Authority (OPA), "General information about the Green Energy and Green Economy Act," 2014.

[7] OPA, "FIT price schedule," Jan 2014. [Online]. Available: microfit. powerauthority.on.ca

[8] P. Menanteau, D. Finon, and M.-L. Lamy, "Prices versus quantities: choosing policies for promoting the development of renewable 
energy," Energy Policy, vol. 31, no. 8, pp. 799-812, 2003. [Online]. Available: http://resolver.scholarsportal.info.proxy.library.carleton.ca/resolve/ 03014215/v31i0008/799_pvqcpfptdore

[9] A. Yatchew and A. Baziliauskas, "Ontario feed-in-tariff programs," Energy Policy, vol. 39, no. 7, pp. 3885 - 3893, 2011, special Section: Renewable energy policy and development. [Online]. Available: http: //www.sciencedirect.com/science/article/pii/S0301421511000437

[10] J. M. Pearce, "Expanding photovoltaic penetration with residential distributed generation from hybrid solar photovoltaic and combined heat and power systems," Energy, vol. 34, no. 11, pp. 1947-1954, 2009.

[11] M. H. Bollen and F. Hassan, Integration of distributed generation in the power system. John wiley \& sons, 2011, vol. 80.

[12] D. Rekioua and E. Matagne, Optimization of photovoltaic power systems: modelization, simulation and control. Springer Science \& Business Media, 2012.

[13] R. Tonkoski, L. Lopes, and T. El-Fouly, "Coordinated active power curtailment of grid connected pv inverters for overvoltage prevention," Sustainable Energy, IEEE Transactions on, vol. 2, no. 2, pp. 139-147, April 2011.

[14] K. De Brabandere, A. Woyte, R. Belmans, and J. Nijs, "Prevention of inverter voltage tripping in high density PV grids," 19th EU-PVSEC, Paris, 2004.

[15] S. Brahma and A. Girgis, "Development of adaptive protection scheme for distribution systems with high penetration of distributed generation," Power Delivery, IEEE Transactions on, vol. 19, no. 1, pp. 56-63, Jan 2004.

[16] Ontario Ministry of Energy, "Feed-in tariff program," 2009.

[17] G. Johnson, A. Wills, and I. Beausoleil-Morrison, "Establishment of a credible reference scenario for comparison with micro-cogeneration systems."

[18] R. Lamberts and J. Hensen, Building performance simulation for design and operation. Spon Press, 2011. 
[19] G. Johnson, I. Beausoleil-Morrison, B. Strathearn, E. Thorsteinson, and T. Mackintosh, "The calibration and validation of a model for simulating the thermal and electrical performance of a $1 \mathrm{kw}$ ac proton-exchange membrane fuel-cell micro-cogeneration device," Journal of Power Sources, vol. 221, pp. 435-446, 2013.

[20] J. Sirchis, Combined Production of Heat and Power. Routledge, 2003.

[21] E. Romero-Cadaval, G. Spagnuolo, L. Garcia Franquelo, C.-A. Ramos-Paja, T. Suntio, and W.-M. Xiao, "Grid-connected photovoltaic generation plants: Components and operation," Industrial Electronics Magazine, IEEE, vol. 7, no. 3, pp. 6-20, 2013.

[22] F. Katiraei and J. R. Aguero, "Solar PV integration challenges," Power and Energy Magazine, IEEE, vol. 9, no. 3, pp. 62-71, 2011.

[23] M. A. Eltawil and Z. Zhao, "Grid-connected photovoltaic power systems: Technical and potential problemsa review," Renewable and Sustainable Energy Reviews, vol. 14, no. 1, pp. 112-129, 2010.

[24] P. J. Boait, R. Rylatt, and M. Stokes, "Optimisation of consumer benefits from microcombined heat and power," Energy and buildings, vol. 38, no. 8, pp. 981987, 2006.

[25] A. Ferguson and V. I. Ugursal, "Fuel cell modelling for building cogeneration applications," Journal of Power Sources, vol. 137, no. 1, pp. 30-42, 2004.

[26] P. Derewonko and J. Pearce, "Optimizing design of household scale hybrid solar photovoltaic + combined heat and power systems for Ontario," in Photovoltaic Specialists Conference (PVSC), 2009 34th IEEE. IEEE, 2009, pp. $001274-$ 001279.

[27] A. H. Nosrat, L. G. Swan, and J. M. Pearce, "Improved performance of hybrid photovoltaic-trigeneration systems over photovoltaic-cogen systems including effects of battery storage," Energy, vol. 49, pp. 366-374, 2013. 
[28] N. Saldanha and I. Beausoleil-Morrison, "Measured end-use electric load profiles for 12 Canadian houses at high temporal resolution," Energy and Buildings, vol. 49, pp. 519-530, 2012.

[29] "Canadian solar cs6p module specifications," http://www.canadiansolar.com/ product/cs6p-p.html, last accessed 28 July 2014.

[30] "Enphase energy micro-inverter specifications," http://enphase.com/ microinverters/, last accessed 28 July 2014.

[31] B. Brooks and C. Whitaker, "Guideline for the use of the performance test protocol for evaluating inverters used in grid-connected photovoltaic systems," Sandia National Labs, 2005.

[32] F. Gao, B. Blunier, and A. Miraoui, Proton Exchange Membrane Fuel Cells Modeling. Wiley Online Library, 2012.

[33] S. Thale and V. Agarwal, "Design and implementation of communication and control architecture for solar PV based microgrid supported by PEM fuel cell based auxiliary source," in Photovoltaic Specialists Conference (PVSC), 2011 37th IEEE, 2011, pp. 002 448-002 453, iD: 1.

[34] L. N. Khanh, J.-J. Seo, Y.-S. Kim, and D.-J. Won, "Power-management strategies for a grid-connected PV-FC hybrid system," Power Delivery, IEEE Transactions on, vol. 25, no. 3, pp. 1874-1882, July 2010.

[35] E. Dursun and O. Kilic, "Comparative evaluation of different power management strategies of a stand-alone PV/Wind/PEMFC hybrid power system," International Journal of Electrical Power \& Energy Systems, vol. 34, no. 1, pp. 81-89, 2012 .

[36] T. Niknam, F. Golestaneh, and A. R. Malekpour, "Probabilistic model of polymer exchange fuel cell power plants for hydrogen, thermal and electrical energy management," Journal of Power Sources, vol. 229, pp. 285-298, 2013.

[37] J. Kopf, "The performance of residential micro-cogeneration coupled with thermal and electrical storage," Ph.D. dissertation, Carleton University Ottawa, 2012. 
[38] D. Melissa, "Electric mobility adoption and precition Ottawa: Developing a strategic approach to enabling electric vehicle technology in the city of Ottawa." [Online]. Available: http://www.pollutionprobe.org/EMAP/ EMAP-Report-Ottawa.pdf

[39] S. Edwards, I. Beausoleil-Morrison, and A. Laperrière, "Representative hot water draw profiles at high temporal resolution for simulating the performance of solar thermal systems," Solar Energy, vol. 111, pp. 43-52, 2015.

[40] S. McMurtry, "On configuration and control of the thermal plant for fuel cell micro-cogeneration," Ph.D. dissertation, Carleton University Ottawa, 2013.

[41] "The esp-r simulation program." [Online]. Available: http://www.esru.strath. ac.uk/Programs/ESP-r.htm

[42] M. Evans and N. Kelly, "Modelling active building elements with special materials," University of Strathclyde, 1996.

[43] D. Thevenard, "Validation of esp-r's equivalent one-diode PV model with data from NIST," CETC-Ottawa, Natural Resources Canada, Ottawa, ON, 2008.

[44] D. Thevenard, "Literature review and source code review of ESP-r's existing photovoltaic(PV) models," CETC-Ottawa, Natural Resources Canada, 2004.

[45] J. A. Clarke, Energy simulation in building design. Routledge, 2001.

[46] M. Mostrel and B. Givoni, "Windscreens in radiant cooling," Passive Sol. J.;(United States), vol. 1, no. 4, 1982.

[47] I. Beausoleil-Morrison, The adaptive coupling of heat and air flow modelling within dynamic whole-building simulation. University of Strathclyde UK, 2000.

[48] Environment Canada, "Canadian climate data." [Online]. Available: http: //climate.weather.gc.ca/

[49] Weather Analytics, "AMY data, Ottawa." [Online]. Available: http: //www.weatheranalytics.com/wa/products/data-weather-files/ 
[50] Environment Canada and The National Research Council of Canada, "Canadian weather energy and engineering data sets," 2003. [Online]. Available: "http://home.cc.umanitoba.ca/ bibeauel/courses/mech4692/ Project/Weather_data_LONGFORM.txt"

[51] G. A. Darbellay and M. Slama, "Forecasting the short-term demand for electricity: Do neural networks stand a better chance?" International Journal of Forecasting, vol. 16, no. 1, pp. 71 - 83, 2000. [Online]. Available: http://www.sciencedirect.com/science/article/pii/S016920709900045X

[52] J. W. Taylor, "Short-term electricity demand forecasting using double seasonal exponential smoothing," The Journal of the Operational Research Society, vol. 54, no. 8, pp. pp. 799-805, 2003. [Online]. Available: http://www.jstor.org/stable/4101650

[53] J. W. Taylor, L. M. de Menezes, and P. E. McSharry, "A comparison of univariate methods for forecasting electricity demand up to a day ahead," International Journal of Forecasting, vol. 22, no. 1, pp. 1 - 16, 2006. [Online]. Available: http://www.sciencedirect.com/science/article/pii/ S0169207005000907

[54] J. Taylor and P. McSharry, "Short-term load forecasting methods: An evaluation based on european data," Power Systems, IEEE Transactions on, vol. 22, no. 4, pp. 2213-2219, Nov 2007.

[55] P. S. Kalekar, "Time series forecasting using Holt-Winters exponential smoothing," Kanwal Rekhi School of Information Technology, vol. 4329008, pp. 1-13, 2004.

[56] E. S. Gardner Jr., "Exponential smoothing: The state of the art." Journal of Forecasting, vol. 4, no. 1, pp. $1-28,1985$. [Online]. Available: http://proxy.library.carleton.ca/login?url=http://search.ebscohost. com $/$ login.aspx $?$ direct $=$ true $\& d b=b t h \& A N=6143091 \&$ site $=$ ehost-live

[57] C. Chatfield, "The Holt-Winters forecasting procedure," Applied Statistics, pp. 264-279, 1978. 
[58] K. J. Arrow, "The economic implications of learning by doing," The review of economic studies, pp. 155-173, 1962.

[59] K. Neuhoff, "Large-scale deployment of renewables for electricity generation," Oxford Review of Economic Policy, vol. 21, no. 1, pp. 88-110, 2005.

[60] D. Rastler, "Challenges for fuel cells as stationary power resource in the evolving energy enterprise," Journal of Power Sources, vol. 86, no. 12, pp. 34 - 39, 2000. [Online]. Available: http://www.sciencedirect.com/science/article/ pii/S0378775399004395

[61] T. Kasuh, "Why does Japan believe in domestic fuel cell? adaptation to European market?" 2013, European Gas Technology Conference. [Online]. Available: "http://www.marcogaz.org/downloads/EGATEC2013/ Day2-May31/PS5/PS5f_6_Kasuh.pdf"

[62] A. F. Pales, "The IEA CHP and DHC collaborative," 2013.

[63] K. Iida, "Trends of hydrogen and fuel cell efforts by the Japanese government," in FY 2010 JHFC International Seminar,(2011 Feb 28eMarch 1) at Tokyo International Forum, 2011.

[64] K. Horiuchi, "Current status of national SOFC projects in Japan," ECS Transactions, vol. 57, no. 1, pp. 3-10, 2013.

[65] Panasonic, "Household fuel cells for condominiums." [Online]. Available: http://panasonic.co.jp/ap/FC/en_doc03_05.html

[66] A. Hawkes, E. Entchev, and P. Tzscheutchler, "A comparative review of microgeneration policy instruments in OECD countries," 2014. [Online]. Available: "http://www.iea-ebc.org/"

[67] Ontario Energy Board, "Conservation and demand management requirement guidelines for electricity distributors eb-2014-0278," December 2014. [Online]. Available: "http://www.ontarioenergyboard.ca/oeb/_Documents/Regulatory/ CDM_Guidelines_Elec_Distributors_20141219.pdf" 
[68] Independent Electricity System Operator, "April 25,2015: microFIT 2015 program update." [Online]. Available: http://microfit.powerauthority.on.ca/

[69] Canadian Electricity Association, "Vision 2050: The future of Canada's electricity system," 2014. [Online]. Available: http://powerforthefuture.ca/ wp-content/uploads/2014/04/Vision2050.pdf

[70] Energy Saving Trust, "Feed-in tariff scheme," 2014. [Online]. Available: http://www.energysavingtrust.org.uk/domestic/content/feed-tariff-scheme

[71] Germany Trade and Invest (GTAI), "The German CHP market generating investment opportunities," 2009. [Online]. Available: "http: //www.gtai.de/GTAI/Content/EN/Invest/_SharedDocs/Downloads/GTAI/ Info-sheets/Energy-environmental/info-sheet-the-german-chp-market-en.pdf"

[72] German Micro CHP Support Programme, "Zuschuss fr mini-kwk-anlagen," 2015. [Online]. Available: "http://www.bafa.de/bafa/de/energie/kraft_waerme_ kopplung/mini_kwk_anlagen/"

[73] "German law on cogeneration: Gesetz fr die erhaltung, die modernisierung und den ausbau der kraft-wrme-kopplung," July 2014.

[74] "German energy tax law: Energiesteuergesetz," December 2012.

[75] German Federal Government, "Erneuerbare energien wrmegesetz eewrmeg (Renewable Energy Heat Act," Berlin, December 2011.

[76] Cogenration Observatory and Dissemination Europe, "D5.1 final cogeneration roadmap pilot member state: Italy," July 2014.

[77] COGEN-Vlaanderen, "Wetgeving Europa (legislation Europe)," 2015. [Online]. Available: http://www.cogenvlaanderen.be/subpage-14/Wetgeving_Europa. php

[78] "Decreet houdende algemene bepalingen betreffende het energiebeleid [citeeropschrift: "het energiedecreet" (decree concerning general provisions relating to energy [quote inscription: "the energy decree"])," August 2009. [Online]. Available: http://codex.vandenbroele.be/Portals/Codex/documenten/1018092.html 
Appendix A

Interview Material 


\section{Interviewee Descriptions}

\begin{tabular}{lll}
\hline Interviewee & Description & Company \\
\hline \hline Raed Abdullah & Strategic Planning Engineer & Hydro Ottawa \\
Jan Buijk & CEO; Board of Director & EPS; Decentralized Energy Canada \\
Ali Golriz & Green Energy Procurement Project Manager & IESO \\
Neetika Sathe & VP of Corporate Development & Powerstream \\
Tim Short & Distributed Energy Market Development & Enbridge \\
Robert Sinclair & Manager of Procurement Operation & IESO \\
Mike Smith & Retired Engineer & \\
Dave Wilkinson & VP of Operations & Waterloo North Hydro \\
\hline
\end{tabular}




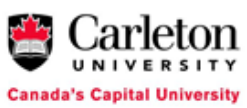

Ethics Clearance Form - New Clearance

\author{
Carleton University \\ Research Ethics Office \\ Research Ethics Board \\ 511 Tory, 1125 Colonel By Drive \\ Ottawa, ON K1S 5B6 Canada \\ Tel: 613-520-2517, ethics@carleton.ca
}

This is to certify that the Carleton University Research Ethics Board has examined the application for ethical clearance. The REB found the research project to meet appropriate ethical standards as outlined in the Tri-Council Policy Statement: Ethical Conduct for Research Involving Human, 2nd edition, and the Carleton University Policies and Procedures for the Ethical Conduct of Research.

Date of Clearance: May 11, 2015

Researcher: Yawen Han (Student Research: Master's Student)

Department: Faculty of Engineering and DesignlMechanical \& Aerospace Engineering (Department of) University: Carleton University

Research Supervisor (if applicable): Prof. Ian Beausoleil Morrison

Project Number: 102958

Alternate File Number (if applicable):

Project Title: Prospects of Extending the Micro-Feed-in Tariff (micro-FIT) Program to Micro-Combined

Heat and Power (CHP) Generators

Funder (if applicable):

Clearance Expires: May 31, 2016

All researchers are governed by the following conditions:

Annual Status Report: You are required to submit an Annual Status Report to either renew clearance or close the file. Failure to submit the Annual Status Report will result in the immediate suspension of the project. Funded projects will have accounts suspended until the report is submitted and approved.

Changes to the project: Any changes to the project must be submitted to the Carleton University Research Ethics Board for approval. All changes must be approved prior to the continuance of the research.

Adverse events: Should a participant suffer adversely from their participation in the project you are required to report the matter to the Carleton University Research Ethics Board. You must submit a written record of the event and indicate what steps you have taken to resolve the situation.

Suspension or termination of clearance: Failure to conduct the research in accordance with the principles of the Tri-Council Policy Statement: Ethical Conduct for Research Involving Humans, 2nd edition and the Carleton University Policies and Procedures for the Ethical Conduct of Research may result in the suspension or termination of the research project.

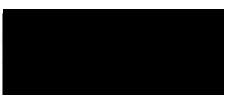

Louise Heslop

Chair, Carleton University Research Ethics Board

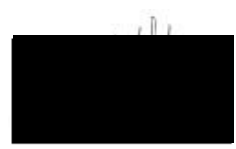

Andy Adler

Vice-Chair, Carleton University Research Ethics Board 
Interview Questions:

What is your name and your professional background?

What are your thoughts on micro-CHP technologies (for residential applications, scale of 1 $\mathrm{kW})$ ? Fuel cells? (policy drivers)

What is your impression of the electricity landscape in the next 5 or 10 years? 20 years?

What objectives do you think the province of Ontario should achieve in terms of electricity generation?

What policies do you think Ontario should implement to increase renewable energy penetration? (What steps do you think the province of Ontario should take to reach its energy generation needs?)

What are your thoughts on the micro-FIT program? How do you think the micro-FIT program may be improved?

What are your thoughts on the CESOP (Clean Energy Standard Offer Program)?

Extension to small scale, residential CHPs?

What possible solutions do you think may be the most effective in increasing the penetration of renewable energy?

What type of policy should be adopted? (FIT, grant, certificate trading, tax reduction, R\&D)

What are the steps necessary deploy such a policy?

What economic/ political/ social challenges do you foresee in the extension of a micro-FIT/net-metering scheme to include backup or storage technologies such as micro-CHP?

Who are the main stakeholders and what are their perspectives on a policy that encourages using micro-CHP technologies to provide backup to renewables?

What projects/policies have you dealt with related to this topic?

What are the most significant challenges to these projects/policies? How have these challenges been met?

Who do you suggest I should request to interview next for my research? 